GÖTTINGER STUDIEN ZUR ENTWICKLUNGSÖKONOMIK / GÖTTINGEN STUDIES IN DEVELOPMENT ECONOMICS

Robert Rudolf

\title{
Employment, Well-Being and Gender
}

Dynamics and Interactions in Emerging Asia 


\section{Robert Rudolf}

\section{Employment, Well-Being and Gender}

This book examines welfare effects of gender-related inequalities in Korean households and labor markets. It uses subjective well-being data to show that reductions of excessive levels of working hours did improve family well-being in the past decade. Moreover, benefits from major life events like marriage can differ greatly by sex if traditional gender roles dominate and women contribute much less than men to household earnings. Furthermore, the study examines dynamics in rural East Asian economies and their impact on individual welfare outcomes. Both land redistribution and productivity-enhancing reforms are found to have been highly beneficial for Korean development. The Indonesian case study demonstrates the importance of cash-crop decisions and the growing non-farm sector for rural development.

Robert Rudolf studied economics at the Universities of Tübingen and Göttingen, where he defended his PhD thesis at the end of 2011. As of 2012 he is an Assistant Professor at Korea University, Seoul. 


\section{Employment, Well-Being and Gender}




\section{Göttinger Studien zur Entwicklungsökonomik Göttingen Studies in Development Economics}

Herausgegeben von/Edited by Hermann Sautter und/and Stephan Klasen

Bd./Vol. 35

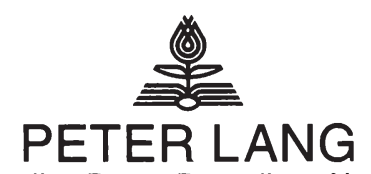

Frankfurt am Main - Berlin - Bern · Bruxelles - New York - Oxford - Wien 
Robert Rudolf

\section{Employment, Well-Being and Gender}

Dynamics and Interactions

in Emerging Asia

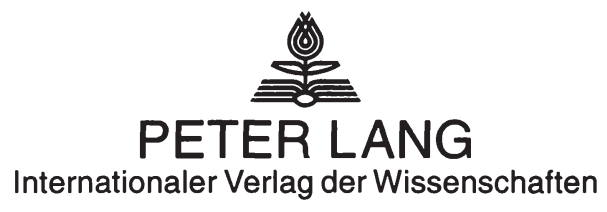




\title{
Bibliographic Information published by the Deutsche Nationalbibliothek
}

The Deutsche Nationalbibliothek lists this publication in the Deutsche Nationalbibliografie; detailed bibliographic data is available in the internet at http://dnb.d-nb.de.

Open Access: The online version of this publication is published on www.peterlang.com and www.econstor.eu under the international Creative Commons License CC-BY 4.0. Learn more on how you can use and share this work: http://creativecommons. org/licenses/by/4.0.

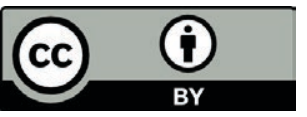

This book is available Open Access thanks to the kind support of ZBW - Leibniz-Informationszentrum Wirtschaft.

Zugl.: Göttingen, Univ., Diss., 2011

Cover design:

@ Olaf Glöckler, Atelier Platen, Friedberg

Gratefully acknowledging financial support by Ibero-Amerika-Institut für Wirtschaftsforschung, Göttingen, Korea Foundation and DAAD.

\author{
D 7 \\ ISSN 1439-3395 \\ ISBN 978-3-631-62302-2 \\ ISBN 978-3-631-75352-1 (eBook) \\ (C) Peter Lang GmbH \\ Internationaler Verlag der Wissenschaften \\ Frankfurt am Main 2012 \\ All rights reserved.
}

All parts of this publication are protected by copyright. Any utilisation outside the strict limits of the copyright law, without the permission of the publisher, is forbidden and liable to prosecution. This applies in particular to reproductions, translations, microfilming, and storage and processing in electronic retrieval systems.

www.peterlang.de 


\section{Acknowledgements}

Writing a $\mathrm{PhD}$ thesis is definitely not an easy task. However, in retrospect, it seems to be true that we grow with our tasks, and therefore, accomplishing a doctoral thesis is nothing out of reach. From my experience, key ingredients of a successful $\mathrm{PhD}$ completion are diligence, perseverance, the ability to keep a certain distance to your own work and to think beyond established theory.

While many people helped me on this journey, there are a few people that I owe special thanks to: The largest source of energy and inspiration continues to be my wonderful wife, Hanna. She is always there with me on the way, particularly from 2008 onwards. I also want to thank my family, for always supporting me in all my decisions, particularly my parents. Very special thanks go to my supervisor, Professor Stephan Klasen. He keeps on inspiring me with his seemingly unlimited dedication to a world free of poverty and inequality. $\mathrm{He}$ gave me the opportunity to unfold my enthusiasm for both teaching and empirical research in Development, Welfare, and Labor Economics within a great research environment in Göttingen. Moreover, I thank the DAAD, the Korea Foundation, and Professor Sung-Jin Kang for giving me the chance to spend one year of my $\mathrm{PhD}$ with a field research scholarship in Seoul. I also gratefully acknowledge working together with Carola Grün, Jan Priebe, Julian Weisbrod, Kristina Meier, Seo-Young Cho, Maria Ziegler, and Florian Johannsen. A very special thanks finally goes to my Buddhist teacher, Ole Nydahl. Without the amazingly practical Buddhist methods I would have been much less efficient and also much less happy on the way.

One last request to all social scientist and applied econometricians: Please never get stuck only in your office, but always make sure to constantly go out, talk to people of all different backgrounds and study their behavior. This will help you understand better the complex world of human interactions and individualspecific approaches to the pursuit of happiness (or call it utility maximization). 
Robert Rudolf - 978-3-631-75352-1

Downloaded from PubFactory at 01/11/2019 06:01:29AM

via free access 


\section{Contents}

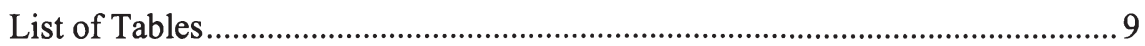

List of Figures ........................................................................................ 11

List of Abbreviations..................................................................................... 13

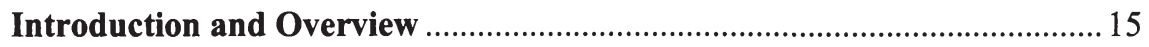

The Gender-Specific Effect of Working Hours Reductions on Family Happiness in South Korea ........................................................2

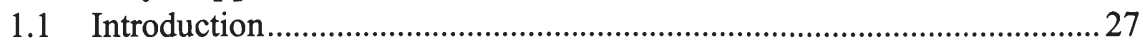

1.2 Background and Related Literature ...........................................................2.

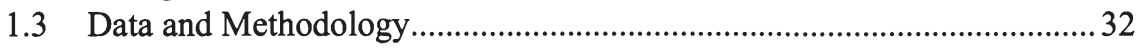

1.4 Satisfaction Regression Results ................................................................40

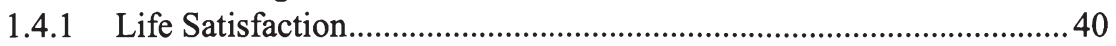

1.4.2 Hours and Job Satisfaction .................................................................... 44

1.4.3 Robustness Checks and Joint Happiness................................................ 46

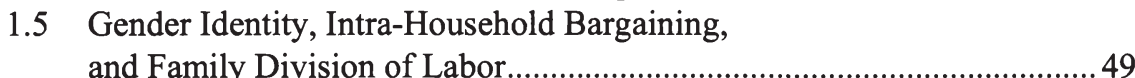

1.6 Concluding Remarks........................................................................... 52

\section{Adaptation under Traditional Gender Roles:}

Testing the Baseline Hypothesis in South Korea ..........................................5

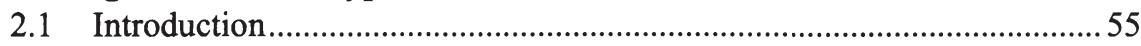

2.2 Gender Gap in Korea …………………………………......................58

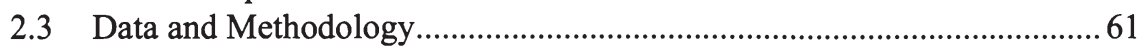

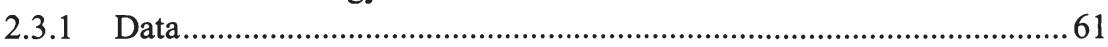

2.3.2 Anticipation and Adaptation Model .....................................................66

2.3.3 Intra-Marriage Gender Happiness Gap Model.....................................67

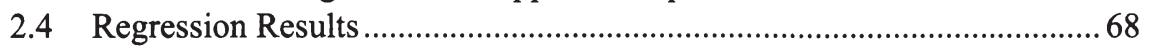

2.4.1 Marriage-Status-Related Events ...........................................................6

2.4.2 Labor Market Events .............................................................................71

2.4.3 Determinants of Intra-Marriage Gender Happiness Gap ..................... 75

2.5 Conclusion ..........................................................................................

Rural Reforms, Agricultural Productivity, and the Biological Standard of Living in South Korea, 1941-1974 ..............79

3.1 Introduction...................................................................................

3.2 Rural Reforms in 1950 and 1962/63 ................................................. 83 
3.3 Effect of Rural Reforms on Agricultural Productivity ............................ 86

3.3.1 Historical Farm Data ........................................................................ 87

3.3.2 Land Reform and Trends of Agricultural Input and Output .............. 88

3.3.3 Econometric Model .......................................................................... 90

3.4 Effect of Rural Reforms on Individual Well-being ................................. 92

3.4.1 Body Height and Individual Welfare ................................................ 92

3.4.2 Testing for Structural Breaks in Time Series ................................... 96

3.5 Concluding Remarks........................................................................... 102

Cash Crop Choice and Income Dynamics in Rural Areas:

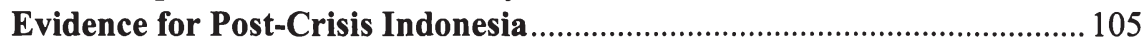

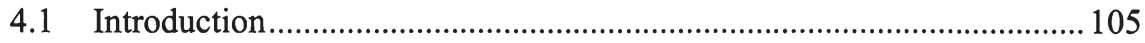

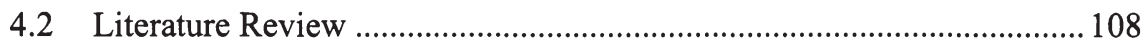

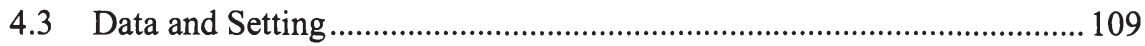

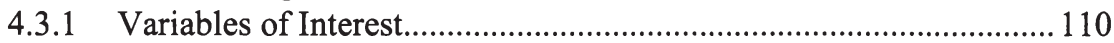

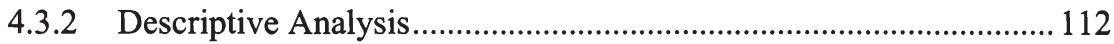

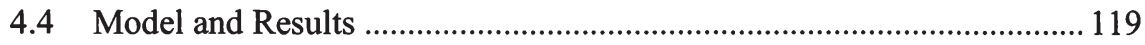

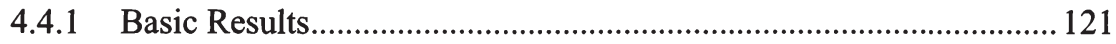

4.4.2 Robustness Checks ....................................................................... 124

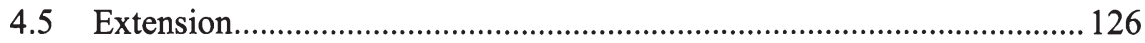

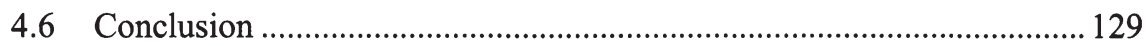

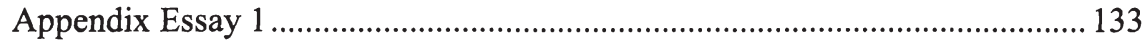

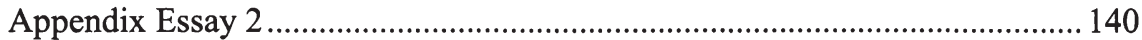

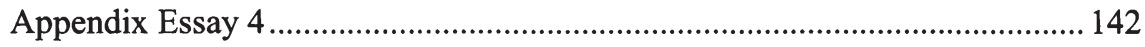

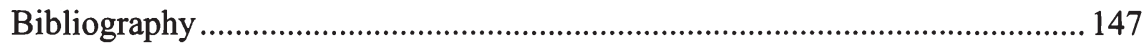




\section{List of Tables}

Table 1.1: Distribution of Satisfaction Measures by Gender (percent) .......... 33

Table 1.2: Average Satisfaction by Working Hours ....................................... 36

Table 1.3: Change in Work Hours Distribution After Introduction

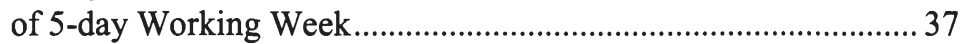

Table 1.4: Life Satisfaction Regressions...................................................... 41

Table 1.5: Hours and Job Satisfaction Regressions ........................................ 45

Table 1.6: Reported Increased Activities After Reduction of

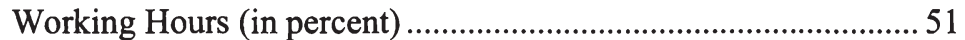

Table 2.1: Gender Gap in Korea in Cross-Country Comparison ..................... 60

Table 2.2: Distribution of Life Satisfaction by Sex ........................................62 62

Table 2.3: Average Life Satisfaction of Leads and Lags by Event and Sex... 65

Table 2.4: Effect of Life and Labor Market Events on Life Satisfaction ....... 69

Table 2.5: Intra-Marriage Happiness Inequality .......................................... 76

Table 3.1: Agricultural input and output summary statistics .........................89

Table 3.2: Determinants of Agricultural Output (1944-1974) ........................ 92

Table 3.3: Observations per birth cohort (of variable height).......................... 94

Table 3.4: Endogenous detection of structural breaks (successive Zivot-Andrews tests)................................................ 98

Table 3.5: Regression estimations with exogenous structural breaks in 1950 and 1963, data for 1941-1974 .......................................... 99

Table 4.1: Summary Statistics (Means) on STORMA households ............... 112

Table 4.2: Cocoa and coffee production .................................................... 114

Table 4.3: Agricultural Diversification - Mean Incomes of

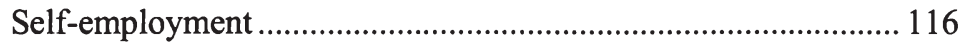

Table 4.4: Income Sector Transition Matrix .................................................... 117

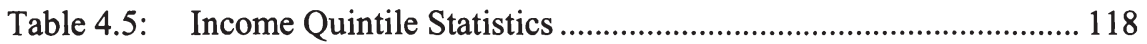

Table 4.6: Determinants of income and income growth ................................ 122

Table 4.7: Selected robustness checks on basic results................................... 124

Table 4.8: Regional OLS Regressions - Comparison .................................... 128

Table A1.1: Gender Gap, Hours Worked and Child Care in Cross-Country Comparison......................................................... 134

Table A1.2: Determinants of Labor Force Participation by Sex....................... 135

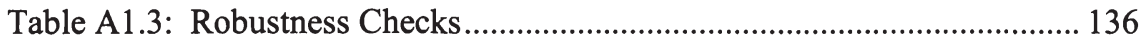

Table A1.4: Joint Happiness and Occupation Interactions.............................. 138

Table A2.1: Effect of First Marriage on Life Satisfaction ............................... 140

Table A2.2: Effect of Working Days Reduction on Different Satisfaction Measures. 
Table A4.1: Description of variables .............................................................. 142

Table A4.2: Comparison of Regional Means................................................ 144

Table A4.3: Regional Multivariate Regression-Comparison II ....................... 145 


\section{List of Figures}

Fig. 1.1: Distribution of Working Hours by Sex and

Trends of Working Hours and Satisfaction ................................... 35

Fig. 1.2: Husbands' share of housework vs. share of market work ............. 50

Fig. 2.1: Adaptation to life and labor market events ............................... 73/74

Fig. 3.1: Korean female and male heights, 1920-1987 ............................... 95

Fig. 3.2: Estimation of trends in farm output and heights with structural breaks in 1950 and 1963 ................................... 101 
Robert Rudolf - 978-3-631-75352-1

Downloaded from PubFactory at 01/11/2019 06:01:29AM

via free access 


\section{List of Abbreviations}

$\begin{array}{ll}\text { ADF } & \text { Augmented Dickey-Fuller unit root test } \\ \text { ALRAA } & \text { Korean Agricultural Land Reform Amendment Act } \\ \text { AR(1) } & \text { First-order autoregressive process } \\ \text { BHPS } & \text { British Household Panel Survey } \\ \text { BP } & \text { Break point } \\ \text { BPS } & \text { National Statistical Office of Indonesia } \\ \text { BSoL } & \text { Biological standard of living } \\ \text { BUC } & \text { "Blow-Up-and-Cluster" estimator } \\ \text { CML } & \text { Conditional marginal logit } \\ \text { CPI } & \text { Consumer price index } \\ \text { CS } & \text { Central Sulawesi } \\ \text { DDT } & \text { Dichlorodiphenyltrichloroethane (insecticide) } \\ \text { FAOSTAT } & \text { Food and Agricultural Organization Statistics } \\ \text { FD } & \text { First differences } \\ \text { FE } & \text { Fixed effects } \\ \text { FF } & \text { Ferrer-i-Carbonell and Frijters } \\ \text { FFA } & \text { Korean Federation of Financial Associations } \\ \text { GDP } & \text { Gross domestic product } \\ \text { GEM } & \text { Gender empowerment measure } \\ \text { GII } & \text { Gender inequality index } \\ \text { GGG } & \text { Global gender gap index } \\ \text { GMM } & \text { General methods of moments } \\ \text { GNI } & \text { Gross national income } \\ \text { GSOEP } & \text { German Socio-Economic Panel } \\ \text { GWB } & \text { General Well-Being } \\ \text { HDI } & \text { Human Development Index } \\ \text { HH } & \text { Household } \\ \text { HILDA } & \text { Household, Income and Labour Dynamics in Australia survey } \\ \text { IDR } & \text { Indonesian Rupiah } \\ \text { IV } & \text { Instrumental Variables } \\ \text { KAA } & \text { Korean Agricultural Association } \\ \text { KAERI } & \text { Korea Agricultural Economic Research Institute } \\ \text { KLIPS } & \text { Korean Labor Income Panel Study } \\ \text { KNHS } & \text { Korean National Health Survey } \\ \text { KRW } & \text { Korean Won } \\ \text { Logit } & \text { Logistic estimator } \\ \text { LM-test } & \text { Lagrange multiplier test } \\ & \end{array}$


MAFF Korean Ministry of Agriculture, Forestry and Fishery

$\mathrm{N}$

Number of observations

NIC Newly industrialized country

NLS US National Longitudinal Surveys

NSE Non-farm self-empoyed

OECD Organization of Economic Cooperation and Development

Ologit Ordered logistic estimator

OLS Ordinary least squares

PPP Purchasing power parity

PSID US Panel Study of Income Dynamics

p.c. Per capita

QoL Quality of life

RE Random effects

R\&D Research and development

ROK Republic of Korea

STORMA Project on the "Stability of rainforest margins in Indonesia"

SUSENAS National Socioeconomic Survey of Indonesia

UK United Kingdom

UN United Nations

UNDP United Nations Developmental Program

UNKRA United Nations Korean Reconstruction Agency

US/USA United States of America

USD US Dollar

USSR Union of Soviet Socialist Republics

WEF World Economic Forum

ZA-test Zivot-Andrews test for structural break

2SLS Two-stages least squares 


\section{Introduction and Overview}

"There are two ways of being happy: We must either diminish our wants or augment our means - either may do - the result is the same and it is for each man to decide for himself and to do that which happens to be easier."

Benjamin Franklin

The international scientific and political debate is currently undergoing a paradigm shift in how to measure well-being. Better individual data availability, new communication tools and a time in which many developed, but also developing countries are looking beyond GDP have led to a situation where international efforts to broaden indicators of well-being enjoy strong momentum. There is consensus that GDP should still play an important role in assessing welfare, however it has been widely acknowledged that a mere increase of "goods and services produced in a geographic entity over the course of a year" is a concept that is often neither inclusive, nor sustainable, nor able to measure individuals' satisfaction with their objective circumstances. For a long time, increasing wellbeing meant solely the maximization of one single dimension, that of GDP or household disposable income. This was justified by a high correlation of income with other dimensions of QoL such as housing and health, and its single monetary value had the appeal of simple accountability. However, exponential increases in computation power, advances in statistics and the availability of complex micro data has led to a shift towards more detailed empirical economics over the last decades. Thus, it has nowadays become possible to study utility with the use of more heuristic methods and in a multi-dimensional way. This has also led to major policy changes. The UNDP in 1990 was among the first to adopt a multi-dimensional welfare measure with the introduction of the Human Development Index which is a combined measure of purchasing power, education, and health. Further milestones were the Millennium Development Goals and multi-dimensional poverty indexes applied by the World Bank. However, all multi-dimensional indexes have in common the problem of somewhat arbitrary selection and weighting of sub-indexes. This implies that preferences worked out by expert committees are applied instead of actual individual preferences, presenting a major drawback of all objective measures of QoL. This has recently led to a high popularity of subjective measures of well-being since their growing inclusion into national household surveys within the last two decades. As advances in this field are fast in developed countries, questions on subjective wellbeing have not yet been introduced into most developing countries' household surveys. The most widely used QoL measure in the class of subjective wellbeing measures is overall life satisfaction, which asks people directly for their 
overall satisfaction with their life at a specific point in time on a scale of e.g. [010]. Subjective measures can provide additional information and thus complement more traditional objective measurement tools. The availability of subjective measures has even led to the rise of a whole new field of economics, the socalled Happiness Economics, which has been rapidly increasing over the past decade.

At the same time, political momentum in favor of a paradigm shift currently appears to be extraordinary high: The Stiglitz Commission on the Measurement of Economic Performance and Social Progress, a group of experts including Nobel Prize winners, recently presented a landmark report re-evaluating the question of welfare measurement (Stiglitz, Sen and Fitoussi, 2009). The commission's main advice is "to shift emphasis from measuring economic production to measuring people's well-being" (Stiglitz et al. 2009, 12). This conclusion rests on the insight that the current discrepancy between what we want to measure and what we actually do measure might lead to serious policy failure and misallocation of scarce resources. Hence the commission's three core suggestions are the following: (i) a revision of economic indicators, (ii) more broadly-based measurement of QoL (including subjective measures) and (iii) more attention paid to sustainability. The commission proposes eight dimensions of QoL to focus on: (i) material living standards (income, consumption, and wealth); (ii) health; (iii) education; (iv) personal activities, including work; (v) political voice and governance; (vi) social connections and relationships; (vii) environment (present and future conditions); and (viii) insecurity, of economic and physical nature. In order to further identify dimensions and sub-dimensions of QoL, it proposes the formation of national round-tables to discuss the issues democratically on the national level. On the basis of national discussions, internationally comparable indicators should then be established which in more supplemented versions should be able to take into account country-specific preferences. The question whether this should lead to a single indicator or a dashboard of indicators needs still further discussion. Several of these indicators or dashboards are currently proposed and discussed on national levels. Many OECD governments have recently pushed the topic forward and have set up different approaches to arrive at new QoL measures. These include both the use of top-down strategies in the form of expert commissions as well as bottom-up approaches in form of national-level surveys. Germany and France's top economic advisory boards have recently published a report together on "Economic Performance, Quality of Life and Sustainability: A Comprehensive Set of Indicators" (Conseil d'Analyse Economique and Sachverständigenrat zur Begutachtung der gesamtwirtschaftlichen Entwicklung, 2010). President of France Nicolas Sarkozy was the one who brought the Stiglitz Commission into being. The UK's Prime Minister David 
Cameron called for the introduction of a measure of "general well-being" (GWB) to complement GDP. Recently the UK's Office of National Statistics has conducted an expensive large-scale project to survey British people's understanding of well-being. Other governments active in the debate include the EU, Italy, Australia, Canada, Spain, the Netherlands, Mexico, Bhutan, China, India, and the US, the latter having the "pursuit of happiness" enshrined in their Declaration of Independence (Kroll, 2011). Among the countries engaged in the debate, there is consensus that subjective measures must now be juxtaposed to objective ones used in the past. Individual well-being measures should not longer be confined to external judgment of how people's life circumstances develop but should be complemented by the extent to which people are happy with them. This is not only one of the key demands of the Stiglitz report but the combined credo of a growing scientific, political and civil movement. One major player in the debate has been the OECD with the organization of several conferences as well as the release of several publications on the topic. A milestone of OECD efforts was the recent launch of its Better Life Index in May 2011. The index facilitates country comparisons over eleven dimensions and is the first major policy index to include life satisfaction. Alongside the subjective well-being measure, other dimensions included are housing, income, jobs, community, education, environment, governance, health, safety, and work-life balance.

\section{Measuring QoL 1: Subjective Well-Being}

As opposed to objective measures like income, questions that ask people directly to rate their overall life satisfaction or happiness are subsumed under the concept of subjective well-being.

Most if not all people want to be happy in life, and this motivates most if not all of their actions. Thus, they make decisions facing individual constraints, bounded rationality, and incomplete information. Individuals are able to maximize expected happiness given the aforementioned restrictions, not actual happiness itself. Mean actual happiness outcomes can therefore differ significantly from expected happiness (Kahnemann, 2000; Clark et al., 2008). Research on subjective well-being can thus not only provide increased information for policy makers about the actual impact of public policies on the people, but also support individuals in lowering information costs in their pursuit of happiness.

Subjective measures provide two major advantages as compared to the traditional revealed preferences approach. First, utility measurement is here more immediate, since no assumptions on preferences need to be made. Second, subjective measures take into account that the effect of objective influences, such as material possessions or employment status, is often mediated by psychological 
processes such as social comparison and hedonic adaptation. These standard concepts in the psychological academic literature have only recently been introduced into economic models of behavior, where they are known as interdependent preferences and habit formation (adaptive preferences) (Easterlin, 2003; Stutzer, 2004; Clark, Frijters, and Shields, 2008). Social comparison or interdependent preferences point out that the utility effect of one's possession of a certain good depends partly on other's possession of the same good. For example, the effect of an individual's income increase on her personal happiness will thus depend on the average income growth of her peer group. Hedonic adaptation or habit formation does then argue that a constantly higher income level can lead to a change in aspirations. In the psychology literature, adaptation has been defined as "a reduction in the affective intensity of favorable and unfavorable circumstances" (Frederick and Loewenstein 1999) while the so-defined concept of "hedonic treadmill" describes the reversion back to an individual's baseline hedonic level following temporary highs and lows in happiness (Brickman and Campbell 1971). Similarly, anticipation is often found, which is the utility arising ex ante in expectation of an event to occur. Most scholars thus conclude that more research is needed to distinguish life domains with transitory happiness effects from those with lasting effects. An individual experiencing an income increase would get used to the new income level and would need even higher income in the future to satisfy her increased needs. This might be due to social comparison on the one hand: A change in the peer group due to own upward social mobility would mean an increased average income of the new reference group translating into a diminished impact of own income. At the same time, comparisons with her own past would also lead to increased aspirations over time and thus to adaptation to the new income level.

Social comparison and hedonic adaptation also help to explain the Easterlin (1974) paradox, which finds that average happiness usually stays flat in economically fast growing countries. Indeed, there is a whole literature showing that status or relative income might be much more important than actual income for happiness (Luttmer, 2005; Clark, Frijters, and Shields, 2008; Di Tella, HaiskenDe New, and MacCulloch, 2010).

However, hedonic adaptation and social comparison are found to differ a lot over various domains in life. While there seems to be stronger adaptation to income and changes in marital status, no or only partial adaptation is usually found to long-term unemployment, disability, or chronic disease (Clark et al., 2008; Oswald and Powdthavee, 2008).

The concept of social comparison is also linked with the concept of identity which was recently introduced into economic models of behavior by Akerlof and Kranton (2000). Being long established in sociology, political science, and 
psychology, it argues that a person's utility does not only depend on own actions, but also on one's identity, others' actions and societal prescriptions for one's chosen identity. Here, identity is a wide concept which can range from gender, race, education or employment status to political or sexual orientation, etc. The more own actions match society's expectations of a certain expected role behavior, the more an individual will be rewarded by others. This concept shows to be useful in many fields, e.g. it can help to explain differences in educational outcomes between children growing up in different neighborhoods of a specific city. It can also help to explain the maintenance of traditional gender roles, when societal expected behavior favors women to be the main responsible for housework and men the main breadwinner.

In happiness research it is crucial to control for individual unobserved heterogeneity such as personality traits. This requires the use of longitudinal data sets. The concept of subjective well-being will be used in two articles below analyzing employment and marital decisions in $21^{\text {st }}$ century South Korea with detailed long-run panel data. The central variables for the analysis are overall life satisfaction, overall job satisfaction, and satisfaction with working hours. The life satisfaction question requires individuals to respond to the following question: "Overall, how satisfied or dissatisfied are you with your life?". The exact wording of the job satisfaction question is "Overall, how satisfied or dissatisfied are you with your main job?", while hours satisfaction is the answer given to the aspect "Working hours" following the question "How satisfied or dissatisfied are you with regard to your main job on the following aspects?". For each of these questions, the respondent is asked to give a score between 1 ("very satisfied") and 5 ("very dissatisfied").

Economists are sometimes skeptical about the validity and reliability of subjective measures of well-being. Do we really measure what we want to measure? And would it be possible to measure the same level of happiness in virtually the same situation again? A large body of psychology and sociology literature has examined this question in the past. Kahnemann and Krueger (2006) and Di Tella and MacCulloch (2006) provide an overview and an analysis of these issues in the Journal of Economic Perspectives. Concerning the validity of the measure, a number of studies have shown that self-reported well-being is highly correlated with ratings of friends or Duchenne smiles - i.e. smiles that cannot be faked. Significant correlation is also found with left frontal brain activity which is considered to be the center of pleasure and approval. Moreover, subjective wellbeing is found to be highly correlated with other psychological measures such as depression scales. Concerning the reliability, life satisfaction scores have been found to have a test-retest correlation of .77 (Lucas et al., 1996). Hence, the general consensus among researchers is that true utility can be measured suffi- 
ciently well with the help of subjective measures, despite some noise in the data due to temporary mood.

\section{Measuring QoL 2: The Conventional Income Measure of Well-Being}

Since the beginning of economics there has been constant debate about how to measure well-being. For its practical use and broad availability, scholars have often resorted to the concept of money-metric utility. According to the classical approach, individuals are assumed to act completely rationally and under full information about their choice set and related utility outcomes. Preferences are assumed to be fixed. If these assumptions hold, then individuals reveal their preferences through purchasing decisions and relative prices will reflect relative preferences. In order to circumvent the specification of a parametric utility function, money-metric utility can be approximated by an individual's income or expenditures. This standard approach is often being used in empirical economics to evaluate individual standards of living (Deaton, 1997). Although economists are aware of incomplete information and bounded rationality today, taking income as a welfare measure on the individual or household level is still the preferred choice in most analysis.

However, the money-metric approach comes with a number of caveats: (1) Income is only an objective input factor to well-being and thus is only partially related with utility outcomes. (2) Incomes can underlie certain measurement error, for example when the rich tend to underreport their incomes. (3) Income as a welfare measure does require imputation for self-produced services and goods consumed in the household. This particularly applies to developing economies and imputation is usually not a simple task. (4) Even if imputation is theoretically possible, often the absence of market prices for certain goods and services renders reasonable value estimates impossible. (5) As income is often measured on the household and not on the individual level, it cannot account for intrahousehold distribution of income. It is usually assumed that higher real income leads to higher quality of life since it allows for a higher consumption bundle which according to classical welfare theory will lie on a higher indifference curve (Boadway and Bruce 1984).

Despite its shortcomings, the income approach is still highly valuable, particularly in the analysis of developing countries. Financial entitlements are highly correlated with the fulfillment of basic human needs and are thus able to free people from poverty and deprivation. While some poor in developing countries are certainly satisfied with what they have, a general increase in output per capita that includes the whole population and takes into account limited resources 
will definitely lead to higher QoL via higher levels of freedom, longer and healthier lives, and increased life choices.

\section{Measuring QoL 3: The Biological Standard of Living}

Being confronted with a lack of both subjective measures of QoL and household income data, which often is the case in the study of economic history, we can resort to anthropometric data to evaluate well-being. The method of the biological standard of living (BSoL) uses individual height data as a proxy for individual welfare during historical periods for which no household income or consumption data is available. The strong relationship between early childhood household economic conditions and heights has been frequently documented (Komlos 1993; Komlos and Baten 1998; Steckel 1995, 2009; Hoddinot et al. 2008; Deaton 2008). Final height outcomes are correlated with nutritional intake during the first three years of a person's life, and here particularly during the first 12 months after birth. Of primary importance is the availability of proteins. To a lesser degree also vitamins $\mathrm{A}, \mathrm{D}$, as well as minerals play a role for final height outcomes (Silventoinen 2003). Nutritional conditions in turn highly depend on relative food prices and a household's income situation. In the case of agricultural self-production, ownership of productive assets is crucial. Thus, welfare trends of a large enough sample of a particular population can be inferred from height data.

When working with height data it is important to deal appropriately with the issue of shrinking of old-age cohorts. While individuals usually reach their final height around the age of 20 to 30, shrinking usually starts from the age of 40 to 50 and then accelerates in later periods of life. Cline et al. (1989) as well as Chandler and Bock (1991) provide gender-specific formulas to adjust for shrinking. These formulas have been applied in the East Asian context by, among others, Pak et al. (2010) on Korean height data, and Morgan (2008) on Chinese height data. Both adjustment methods will be applied in the below article on Korean rural reforms.

\section{Employment and Gender}

One of the central issues studied in Economics is the effect of employment which is found to be an important determinant of QoL. Employment provides a means of both income generation and social participation. Moreover, own earnings are associated with higher levels of self-confidence and financial independence allowing for broader choice sets in life. From a developing country's perspective, employment is most directly related to the fulfillment of basic needs such as nutrition, clothing and housing. Moving from the stage of a developing 
towards a developed economy depends on the ability of a country to increase labor productivity over time, at early stages particularly in agriculture (World Bank, 2007).

In the literature on Happiness Economics it is found, in studies mainly focusing on developed countries, that working contributes to happiness even after controlling for income effects (Clark and Oswald, 1994; Winkelmann and Winkelmann, 1998). It is argued that this is the case because working can be a mechanism for social participation and engagement, which are known to be important factors of happiness. However, given expected roles and labor division between men and women present in most societies, the effects of employment may not be gender-neutral but create gender-specific effects. Relative earnings of husband and wife are usually found to be important determinants of bargaining power and decision making within the household (Haddad, Hoddinott and Aldermann, 1997). Akerlof and Kranton (2000) contribute to the debate in explaining how identities related to gender roles and social gender prescriptions might influence individual behavior. Since others actions and social prescriptions enter an individual's utility function, we are not free of what others think and do. Thus, it can be often observed that female labor force participation in a particular society is strongly related to its prescribed gender ideals. This can lead to women preferring to stay at home even if that would not have been their preferred choice in the first place. Additional burden for women in the fields of housework and childcare present further constraints for female participation in the labor market. Part-time employment can be a potential solution here, however the availability of such options strongly depends on the willingness of employers or governmental regulation (Booth and van Ours, 2008; 2009). Particularly countries with very long working hours show low female labor force participation.

\section{Contributions}

This dissertation analyzes impacts of public policies as well as of individual behavior on well-being outcomes at different stages of economic development in Emerging Asia. While two papers are related with earlier stages of economic development and issues concerning agricultural productivity and rural income dynamics, the other two are located within a modern high-income economy with substantial levels of gender inequality. All four papers have in common that they analyze dynamic impacts of certain events, all of which are directly or indirectly related to employment decisions, on individual well-being. Therefore the before in detail discussed question of how to measure well-being or QoL becomes central in the analysis. According to different stages of economic development, dif- 
ferent purposes of analysis, and differences in data availability in the below articles well-being will be measured in three ways.

Essay 1 studies the impact of working hours reductions on family happiness in South Korea using various subjective well-being measures (life satisfaction, overall job satisfaction, satisfaction with working hours). The analysis puts particular attention on inertial gender dynamics responsible for on-going high levels of gender discrimination in the Korean labor market at the beginning of the $21^{\text {st }}$ century. Findings indicate that hours of work reductions between 1998 and 2008 significantly increased family happiness. However, significant gender-specific effects are found. Well-being can be further improved through future hours reductions and the simultaneous creation of a more family-friendly working environment for women.

Essay 2 analyzes anticipation and adaptation to several life and labor market events in Korea using life satisfaction as the main well-being measure. The intertemporal effect of the following events on individual happiness is studied: marriage, divorce, widowhood, unemployment, first job entry, and reduction of the working week from six to five days. While the findings indicate full adaptation after some events, and more so for women, after other events no or only partial habituation can be seen. Yet, there are striking gender-specific differences particularly in the impact of events related to marital status change. Compared to women, husbands remain on a higher happiness level throughout marriage. Men suffer more from divorce and widowhood than women. We show that an important determinant of the intra-marriage happiness gap between husband and wife is their earnings difference providing evidence for both intramarriage bargaining and Akerlof and Kranton's (2000) gender identity hypothesis. The studied labor market events point to a gender-segregated labor market.

Essay 3 analyzes South Korea's agriculture-based economy at the beginning of its rapid development. Korea is often taken as an example of best practice for development, as it moved within 50 years from a per-capita income level equal to the then Sub-Saharan African average to a highly industrialized, high-income innovating economy. The essay thus analyzes one of the crucial starting points of its Growth Miracle, the move towards asset equality via large-scale land reforms. It studies productivity and welfare effects of rural reforms in 1950 and 1963, the former being a pure redistribution of land to its tillers and the latter Green-Revolution-type technology and infrastructural reforms. In the absence of sufficient micro-level income data for this historic period, individual well-being can be proxied by contemporaneous anthropometric data projected onto individuals' birth year, thus making use of the concept of the Biological Standard of Living (BSoL). Main results indicate that both land redistribution and intensifi- 
cation reforms had important impacts on agricultural productivity and individual well-being. However, the findings make clear that a mere land redistribution without complementary productivity enhancing reforms would have only limited success.

Essay 4 also studies issues of rural development while focusing on Indonesia's rural economy at the start of the 21 st century. For the analysis, the conventional measure of per-capita household income is applied to analyze the welfare dynamics related to cash-crop choice and employment decisions of rural households living at the rainforest margin. We find that local innovations related to the adoption and intensification of new cash crop varieties, more specifically the shift from coffee to cocoa production, can explain a substantial part of the observed post-crisis income growth. Moreover, increased engagement in the nonfarm sector is seen to be highly beneficial for rural households. However, initially poor households were largely excluded from the developments in the nonfarm sector.

\section{Policy Implications}

The findings of my dissertation are manifold and diverse, as are its individual essays. Results can hold important lessons for other developing and emerging economies.

In the process of development, and particularly in rural economies, overcoming asset inequality has the potential to lead to both equity and efficiency gains if land redistributions are well designed. Moreover, land reforms will have larger impacts if combined from the first with productivity-enhancing reforms that focus on improving farmers' access to inputs, credits, and technological know-how. Well-informed farmers will also be able to make more rational decisions concerning crop choice which might lead to further agricultural productivity increases. Governments should also be inclined to support rural non-farm employment which can lead to further labor productivity gains in the rural economy. Here it should be noted that in the absence of properly working credit markets, entry barriers exist particularly for poor households to engage in non-farm employment. This opens scope for government intervention.

Findings from the two studies on welfare and gender issues related to the Korean labor market at the beginning of the $21^{\text {st }}$ century suggest the following: First, adaptation and the impact of life and labor market events might differ significantly by sex, particularly in societies with high levels of gender inequality. Second, extreme long working hours are detrimental to QoL. As for Korea, further working hours reductions have the potential to both increase family happiness and female labor force participation. Third, much more needs to be done if 
gender equity is to be ensured in Korea. As traditional gender roles and a highly male-dominated labor market continue to be major obstacles to the pursuit of gender equity in happiness, reforms in this area should be continued and require critical evaluation. A family-friendly working environment should be the main target. Equality of chances at the work place, including equal pay and equal promotion chances, a rethinking of gender identities, as well as flexible job and childcare solutions including part-time jobs in high-skilled employment all need to be considered. As Akerlof and Kranton (2000) point out, individuals and firms tend to underinvest in unilateral action to change gender identities, since they would be facing the costs alone while being unable to internalize potential benefits of such action; thus further government action is required to escape from a potential prisoner's dilemma. 
Robert Rudolf - 978-3-631-75352-1

Downloaded from PubFactory at 01/11/2019 06:01:29AM

via free access 


\title{
Essay 1
}

\section{The Gender-Specific Effect of Working Hours Reductions on Family Happiness in South Korea}

\begin{abstract}
This paper uses detailed longitudinal data from the Korean Labor and Income Panel Study (KLIPS) stretching from 1998 to 2008 to analyze the relationship between working hours and their reduction on family happiness in South Korea. The Korean labor market is characterized by very long yet decreasing working hours, high gender gaps in earnings and promotion prospects, as well as low post-marriage female labor force participation. Working hours reductions can be treated exogenous since they were largely driven by the introduction of the 5-day working week in 2004 . Running fixed-effects ordered logit models on married couples with children, the findings indicate that while working hours reductions increased family happiness in Korea, still significant gender-specific effects remain. Married women report highest satisfaction when either not-working or working 31 to 40 hours per week. Both parttime and overtime work reduce women's happiness. Korean husbands are best off when being full-time employed. Staying at home or being only part-time employed is strongly detrimental to their happiness. Both sexes show strong cross-partner effects. In order to further increase female labor force participation and family happiness, further reductions in working hours should be flanked by policies promoting equal chances at the work place, a rethinking of gender identities, and flexible job and child-care solutions.
\end{abstract}

\subsection{Introduction}

This paper investigates how working hours of married and co-residing couples affect family happiness, measured by self-reported working hours, job and life satisfaction, respectively. Testing for interdependence between partners' utility functions, cross-partner effects will be taken into account. The study employs panel data from the first eleven waves of the Korean Labor and Income Panel Study (KLIPS) over the period 1998 to 2008 . To the best of the author's knowledge, this paper is the pioneer study on the effects of working hours on family happiness using large-scale panel data in an Asian economy. It can provide interesting implications also of relevance to other developing and industrialized countries. 
The study can contribute to the literature in several ways. First, the data allows to directly assess the effect of an exogenous reduction in working hours. During the period under consideration, average working hours declined by about ten percent due to the introduction of the 5-day working week in 2004. This natural experimental setting allows us to directly estimate the effect of the observed reductions on worker's individual and family happiness. Second, the analysis of the Korean labor market strongly calls for a focus on gender-specific effects related to labor force participation and working hours. The Republic of Korea is one of the high-performing East Asian economies with dynamic socio-economic structures. After rapid economic growth over the past five decades which allowed Korea to catch-up with the rich OECD countries, the country is recently also experiencing important changes in its traditional systems of cultural and social values (Chung and Das Gupta, 2007). This does also include gender identities in general and the perceived role of women in particular, which today is already much different from some years ago. However, gender variables seem to catch up much slower than economic indicators. According to cross-country comparisons, the gender gap in Korea is still much higher than in other OECD countries with similar GDP per-capita or HDI ranks (see Table A1 in appendix). Continued high gender gaps in earnings, lacking economic and political empowerment, the absence of family-friendly job opportunities in the high-skilled sector, as well as still very traditional gender roles within the household have led to only modest increases of female labor force participation over the past decade. Extremely long average working hours and insufficient supply of child care continue to be further major obstacles for female engagement in the labor market. This makes it understandable that many women, when able to afford it, prefer to stay at home as a housewife (compare Table A2 in appendix). Thus, a study on South Korea can provide enriched empirical evidence on the interactions between changing gender identity, women's preferences for work, supply side factors such as working hours and potential conflicts brought about by these dynamics. It can provide lessons for other emerging economies going through similar social transitions. Third, in contrast to many other papers in the field, this study takes into account individual unobserved heterogeneity while not having to relax the assumption of an ordinal satisfaction scale at the same time. On the one hand, unobserved heterogeneity particularly in personality traits is an important determinant of individual happiness and, without controlling for such arguably time-invariant effects, empirical results can be subject to substantial estimation bias. On the other hand, assuming ordinality is important to re-examine Ferrer-i-Carbonell and Frijters' (2004) recent proposition that assuming cardinality and ordinality does not lead to differences in the results of happiness models. 
Therefore, this paper compares the two most recently proposed fixed-effects ordered logit estimators with the results of a standard linear fixed-effects model.

This paper finds that hours of work reductions led to increased average happiness of the Korean work force through transitions of the working hours distribution towards more satisfying categories. Moreover, strong gender-specific effects exist of how working hours affect family happiness. Controlling for percapita family income, women are most satisfied when staying at home or when being employed 31 to 40 hours. Men, in contrast, are most happy when being full-time employed between 31 and 50 hours. Not being employed or working below 30 hours a week is strongly detrimental to men's happiness. For both sexes, cross-partner effects are strongly significant and often equivalent to their partner's own preferences.

The paper is proceeds as follows. In section 1.2 relevant literature and background motivations for the analysis are discussed. Section 1.3 is presents data and methodology, followed by empirical results in section 1.4. The results section presents effects of the distributional change in working hours on overall satisfaction with life, the main job, and with one's working hours. Several robustness checks confirm and decompose the main findings further. In section 1.5, the division of labor between husband and wife inside and outside the home is analyzed with the help of more detailed time-use data. Section 1.6 concludes and derives policy implications.

\subsection{Background and Related Literature}

Empirical studies on subjective well-being and happiness have shown strong growth in the economic literature over the last decade. ${ }^{1}$ One of the central issues studied is the effect of employment which is found to be an important determinant of individual happiness (Clark and Oswald, 1994; Winkelmann and Winkelmann, 1998). In most studies, working contributes to happiness even after controlling for income effects. It is argued that this is the case because working can be a mechanism for social participation and engagement, which are known to be important factors of happiness. However, given expected roles and labor division between men and women present in most societies, the effects of employment may not be gender-neutral but create gender-specific effects. Booth

E.g. Alesina et al. (2004); Blanchflower and Oswald, 1998; Booth and Van Ours (2008; 2009); Clark (1997; 2003); Clark and Oswald (1994); Di Tella et al. (2001); Dolan et al. (2008); Ferrer-i-Carbonell and Van Praag (2002); Frey and Stutzer (2002); Frijters (2000); Frijters et al. (2004); Luttmer (2005); Pradhan and Ravallion (2000); Van Praag and Frijters (1999); Winkelmann and Winkelmann (1998). 
and van Ours $(2008 ; 2009)$ empirically study the question whether working hours affect life satisfaction of men and women differently, based on the gender identity hypothesis proposed by Akerlof and Kranton (2000) ${ }^{2}$. Through country case studies in the United Kingdom and Australia they find that women have certain preference for part-time jobs in both countries and women's decision to work full time decreases life satisfaction particularly in Australia. Their findings suggest that part-time jobs can be a good option for women to pursue both family responsibilities and social participation, supporting the gender identity hypothesis. They argue that traditional gender roles are still more prevalent in Australia than in the UK, which they conclude from the fact that Australian women are indifferent between working and not-working, while British women strictly prefer working. Looking at the gender gap measures in Table A1, the observed gender difference between the two countries seems minimal. However, there is a major difference in the public funding of and the enrolment in early childhood education institutions, seeing Australia lacking far behind the UK. The case of Korea stands out as a special case of high gender inequality since here all gender sub-indicators score worse than the two before-discussed country cases. It also ranks worse compared to Spain in most indicators, a country with a similar GNI per capita, and in fact, Korea's overall gender gap comes closest to that of Mexico in this sample of countries.

As Booth and van Ours admit, women's desirability of part-time jobs strongly depends on the latter's characteristics in a specific labor market and thus looking only at the number of working hours would have a few drawbacks. First, the choice of part-time jobs is not only dependent on gender identity or gendered roles but also the availability and quality of such jobs provided by a society. If part-time jobs are only available in the low-skilled sector with low pay and no career prospects, they might be less fulfilling and above that discredited by societal values. Thus, working part-time may no longer be a voluntary, preferred choice for a woman to combine family and career goals, but rather a pure necessity in case of insufficient earnings by her husband. This might then trigger dissatisfaction on her working hours, job and life. Especially in developing and emerging economies, part-time jobs are almost not existent beyond lowskilled service sector jobs. This, too, is likely to change when a country catches up with the most developed economies and women's rights are more pronounced. However, if women actually prefered to work lower hours, holding job quality fixed, yet the market didn't offer these opportunities, then we would be facing market failure, and there would be scope for government intervention. In

2 Akerlof and Kranton update Becker's (1965) gender-neutral hypothesis on labor division in the household by introducing the gender identify concept. 
fact, in most developed countries, family friendly working conditions were not the outcome of the free play of the market, but rather of targeted government action.

Second, as Akerlof and Kranton also point out in their paper, gender identity is dynamic rather than a time-invariant value. If a country experiences rapid changes in societal values and systems, expected roles of women and men are also arguably subject to changes and perception on professional, career-oriented women (or men engaging in housework) can be shifted from negative to positive (or vice versa).

Taking into account the arguments above, South Korea presents a unique country-study. In 2009, Korean workers exhibit the second longest working hours among OECD countries: 47.0 weekly hours per worker on average, while this is only 33.3 hours in the Netherlands, 38.1 in the UK and 44.2 in Mexico. ${ }^{3}$ Working long hours is presumably an accepted social standard in Korea and the availability of family-friendly jobs for women is limited. Thus, it is not surprising that "the land of the morning calm" ranks at the end of female labor force participation rates in the OECD. Nevertheless, women seeking serious career development also rapidly increased over the past decade. For instance, women account for 50.5 percent of all college graduates in 2005, a figure that increased from 37 percent in 1985; 44.5 percent of those who passed the bar examination were females in 2010, a sharp increase from 10 percent in 1995 (Korean Ministry of Education and Bar Examination Committee 1985-2010). However, enrollment in tertiary education is still much higher for males than for females (compare Table A1 in appendix). Women's commitments to their own career became more prominent after the Asian Financial Crisis in 1998 because the Crisis destroyed permanent employment systems practiced in Korea and therefore men lost their position as a stable breadwinner temporarily (Kim and Voos, 2007; Lee and Cho, 2005). While female higher education and women's careeraspirations have been increasing, opportunities for women to pursue such career development through part-time jobs are practically absent ${ }^{4}$. This makes it particularly hard to stay in employment for women as soon as they get married or start raising offspring. Consequently, one can surmise that while a high-skilled part-

These numbers are for average usual weekly hours worked in the main job for those aged 25 to 54 and all forms of employment (i.e. dependent and self-employed; part-time and full-time, etc.). Korea is only surpassed by Turkey with working hours as high as 49.7 (OECD Labor Statistics).

4 Booth and Van Ours (2008: 2009) also point out that part-time jobs are also less privileged in the United Kingdom and Australia. Given the long average working hours in Korea, part-time jobs are not only less privileged but also difficult to find in most occupations. 
time job may be the preferred choice for many Korean women, the current shape of the labor market with its long working hours and its absence of privileged part-time jobs hinders potential career building of a whole new group of highly qualified women. Thus, a new conflict arises between dynamic changes of women's status and traditionally expected gendered roles. In such cases many women will be caught in a trap to opt for one of two extremes: the triple burden of working overtime, organizing child care, and doing the major part of the housework. Or alternatively sacrifice all career aspirations and comply with traditional gender expectations to become a housewife. Lee et al. (2008) find that while there is a positive correlation between women's education and their labor force participation before marriage, after marriage this relation becomes negative.

\subsection{Data and Methodology}

Data for the analysis comes from the Korean Labor and Income Panel Study (KLIPS) for the years 1998 to 2008. KLIPS is a nationally representative longitudinal study of urban Korean households, modeled after the National Longitudinal Surveys (NLS) and the Panel Study of Income Dynamics (PSID) of the US. It is conducted annually by the Korea Labor Institute, a governmentsponsored research institute. The study started in 1998 with 5,000 households and 13,783 individuals aged 15 years or older. KLIPS collects a wide range of information on individuals, such as earnings, family, education, and employment backgrounds, and demographic characteristics. In addition, it offers broad information on subjective well-being.

The data quality KLIPS provides satisfies international standards. KLIPS maintains $76.5 \%$ of the original sample. The maintained level of KLIPS is similar to those of the US PSID (78\%); the German Socio-economic Panel (GSOEP, 79\%); and the British Household Panel Survey (BHPS 77\%). Kang (2010) shows that potential biases produced by attritions are negligible in KLIPS.

The main sample is restricted to married and co-residing couples living with children and excludes a few individuals which report enrollment in educational institutions as the current main occupation. Women are restricted to ages 20 to 54 , since these are the prime years of motherhood in which families face conflicting decisions between the woman staying at home or following market work. Men are restricted to ages 20 to 64 to allow for often slightly older husbands. ${ }^{5}$ The panel is unbalanced and thus the minimal requirement to the data is

5 Note that in the below analysis only very few men are in age cohorts exceeding 54 since cross-partner variables used in all models require information from both partners. 
that couples be present in at least two waves. These restrictions yield a sample of 25,461 person-year observations for females and 25,214 person-year observations for males.

The central variables for the analysis are overall satisfaction with life, with the main job, and satisfaction with working hours. The life satisfaction question requires individuals to respond to the following question: "Overall, how satisfied or dissatisfied are you with your life?". The exact wording of the job satisfaction question is "Overall, how satisfied or dissatisfied are you with your main job?", while hours satisfaction is the answer given to the aspect "Working hours" following the question "How satisfied or dissatisfied are you with regard to your main job on the following aspects?". For each of these questions, the respondent is asked to give a score between 1 ("very satisfied") and 5 ("very dissatisfied"). For reasons of easier interpretation, I recoded the scale so that a higher number indicates a higher level of satisfaction. Note that while life and hours satisfaction are available in all survey waves, job satisfaction was added to the questionnaire only from wave 3 onwards.

Working hours in this paper refer to "average weekly working hours" which are ask separately for wage-earners and self-employed in the KLIPS questionnaire. Wage-earners are asked for usually worked hours in a normal week, including overtime but excluding lunchtime. Self-employed are asked for the number of weekly hours that they usually work at their job.

Table 1.1: Distribution of Satisfaction Measures by Gender (percent)

\begin{tabular}{|c|c|c|c|c|c|c|}
\hline & \multicolumn{3}{|c|}{ Wifes } & \multicolumn{3}{|c|}{ Husbands } \\
\hline & $\begin{array}{c}\text { Life } \\
\text { satis- } \\
\text { faction }\end{array}$ & $\begin{array}{l}\text { Hours } \\
\text { satis- } \\
\text { faction }\end{array}$ & $\begin{array}{c}\text { Job } \\
\text { satis- } \\
\text { faction }\end{array}$ & $\begin{array}{c}\text { Life } \\
\text { satis- } \\
\text { faction }\end{array}$ & $\begin{array}{l}\text { Hours } \\
\text { satis- } \\
\text { faction }\end{array}$ & $\begin{array}{c}\text { Job } \\
\text { satis- } \\
\text { faction }\end{array}$ \\
\hline $\begin{array}{l}1 \text { (very } \\
\text { dissatisfied) }\end{array}$ & 1.5 & 2.7 & 1.0 & 1.4 & 3.00 & 1.0 \\
\hline 2 & 11.4 & 23.0 & 13.8 & 11.1 & 23.7 & 15.1 \\
\hline 3 & 54.8 & 43.5 & 58.6 & 54.4 & 45.4 & 56.9 \\
\hline 4 & 31.5 & 29.5 & 25.9 & 32.1 & 26.9 & 26.3 \\
\hline 5 (very satisfied) & .8 & 1.3 & .8 & .9 & 1.1 & .8 \\
\hline Total & 100 & 100 & 100 & 100 & 100 & 100 \\
\hline Mean & 3.19 & 3.04 & 3.12 & 3.20 & 2.99 & 3.11 \\
\hline $\mathrm{N}$ & 25,461 & 11,411 & 9,610 & 25,214 & 21,509 & 18,267 \\
\hline
\end{tabular}

Hours and job satisfaction only for individuals with non-missing and non-zero working hours.

Hence, couples' person-year observations are excluded from the analysis as soon as women's age is above 54 . 
Table 1.1 shows the distribution of life, hours and job satisfaction by gender. The modes of all distributions are in category 3, which is "neither satisfied nor dissatisfied". It is striking how low the relative frequency of the extreme values "very dissatisfied" and "very satisfied" are. While this is quite normal for the lower satisfaction boundary, it is fairly unusual in Western cultures. For example, in life satisfaction studies using German GSOEP or British BHPS data, the highest category has a relative frequency of about 7 to 10 percent even in scales with 11 and 7 different categories, respectively (compare Clark et al., 2008; Booth and Van Ours, 2008). This might be explained by Korean culture which rewards a more modest use of language and might be a hint for caution when conducting cross-country happiness analysis. Most variation in the data used in this study is indeed between categories 2 to 4 . Average life and job satisfaction of men and women are comparable and range around 3.2 and 3.1 respectively. Hours satisfaction is somewhat lower and also differs between women and men.

Figure 1.1 shows the distribution and trend of weakly working hours and trends of life, hours, and job satisfaction from 1998 to 2008 in the sample. Official working time until 2004 was 48 hours and 6 days a week. With the new legislation in mid 2004 this changed to 40 hours and 5 days a week. However, transition towards new working hours has not been an abrupt discrete adaptation but a rather gradual change in hours given that labor unions are relatively week in Korea. The graph on the left gives proof of extremely long working hours in Korea. It shows that the majority of working husbands and wives were working between 40 and 60 hours over the observed decade. While more women than men worked below 40 hours, men were more present in extremely long hours $(>60)$. Note that only 29 percent of all working women were able to secure a job with working hours below 40 . The graph makes clear that a large share of workers of both sexes with family duties were working extremely long hours. 

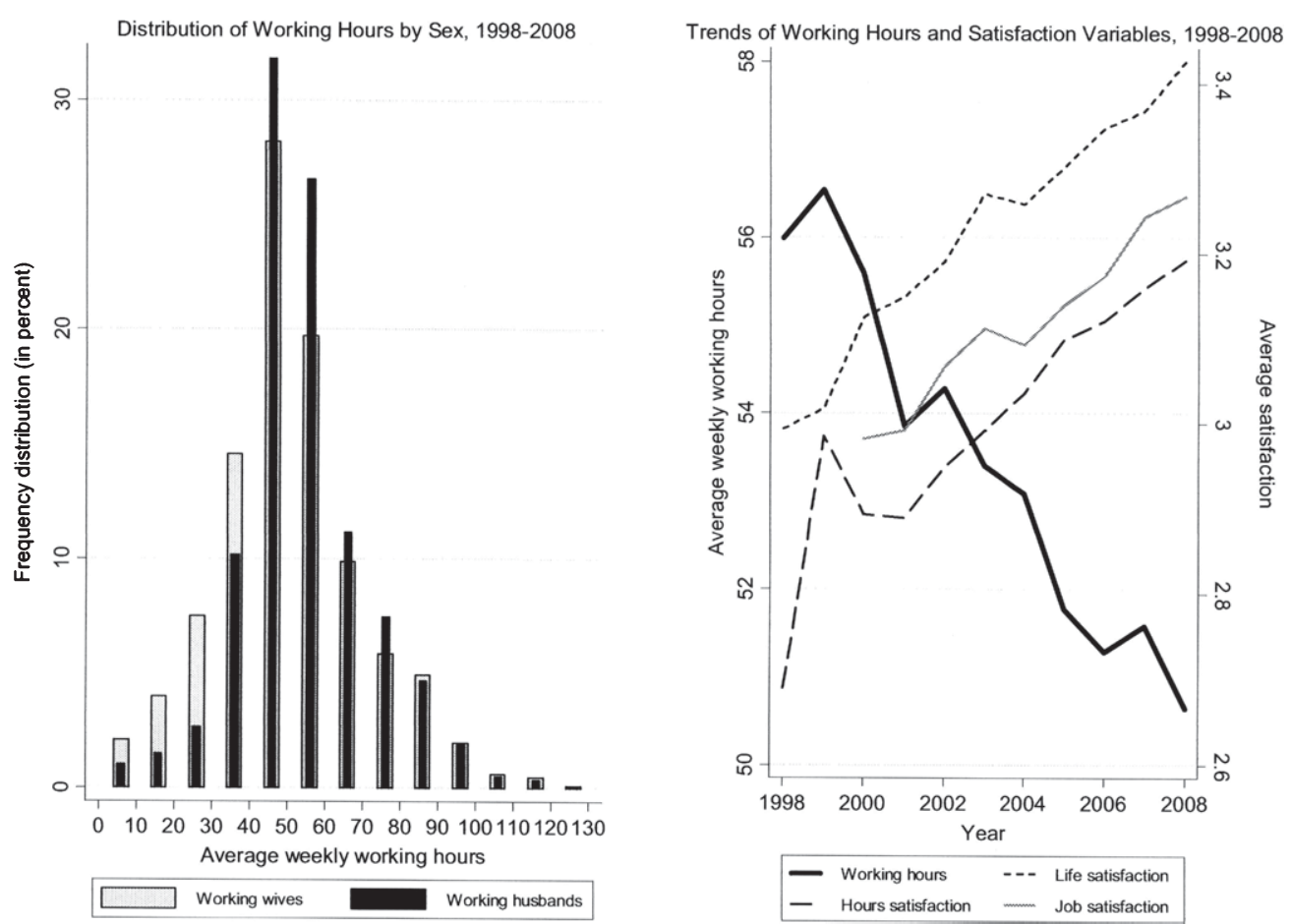

Fig. 1.1: Distribution of Working Hours by Sex and Trends of Working Hours and Satisfaction Variables 
The graph on the right shows that working conditions have significantly been improved in Korea. Average working hours have already drastically decreased over this decade from above 56 hours in 1999 to below 51 hours in 2008. This has probably had a positive effect on hours and job satisfaction, as well as on life satisfaction. During the period under study, all three measures increased gradually.

Table 1.2: Average Satisfaction by Working Hours

\begin{tabular}{|c|c|c|c|c|c|c|c|c|}
\hline & \multicolumn{4}{|c|}{ Wifes } & \multicolumn{4}{|c|}{ Husbands } \\
\hline & $\begin{array}{c}\text { Life } \\
\text { satis- } \\
\text { faction }\end{array}$ & $\begin{array}{l}\text { Hours } \\
\text { satis- } \\
\text { faction }\end{array}$ & $\begin{array}{c}\text { Job } \\
\text { satis- } \\
\text { faction }\end{array}$ & $\begin{array}{c}\text { Percen- } \\
\text { tage } \\
\text { wage- } \\
\text { empl. }\end{array}$ & $\begin{array}{c}\text { Life } \\
\text { satis- } \\
\text { faction }\end{array}$ & $\begin{array}{l}\text { Hours } \\
\text { satis- } \\
\text { faction }\end{array}$ & $\begin{array}{c}\text { Job } \\
\text { satis- } \\
\text { faction }\end{array}$ & $\begin{array}{c}\text { Percen- } \\
\text { tage } \\
\text { wage- } \\
\text { empl. }\end{array}$ \\
\hline Hours & 3.23 & - & - & - & 2.68 & - & - & - \\
\hline 0 & (13390) & & & & (2137) & & & \\
\hline $\begin{array}{l}\text { Hours 1- } \\
30\end{array}$ & $\begin{array}{c}3.13 \\
(1636)\end{array}$ & $\begin{array}{c}3.31 \\
(1546)\end{array}$ & $\begin{array}{c}3.05 \\
(1291)\end{array}$ & 57.2 & $\begin{array}{c}2.99 \\
(1192)\end{array}$ & $\begin{array}{c}2.92 \\
(1131)\end{array}$ & $\begin{array}{c}2.77 \\
(912)\end{array}$ & 47.0 \\
\hline Hours & 3.27 & 3.43 & 3.28 & 71.0 & 3.34 & 3.37 & 3.26 & 72.7 \\
\hline $31-40$ & $(1751)$ & $(1676)$ & (1508) & & (2328) & $(2231)$ & (2054) & \\
\hline Hours & 3.27 & 3.34 & 3.27 & 80.1 & 3.36 & 3.32 & 3.25 & 76.8 \\
\hline $41-50$ & (3388) & (3152) & (2789) & & $(7322)$ & $(6814)$ & (5934) & \\
\hline Hours & 3.09 & 2.88 & 3.05 & 65.7 & 3.24 & 2.93 & 3.07 & 67.0 \\
\hline $51-60$ & (2370) & $(2250)$ & (1949) & & (6111) & $(5660)$ & (4894) & \\
\hline Hours & 2.98 & 2.43 & 2.90 & 31.2 & 3.14 & 2.52 & 2.96 & 50.1 \\
\hline $60+$ & (2881) & (2787) & (2073) & & $(6053)$ & $(5673)$ & (4473) & \\
\hline
\end{tabular}

Table 1.2 shows average satisfaction by working hours separately for men and women. Starting with 0 hours of work, women show much higher life satisfaction than men. This is mainly due to different reasons for "not working". While women stay at home often voluntarily or due to household and childcare duties, Korean men consider it as their main task to earn the major part of a household's income. Thus, not being at work means they cannot fulfill their socially assigned role which in turn strongly decreases their happiness. ${ }^{67}$ Both

6 In Confucianism the probably most important duty of an individual is to comply with the role that society expects from someone. This is sometimes expressed as the importance of "rectification of names", implying that members of society are reward for acting according to their predefined "name" or "role". Thus a husband should try to be a perfect husband, and a wife a perfect wife. If every member of society does her best to fulfill her role, then it is believed that society is in a state of equilibrium. However, this does not mean that no social mobility is possible. If predefined roles change, then socie- 
men and women show highest life and job satisfaction when working 31 to 50 hours, thus when working normal full-time. There seems to be no significant difference in happiness between women in the latter group and non-working women. The share of wage-employed is highest in normal full-time jobs. In contrast, being non-wage employed varies much more in terms of working hours. Women's life satisfaction is lowest when working more than 60 hours, while for men this is the case when not working at all or when being only part-time employed. Female hours satisfaction decreases more rapidly as working hours increase.

Table 1.3: Change in Work Hours Distribution After Introduction of 5-day Working Week

\begin{tabular}{|c|c|c|c|c|c|c|}
\hline & \multicolumn{3}{|c|}{ Women } & \multicolumn{3}{|c|}{ Men } \\
\hline & $\begin{array}{c}\text { Before } 2004 \\
(\%)\end{array}$ & $\begin{array}{l}\text { After } 2004 \\
(\%)\end{array}$ & Change & $\begin{array}{c}\text { Before } 2004 \\
(\%)\end{array}$ & $\begin{array}{c}\text { After } 2004 \\
(\%)\end{array}$ & Change \\
\hline Hours 0 & 53.2 & 51.8 & -1.4 & 9.4 & 6.7 & -2.7 \\
\hline Hours $1-30$ & 6.9 & 5.9 & -1.0 & 5.2 & 4.2 & -1.0 \\
\hline Hours $31-40$ & 4.7 & 9.8 & +5.1 & 5.2 & 14.8 & +9.6 \\
\hline Hours 41-50 & 12.4 & 14.7 & +2.3 & 27.6 & 31.2 & +3.6 \\
\hline Hours $51-60$ & 9.4 & 9.3 & -.1 & 25.1 & 23.5 & -1.6 \\
\hline Hours $60+$ & 13.4 & 8.6 & -4.8 & 27.5 & 19.6 & -7.9 \\
\hline Total & 100 & 100 & & 100 & 100 & \\
\hline
\end{tabular}

Notes: "Before 2004" includes years 1998-2003,

"After 2004" includes years 2004-2008. Data: KLIPS 1998-2008.

In order to analyze the utility effect of the introduction of the 5-day working week in 2004 in Korea, it is important to know how exactly the distribution of hours changed before and after the reform. Table 1.3 shows that for women there was a substantial shift from not-working, part-time and overtime work towards more regular full-time hours (31-50 hours weekly). For men, the same shift took place, and it was even stronger in the male distribution. Therefore, what needs to be analyzed in the following multivariate analysis is whether these shifts towards more full-time employment were indeed associated with increasing satisfaction levels.

Using KLIPS data, this paper analyzes the determinants of hours, job, and life satisfaction for married Korean couples co-residing in the same household.

ty changes, too. Thus the identity concept is of high relevance for South Korea, as it is among the countries most influenced by Confucian thought until today.

7 This is in line with Jang et al. (2009) who show that Korean men suffer much more from depressive symptoms than their female counterparts when unemployed, early retired or out-of-labor-force. 
As 84 percent of the couples in the sample have children in the household, and since the focus is on the combination of work and children, the analysis will be restricted to couples with children. The satisfaction variable $S$ is of an ordinal response type and has categorical scale ranging from $k=1, \ldots, 5$. It is an ordinal representation of its underlying latent continuous distribution $S^{*}$. Hence, in order to estimate effects of working hours on satisfaction of individual $i$ in year $t$ the estimation procedure begins with an ordered logit specification. The latent variable representation is denoted in the following equations:

$$
\begin{gathered}
S_{i t}^{*}=x_{i t} \beta+\varepsilon_{i t}, \quad i=1, \ldots, N \quad t=1, \ldots, T \\
S_{i t}=k \Leftrightarrow \lambda_{k} \leq S_{i t}^{*}<\lambda_{k+1} \quad k=1, \ldots, K
\end{gathered}
$$

Here, $x$ is a vector of explanatory variables, the error $\varepsilon$ is assumed to be orthogonal to $x$, and $\beta$ and $\lambda$ are parameters to be jointly estimated, the latter being category-specific and often called thresholds. ${ }^{8}$ Thresholds $\lambda$ are assumed to be strictly increasing $\left(\lambda_{k}<\lambda_{k+1}, \forall k\right)$ and $\lambda_{1}=-\infty, \lambda_{K+1}=\infty$. The corresponding probability function is then:

$\operatorname{Pr}\left(S_{i t}=k \mid x_{i t}\right)=\Lambda\left(\lambda_{k}-x_{i t} \beta\right)-\Lambda\left(\lambda_{k-1}-x_{i t} \beta\right)$

where $\Lambda$ indicates the logistic cumulative distribution function. The probability that the observed dependent variable $S_{i t}$ equals $k$ is the probability that the latent variable $S_{i t}^{*}$ is between the thresholds $k-1$ and $k$.

In the presence of individual unobservable factors that affect both a person's perceived satisfaction level and the covariates used in the model, cross-sectional estimates are likely to be biased. For example, an active-optimistic personality trait might both increase life satisfaction and decrease the risk of being unemployed. Therefore it is essential to control for these fixed effects. Different estimators have been suggested recently in the literature, but there is no standard way of controlling for fixed effects while assuming ordinality yet. Two different estimation approaches proposed by Ferrer-i-Carbonell and Frijters (2004) and Baetschmann, Staub, and Winkelmann (2011) will be applied.

The fixed-effects ordered logit specification as proposed by Ferrer-i-Carbonell and Frijters (2004), in the following denoted 'FF-estimator', was used by Booth and van Ours $(2008,2009)$ for their study of working hours and life satisfaction in the UK and Australia. In their FF-estimation model, the above equations require a slight change in that individual fixed effects $u_{i}$ and individualspecific thresholds $\lambda_{i k}$ need to be introduced.

$\operatorname{Pr}\left(S_{i t}=k \mid x_{i t}\right)=\Lambda\left(\lambda_{i k}-u_{i}-x_{i t} \beta\right)-\Lambda\left(\lambda_{i, k-1}-u_{i}-x_{i t} \beta\right)$

8 The thresholds are only estimated in the ordered logit case, not in the following conditional logit (FF and BUC estimators). 
Instead of a common cutoff point, for each individual in the sample an individual cutoff point $\lambda_{i k}$ is chosen. ${ }^{9}$ As Ferrer-i-Carbonell and Frijters (2004) show, this then allows the fixed-effects ordered logit model to be reformulated as a fixedeffects binomial logit. The reformulation then allows an estimation using Chamberlain's method. ${ }^{10}$

However, very recently, Baetschmann, Staub and Winkelmann (2011) argued the FF-estimator is likely to be biased since cutoff points are chosen endogenously. This is obviously problematic and they show theoretically and in Monte-Carlo simulations that the significance of a slight but significant downward bias cannot be rejected.

The authors then go on and present an own estimator which is recently receiving increased attention. The BUC estimator is based on an approach of Das and van Soest (1999) who take advantage of the fact that dichotomizing and estimating at every possible common cutoff point (e.g. $k=1, \ldots, 5$ in the satisfaction variables) provides a consistent estimate of $\beta$. After using Chamberlain's method for all possible estimations, they combine the resulting estimates and weight them by the inverse of their variance. Since this estimator has been criticized to be imprecise when only very few observations are available for some categories, Baetschmann, Staub and Winkelmann (2011) propose a modified form of it. In contrast to the two-step combinations of all possible dichotomizations used by Das and van Soest, they suggest to estimate all dichotomizations jointly. The resulting BUC ("Blow-Up and Cluster") estimator replaces every observation in the sample by $K-1$ copies of itself, and dichotomizes every $K-1$ copy of the individual at a different cutoff point. Then CML logit is estimated using the entire sample and clustering at the individual level to correct standard errors. In subsequent Monte-Carlo simulations conducted in their paper, the authors then compare different fixed-effects ordinal logit estimators. The BUC-

9 Here we use the mean-version of the estimator, i.e. we calculate individual specific thresholds in the following way: $\lambda_{i}=n_{i}^{-1} \sum_{t} S_{i t}$, where $n_{i}$ is the total number of observations of individual $i$. The dichotomization of the categorical scale is then done by transforming all observations for which $S_{i t}>\lambda_{i}$ into $z_{i t}=1$, and all observations for which $S_{i t} \leq \lambda_{i}$ into $z_{i t}=0$.

10 In the past, researchers used different approaches to overcome the lack of a fixed-effects ordinal probit and logit methods. While psychologists and sociologists often interpreted satisfaction scores as cardinal and estimated OLS-type models, many economists transformed the satisfaction scores to a binary $(1,0)$ outcome variable. By choosing an arbitrary cutoff point that was common for all individuals, this implied the loss of a large amount of information since only individuals that were moving along the threshold were considered in the FE analysis. 
estimator appears to be consistent and efficient among a number of different estimators including the FF-estimator.

The question might arise why in the presence of the BUC-estimator one should still be interested in results from the FF-estimator. There are several reasons: First of all, in their simulations, the FF-estimator nevertheless converges to the true value as $T$ and $N$ rise and $K$ decreases. Thus, given the characteristics of the sample, estimates are likely to be only marginally biased, if biased at all. Second, in order to compare the results to the findings made by Booth and van Ours $(2008,2009)$, it is helpful to apply the same estimation technique as they did. And third, the performance of the BUC estimator has not been tested in a lot of applications yet due to its recent appearance. Thus, it needs to be seen how it performs under different circumstances, e.g. under extreme distributions in the categorical dependent variable or in unbalanced panels. Thus, I decide to make use of both estimators which I think are the best currently available options to account for fixed effects in an ordinal choice analysis. As a further robustness check, I will compare the results to linear fixed-effects regressions. As argued by Ferrer-i-Carbonell and Frijters (2004), assuming cardinality and estimating models of life satisfaction using linear fixed-effects makes little difference for the results. Linear estimation has the additional advantage of providing a more straight-forward interpretation of estimation coefficients. ${ }^{11}$

\subsection{Satisfaction Regression Results 1.4.1 Life Satisfaction}

Table 1.4 shows regression results of the effect of working hours on the main happiness variable, life satisfaction. First, let us take a look at the results of the ordered logit pooled cross-section estimations in columns (1) and (5). Life satisfaction is positively related to own per-capita household income and negatively to average regional per-capita incomes. This confirms the usually found relative income hypothesis (e.g. Luttmer, 2005; Kang, 2010). It is interesting that relative income is more important for the happiness of wives than of husbands. This probably reflects broader social networking and higher social comparison be-

11 In fact, calculating marginal effects is not possible for the conditional logit models of the FF- and the BUC-estimator unless one makes an assumption about the unknown fixed-effect (e.g. the implausible one that fixed effects are zero). However, interpreting signs of coefficients (and of course significance levels) is still possible and magnitudes can be compared within one regression. 
Table 1.4: Life Satisfaction Regressions

\begin{tabular}{|c|c|c|c|c|c|c|c|c|}
\hline \multicolumn{9}{|l|}{ Dependent Variable: Life Satisfaction } \\
\hline & \multicolumn{4}{|c|}{ Wife } & \multicolumn{4}{|c|}{ Husband } \\
\hline & Ordered logit & BUC & FF & FE-OLS & Ordered logit & BUC & FF & FE-OLS \\
\hline & (1) & (2) & (3) & (4) & (5) & (6) & (7) & $(8)$ \\
\hline \multicolumn{9}{|l|}{ Family } \\
\hline Log per-capita income & $.414^{* * *}$ & $.183^{* * *}$ & $.189 * * *$ & $.056^{* * *}$ & $.401^{* * *}$ & $.195^{* * *}$ & $.202^{* * *}$ & $.059 * * *$ \\
\hline Log of regional per-capita income & $-.809 * * *$ & $-.700^{* * *}$ & $-.810^{* * *}$ & $-.203 * * *$ & $-.437 * *$ & $-.585^{* * *}$ & $-.425^{*}$ & $-.149 * * *$ \\
\hline Own house & $.521^{* * *}$ & $.293^{* * *}$ & $.283^{* * *}$ & $.076^{* * *}$ & $.506^{* * *}$ & $.308^{* * *}$ & $.326^{* * *}$ & $.085^{* * *}$ \\
\hline $\mathrm{N}$ of old females & -.006 & .062 & .035 & .014 & .010 & -.010 & -.101 & .002 \\
\hline $\mathrm{N}$ of old males & -.012 & $-.496 * * *$ & $-.461^{* * *}$ & $-.140 * * *$ & -.086 & $-.469^{* *}$ & $-.465^{* * *}$ & $-.120 * * *$ \\
\hline $\mathrm{N}$ of sons age $0-14$ & -.026 & $-.145^{* *}$ & $-.121^{* *}$ & $-.036^{* *}$ & .005 & -.047 & -.025 & -.013 \\
\hline $\mathrm{N}$ of daughters age $0-14$ & .024 & $-.111^{*}$ & -.040 & $-.031^{* *}$ & .021 & $-.137^{* *}$ & $-.107^{*}$ & $-.032 * *$ \\
\hline $\mathrm{N}$ of sons age $15-30$ (econ. dep.) & .037 & -.002 & -.014 & -.002 & .033 & -0.039 & -.055 & -.010 \\
\hline $\mathrm{N}$ of daughters age $15-30$ (econ. dep.) & -.049 & $-.127^{* *}$ & -.069 & $-.037 * *$ & .009 & -.098 & -.091 & $-.028^{*}$ \\
\hline \multicolumn{9}{|l|}{ Own working hours } \\
\hline Hours $1-30$ & $-.218^{* * *}$ & -.117 & -.058 & -.028 & $.619 * * *$ & $.606^{* * *}$ & $.574^{* * *}$ & $.176^{* * *}$ \\
\hline Hours $31-40$ & -.063 & -.085 & -.055 & -.018 & $1.18^{* * *}$ & $.871^{* * *}$ & $.854^{* * *}$ & $.259^{* * *}$ \\
\hline Hours 41-50 & $-.083^{*}$ & -.087 & -.092 & -.019 & $1.25^{* * *}$ & $.947^{* * *}$ & $.918^{* * *}$ & $.283^{* * *}$ \\
\hline Hours 51-60 & $-.288^{* * *}$ & $-.117^{*}$ & $-.128^{*}$ & $-.029^{*}$ & $1.02^{* * *}$ & $.843^{* * *}$ & $.786^{* * *}$ & $.255^{* * *}$ \\
\hline Hours 60+ & $-.349 * * *$ & -.065 & -.020 & -.011 & $.958^{* * *}$ & $.910^{* * *}$ & $.856^{* * *}$ & $.274^{* * *}$ \\
\hline \multicolumn{9}{|l|}{ Partner's working hours } \\
\hline Hours 1-30 & $.395^{* * *}$ & $.455^{* * *}$ & $.509^{* * *}$ & $.151^{* * *}$ & $-.199 * * *$ & $-.130^{*}$ & -.095 & $-.037^{*}$ \\
\hline Hours $31-40$ & $.863^{* * *}$ & $.678^{* * *}$ & $.673^{* * *}$ & $.203^{* * *}$ & -.059 & -.021 & .003 & -.005 \\
\hline Hours 41-50 & $.924^{* * *}$ & $.748^{* * *}$ & $.730^{* * *}$ & $.220 * * *$ & $-.084^{*}$ & -.050 & -.020 & -.010 \\
\hline Hours 51-60 & $.703^{* * *}$ & $.647^{* * *}$ & $.657^{* * *}$ & $.197^{* * *}$ & $-.215^{* * *}$ & -.002 & -.012 & .003 \\
\hline Hours $60+$ & $.684^{* * *}$ & $.711^{* * *}$ & $.730^{* * *}$ & $.216^{* * *}$ & $-.368^{* * *}$ & $-.166^{* *}$ & $-.162^{* *}$ & $-.042^{* *}$ \\
\hline Log likelihood & $-23,622$ & $-12,220$ & $-9,163$ & - & $-23,261$ & $-12,198$ & $-8,999$ & - \\
\hline Observations & 25,153 & 33.779 & 22,349 & 25,153 & 24,919 & 34,162 & 22,160 & 24,919 \\
\hline Individuals & - & 13,634 & 3,121 & 4,024 & - & 13,542 & 3,096 & 3,998 \\
\hline Clusters & 4,024 & 3,227 & - & - & 3,998 & 3,226 & - & - \\
\hline
\end{tabular}

Data: KLIPS 1998-2008. Reference category for working hours: 0 hours per week (not working).

Notes: All specifications inchide control vartables for household head and spouse as well as dummies for year of survey. Pooled cross-sectlonal orderered logil specifications in (I) and (5) include additionally age. age2, years of schooling. and duminies for province of residence. These specifications were also corrected for clustering of observations. ${ }^{* * *} / * * / *$ indicate a parameter estimate is significant at the $1 \% / 5 \% / 10 \%$ level. respectively. Numbers of observations and individuals of BUC estination are not directly comparable with other regressions due to particular estimation procedure ("blow up and cluster"). 
tween women. Household wealth as proxied by the variable "living in an 'own house"" is positive and significant as expected. Household composition does not play a role in the cross-sectional analysis.

The influence of working hours on life satisfaction is different for women and men. For wives, results suggest that compared to the reference category "not working", women have significant negative effects for all hours categories except for working 31 to 40 hours per week. In contrast, husbands do experience strong positive effects from being at work with preferred hours in the category 41 to 50 hours. Strong cross-partner effects show that both partner's life satisfaction is mutually affected by the spouse's working hours status. Cross-partner effects are of somewhat lower magnitude as own effects but of similar statistical significance. Corresponding to her spouses' own preferences, women prefer their husbands to work, preferably full time, while men prefer their women to stay at home or to work 31 to 40 hours. Having a wife working long hours strongly reduces husband's happiness.

Keeping in mind that cross-sectional results are likely to be biased due to individual unobserved factors, fixed-effects results as in columns (2)-(4) and (6)-(8) should be preferred. I compare different state-of-the-art estimation techniques to synthesize the findings. Magnitudes cannot be directly interpreted in the conditional logit case of the BUC and the FF estimators. Nevertheless, what is possible to interpret and what is essential for this paper's analysis of conditional logit estimations, are signs of coefficients, their significance levels as well as, within one particular estimation, their relative magnitudes. Results for income and wealth variables are confirmed in the fixed-effects estimations. Compared to the previous cross-sectional analysis, now also interesting findings emerge in the household composition variables. First, the estimates indicate that having an elderly man in the household does decrease life satisfaction of the married couple. In Korea, traditionally it was the obligation of the eldest son to take care of the parents when they grow older. Although changing nowadays, this tradition is kept alive in many families until today. Since age, seniority, and patriarchy are important concepts in Korea's Confucianist society, old males usually receive highest social respect and thus exert strong influence on daily family life even when living in their children's household (Zhang et al., 2005). This might negatively influence family life. Second, the number of sons and daughters in a household does contribute in different ways to parent's happiness. While mothers seem to be negatively affected by young children in general ( 0 14 years), it looks as if young boys are associated with lower happiness than 
girls. ${ }^{12}$ Interestingly, older children (15-30 years, unmarried and economically dependent) have a negative effect only when they are daughters. Fathers only show robust negative effects in the case of young daughters. While negative effects of having children are often found in the literature (Dolan et al., 2008), the results suggest that son preference is still present at the beginning of the $21^{\text {st }}$ century in Korea (compare Chung and Das Gupta, 2007). The finding that household composition does not have an effect in the cross-sectional analysis whereas it has undeniable effects in the fixed-effects analysis suggests two things. First, it shows once more the importance to control for unobserved heterogeneity. And second, there might be adjustment effects going on to household composition changes, i.e. parents adjusting to new circumstances such as a child birth over time (see e.g. Clark et al., 2008).

Concerning working hours, fixed-effects results confirm the strong positive cross-sectional findings for men, while negative results for women lose significance except for overtime work (51 to 60 hours). Controlling for household income, as in all regressions, the results indicate that husbands are most satisfied when working 41 to 50 hours. It is surprising that both women and men show relatively high life satisfaction when working more than 60 hours. This might suggest that Korean society is characterized by a high work ethic and thus working long hours is socially accepted. Second, working very long hours often implies higher responsibilities at the work place which can be more fulfilling, particularly within highly hierarchical Korean enterprises structures.

Cross-partner effects in the fixed-effects analyses are similar for women to those in the cross-sectional analysis. Women strongly prefer their husbands to work, because an unemployed husband often means an unhappy husband, even if household income is kept constant. Men, in contrast, dislike their wives to work in low-paid and low-responsible 1-to-30-hours part-time jobs as well as in long-overtime jobs.

Life satisfaction results have shown that partnered women with children are indifferent between working and not-working, once household income is controlled for. Men, on the other hand, seem to obtain strong beyond-income satisfaction from being at work. ${ }^{13}$

12 We tried to estimate additionally with number of girls and boys aged $0-3$. This did not change the main findings. While boys show no significant effect, little girls showed positive significant effects.

13 Note that year effects, which are not displayed in the table, are significant and increasing over time. Thus, there is a positive unexplained trend in happiness which might reflect general improvements in living standards after the Asian Financial Crisis. Results do not change if 5-year age cohorts are controlled for. 


\subsubsection{Hours and Job Satisfaction}

The picture about the effect of working hours on satisfaction becomes clearer when looking at hours and job satisfaction results in Table $1.5 .{ }^{14}$ Ceteris paribus, Korean women's hours satisfaction is highest when working part-time (1-30 hours), which is the reference category, or short full-time (31-40 hours). All additional hours spent at work gradually decrease women's hours satisfaction. These results hold for all estimation methods. Compared to working part-time, Korean men prefer to work between 31 and 50 hours, and their hours satisfaction significantly declines when working overtime hours. Controlling for household income, men who work 31 to 40 hours have highest hours satisfaction. Compared to the above life satisfaction analysis, cross-partner effects play a minor role when individuals rate their satisfaction with working hours. Still, men seem to be more satisfied with their own working hours in case their wife works 31 to 40 hours a week.

Women's preferences at work are confirmed and clarified when looking at job satisfaction estimates. Here, working 31 to 40 hours is the preferred choice. The fact that women prefer this category to part-time employment probably stems from the latter job's low-quality nature. Working more than 40 hours is not significantly different from part-time employment in terms of job satisfaction. Here potential benefits of increased job quality are outweighed by long working hours, conflicting with family duties.

Men have significantly higher job satisfaction when working in normal fulltime positions without overtime (31-50 hours). However, overtime work (i.e. $\geq 50$ hours) is still more beneficial than part-time work. Higher social status and more fulfilling tasks might be potential explanations. Interestingly, women report highest cross-partner effects when their husbands work between 31 and 40 hours. Husbands who don't work overtime might be more willing to contribute to housework and childcare, reducing women's double burden and helping to increase women's happiness at work.

14 Regressions in Table 1.5 include several control variables that were already included in the life satisfaction regressions. Apart from that, further controls included here are a dummy variable that controls for job type ( 1 =wage; $0=$ non-wage), 10 occupation dummies, and 16 industry dummies. Of course only those currently employed are interviewed. 


\begin{tabular}{|c|c|c|c|c|c|c|c|c|}
\hline & \multicolumn{4}{|c|}{ Wife } & \multicolumn{4}{|c|}{ Husband } \\
\hline & Ordered logit & BUC & FF & FE-OLS & Ordered logit & BUC & FF & FE-OLS \\
\hline Dep. Variable: Hours Satisfaction & (1) & (2) & (3) & (4) & (5) & (6) & (7) & (8) \\
\hline Job type ( $1=$ wage: $0=$ non-wage $)$ & .091 & $.527^{* * *}$ & .045 & .034 & $-.201 * * *$ & $.213^{* * *}$ & $-.360 * * *$ & $-.106^{* * *}$ \\
\hline \multicolumn{9}{|l|}{ Own working hours } \\
\hline Hours $31-40$ & .001 & -.025 & -.036 & -.004 & $.826^{* * *}$ & $.491^{* * *}$ & $.579 * * *$ & $.199^{* * *}$ \\
\hline Hours 41-50 & $-.269 * * *$ & $-.246^{* *}$ & $-.233^{* *}$ & $-.076^{* * *}$ & $.644^{* * *}$ & $.346^{* * *}$ & $.418^{* * *}$ & $.155^{* * *}$ \\
\hline Hours 51-60 & $-1.11^{* * *}$ & $-.941^{* * *}$ & $-.982^{* * *}$ & $-.319 * * *$ & $-.206^{* * *}$ & $-.238^{* * *}$ & $-.274^{* * *}$ & $-.086^{* * *}$ \\
\hline $\begin{array}{l}\text { Hours } 60+ \\
\text { Partner's working hours }\end{array}$ & $-2.06 * * *$ & $-1.62^{* * *}$ & $-1.58^{* * *}$ & $-.579 * * *$ & $-1.13^{* * *}$ & $-.911^{* * *}$ & $-.949 * * *$ & $-.359 * * *$ \\
\hline Hours 0 & -.077 & .075 & .005 & -.002 & $.168^{* * * *}$ & .101 & .068 & .024 \\
\hline Hours $31-40$ & $.232^{* *}$ & .180 & .170 & .059 & .124 & $.160^{*}$ & .104 & $.050^{*}$ \\
\hline Hours 41-50 & $.189^{* *}$ & .156 & $.225^{*}$ & $.063^{*}$ & .056 & .036 & -.002 & .022 \\
\hline Hours 51-60 & .122 & .090 & .066 & .030 & .080 & .073 & .067 & .038 \\
\hline Hours $60+$ & .033 & .058 & .049 & .032 & -.041 & .002 & -.011 & .026 \\
\hline Log likelihood & -11.535 & $-6,201$ & $-3,816$ & - & $-22,618$ & $-13,828$ & -7.931 & - \\
\hline Observations & 11,128 & 19.693 & 9,587 & 11,128 & 21,182 & 45,511 & 19,219 & 21,182 \\
\hline Individuals & - & 4,035 & 1,709 & 2,539 & - & 12,281 & 2,917 & 3.791 \\
\hline Clusters & 2,539 & 1,875 & - & - & 3,791 & 3,222 & - & - \\
\hline Dep. Variable: Job Satisfaction & (9) & (10) & (11) & (12) & (13) & (14) & (15) & (16) \\
\hline Job type $(1=$ wage; $0=$ non-wage $)$ & .101 & -.111 & -.092 & -.008 & -.037 & -.068 & $-.215^{* *}$ & $-.049 * *$ \\
\hline \multicolumn{9}{|l|}{ Own working hours } \\
\hline Hours $31-40$ & $.255^{* * *}$ & .086 & $.212^{*}$ & $.054^{*}$ & $.897^{* * *}$ & $.314^{* * *}$ & $.612^{* * *}$ & $.163^{* * * *}$ \\
\hline Hours 41-50 & $.262^{* * *}$ & .062 & .144 & $.046^{*}$ & $.861^{* * *}$ & $266^{* * *}$ & $.544^{* * *}$ & $.161^{* * *}$ \\
\hline Hours 51-60 & .095 & -.074 & .035 & .024 & $.559^{* * *}$ & .136 & $.336^{* * *}$ & $.111^{* * *}$ \\
\hline \multicolumn{8}{|l|}{ Partner's working hours } & $.084^{* * *}$ \\
\hline Hours 0 & .195 & -.041 & .077 & -.001 & $.213^{* * *}$ & $.152^{*}$ & -.007 & .021 \\
\hline Hours $31-40$ & $.481^{* * *}$ & $.236^{*}$ & $.378 * *$ & $.080^{* *}$ & -.063 & .0001 & -.102 & -.013 \\
\hline Hours 41-50 & $.296 * * *$ & .063 & .229 & .045 & -.053 & 0.00001 & -.076 & -.010 \\
\hline Hours 51-60 & $.264^{* *}$ & .118 & .221 & .036 & -.068 & -.077 & -.075 & -.006 \\
\hline Hours $60+$ & $.191^{*}$ & .147 & .228 & .048 & -.089 & .056 & -.100 & -.002 \\
\hline Log likelihood & -8.427 & $-6,137$ & $-2,797$ & - & $-16,814$ & $-13,529$ & $-5,983$ & - \\
\hline Observations & 9,439 & 22,616 & 7,256 & 9,439 & 18,097 & 48,285 & 14,980 & 18,097 \\
\hline Individuals & 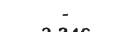 & 2.853 & 1,377 & 2,346 & - & 9,544 & 2.415 & 3.563 \\
\hline Clusters & 2,346 & 1,824 & $\cdot$ & - & 3,563 & 3,113 & - & - \\
\hline
\end{tabular}




\subsubsection{Robustness Checks and Joint Happiness}

A number of robustness checks were run to support the findings with different model specifications. These are displayed in Table A2 in the appendix. ${ }^{15}$

First, one could argue that the composition of the reference category is not directly comparable between women and men. Large shares of men that do not work are unemployed and thus not voluntarily staying at home. The negative effect of unemployment on happiness has been frequently documented in the literature (Di Tella et al., 2001; Clark and Oswald, 1994; Winkelmann and Winkelmann, 1998). On the other hand, most women that do not work are housewives and might have accepted this role. The much lower number of men that stay at home does also imply that e.g. individuals who are suffering from illness or disability and are thus out of the labor force have a higher share in the reference group applied in estimations (1) throughout (8) of Table 1.4. I thus re-ran the estimations for different reference groups. Changes in reference groups can clarify results from Table 1.4. As found before, men show much higher beyondincome benefits from working than women. Results of a model using only the unemployed as the reference category can be seen in columns (1) and (5) of Table A2 in the appendix. Holding household income fix and controlling additionally for different categories of "not working" reveals that women prefer being housewives to all categories of working. ${ }^{16}$ If they can afford to be a housewife, than many women are likely to choose this option. At the same time, working does not seem to be associated with higher life satisfaction compared to being unemployed for women. This is much different for men: The positive effect of work is of both high magnitude and high significance. Moreover, as opposed to women's own preference, men have a clear preference in that they significantly disprefer their wives to be unemployed. Thus, while unemployment seems to be a major psychological concern for men, this does not seem to be the case for women. Results also suggest that men have a relatively stronger preference for retirement, which they also seem to project on their women's retirement status. Last but not least, there is a small relatively "happy" group of houseman.

15 Results displayed in Table A2 are for the BUC estimator and the dependent variable life satisfaction. All other robustness checks, e.g. using job and hours satisfaction, and/or the sample of all married, including those without children, confirm the main results but are not printed here for space reasons. The same is true for the use of different fixedeffects techniques which deliver all very similar results. Note that all robustness regressions are available from the author on request.

16 Housewife/man is defined as "looking after family or home" or "child-rearing" as the main occupation during the last week while not having a job at the same time. 
Second, the regressions were re-run with log individual earnings instead of log per-capita household income. ${ }^{17}$ The results are displayed in columns (2) and (6) of Table A2. Interestingly, a large part of the positive effect of working is now absorbed by individual earnings. Husbands still have the highest satisfaction when working full time, however the beyond-earnings effects cease to be significant. Wives' life satisfaction is lowest in part-time jobs, a finding that suggests once more low-quality employment in this sphere.

Third, as had been seen in the descriptive information in Table 1.2, nonwage employed individuals have much higher variation in working hours than wage receivers. Moreover, it is possible that differences exist in how dependent vs. self-employment influence personal happiness. Using UK, US, and international data, Blanchflower and Oswald (1998) find robust positive effects of being self-employed. Alesina et al. (2004), using US and European data, find that the positive effect is limited to the rich. In the following model, the number of hours of work controls are doubled in order to explicitly control for wage vs. non-wage employment (resulting in the following 10 dummies for each own and partner's hours: 1-30wage, 31-40w, 41-50w, 51-60w, 60+w, 1-30non-wage, 3140nw, 41-50nw, 51-60nw, 60+nw). Results in columns (3) and (7) of Table A2 suggest that in Korea wage-employed are slightly happier. This might be explained with higher levels of job stability, public goods provision and social interaction in larger enterprises. It might also reflect less risk taking in dependent employment. Comparing different work categories, the most dispreferred work for men is 1-30 hours in dependent employment and 1-40 hours in selfemployment. For women it is 41-50 hours in self-employment. However, men additionally dislike if their woman is self-employed in part-time (1-30 hours) or heavy overwork (60+ hours).

In a fourth check, a subjective health measure is included into the set of control variables. This variable which asks individuals to rank their health status on a [1-5] scale with 5 being "excellent" and 1 being "very poor", is often included in satisfaction models (see e.g. Booth and van Ours, 2008; 2009), yet it is obviously problematic due to its endogenous nature. The variable is available for the KLIPS data set from wave 6 (2003) onwards. Results in columns (4) and (8) of Table A2 show that subjective health is positively related to subjective wellbeing and its inclusion has no effect on the main results.

Finally, it would be an interesting exercise to see how joint couple happiness can be maximized. Table A4 in the appendix shows three different models with

17 Due to some missing values in the earnings variables, the number of observations is somewhat lower in this regression. However, descriptive analyses comparing the two groups indicate no selection bias. 
the sum of wife's and husband's life satisfaction on the left hand side of the regression. Since adding up the two measures requires assuming cardinality, all models are now estimated using only linear fixed-effects. Results in column (1) show that joint happiness is maximized if the husband is at work with at least full-time hours and if the wife is not employed neither in part-time, nor in overtime work. Using individual earnings instead of household income in column (2) does not change these findings. A final very interesting exercise is the estimation in column (3). Here occupations are coded in five alternative categories: housewife/man, part-time (1-30 hours), full-time (31-50 hours), overtime work (above 50 hours), and a category collecting all other occupations. This then results in twenty-five possible combinations for how wife and husband can share work. All combinations were used as covariates in model (3) in Table A4, with the exemption of the reference category "husband overtime \& housewife". The latter could be called Korea's classical traditional gender role model as it is the number one ranked time sharing category of Korean married couples in this age band (23.9 percent), followed by "husband full-time $\&$ housewife" (21.1 percent), "husband overtime \& wife overtime" (12.6 percent) and "husband fulltime \& wife full-time" ( 9.6 percent). Hence, as much as 45 percent of all observations fall into the classical gender model.

However, which combination makes the couple the most happy, which the least? Results in column (3) show that most combinations are not significantly different from the reference classical time-sharing combination. For example, it does not make a difference for joint couple happiness if the husband works fulltime or overtime while the wife stays at home. No combination is significantly better than the reference category. However, several combinations are ranked inferior. Regardless of the wife's status, joint marital happiness suffers the most if the husband falls into the category "other occupation", as this most often means an unemployed husband. Joint couple happiness is also significantly lowered if the husband is underemployed (part-time). Columns (4) and (5) use the same set of combinations, yet now as interaction effects for the individual happiness regression. The main effects show a negative impact of being unemployed for both men and women. Additionally, working part-time reduces men's happiness. However, unemployment of women is mitigated by a working husband. Also, the negative effect of part-time for men can be mitigated by the woman in case she is not unemployed. The positive effect of an overtime working husband is strongest if the woman takes care of household and children.

To sum up, this section's findings clearly indicate that traditional gender roles are still strongly at work within Korean households, and that, once they are not fulfilled, the married couple suffers the most. Moreover, the analysis has shown that the observed shift in the distribution of working hours as discussed 
in Table 1.2 indeed was a shift towards on average more satisfactory hours conditions for both married women and men.

\subsection{Gender Identity, Intra-Household Bargaining, and Family Division of Labor}

Akerlof and Kranton (2000) show how the concept of gender identity can be introduced into economic models and provide some empirical evidence. Using PSID data for the period 1983 to 1992 they analyze the division of labor within US families. Becker (1965) argued that household members tend to specialize in occupations according to their comparative advantage. Therefore, the partner with relatively higher market efficiency would concentrate on market work while the other partner would do the major part of the housework. Whoever works more outside the home would work less inside the home, whether it be the husband or the wife. However, empirical findings point into another direction. When US husbands in Akerlof and Kranton's sample were doing all the market work, they contributed an average share of 10 percent to total housework. For higher women's shares of market work, men's shares of housework increased, yet under-proportionally. In fact, men's average share of housework did never rise above 37 percent even when wives were doing all the market work. Similar results were found by Booth and van Ours (2009) using Australian HILDA surveys from 2001-2004. Here, Australian men with wives doing almost all of the market work contributed around 50 percent of the housework. The evidence suggests that Becker's assumption of non-discriminating time sharing between husband and wife does not hold. Rather, these findings provide evidence for Akerlof and Kranton's gender identity hypothesis. Societal gender prescriptions seem to matter for individual behavior.

However, there is a second theoretical thread of literature that should not be forgotten in this context, and this is the theory of intra-household bargaining. These models relate bargaining power in the household to relative earnings of husband and wife, assets brought into marriage, and even physical appearance. According to the predictions of these models, higher bargaining power determines decision-making processes which eventually translate into relative utility outcomes for husband and wife. The models have been confirmed empirically in many cases, especially in the context of developing countries where gender differences are more pronounced (for an introduction see Haddad, Hoddinott, and Alderman, 1997). This approach thus puts a stronger focus on economic variables in order to explain individual-specific occupation and consumption outcomes. In Korea, not only incomes are strongly gender-biased, also inheritance 
customs favor men at the stage of marriage (Lee et al., 2008).$^{18}$ Both factors, identity and bargaining, should be viewed as causing and reinforcing each other.

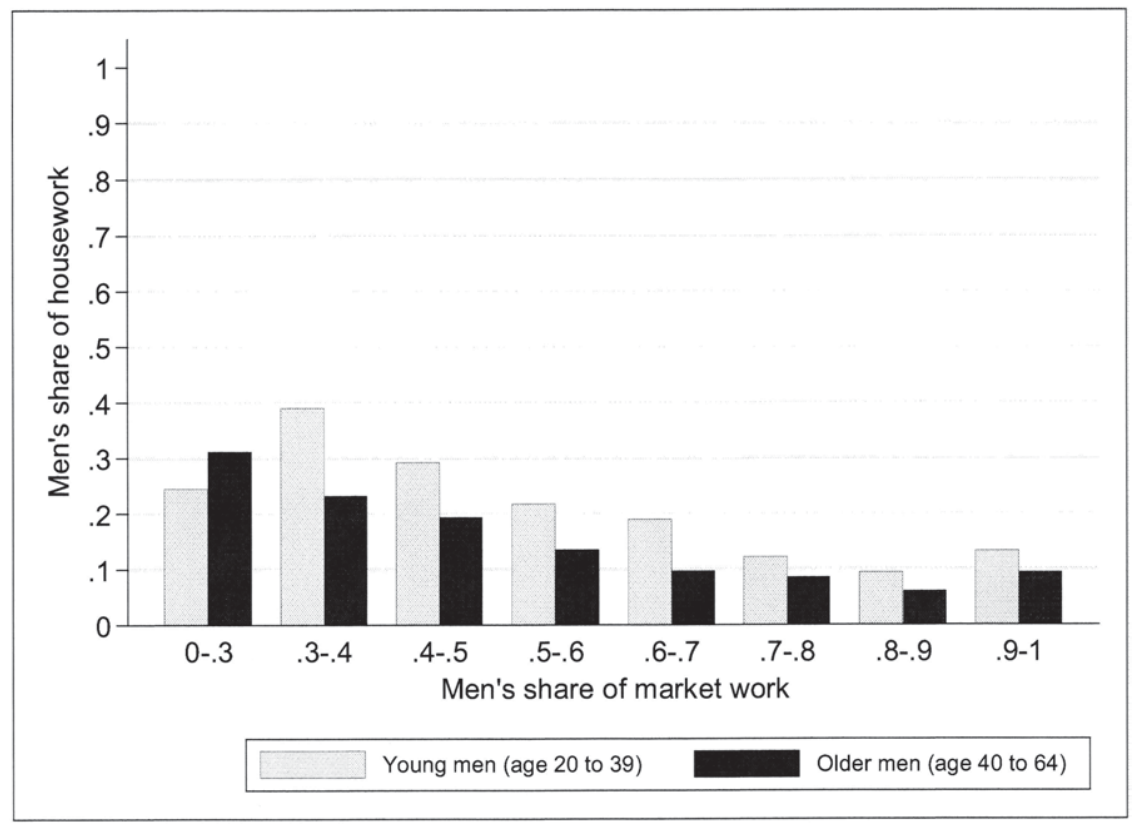

Fig. 1.2: Husbands' share of housework vs. share of market work

Figure 1.2 shows results of a similar analysis using KLIPS data. The data forms part of the additional "Work Hours and Leisure Survey" conducted only in wave 7 in $2004 .{ }^{19}$ The graph shows that the division of labor in Korea in 2004

18 Men are often paid more for the same work and have higher chances to be promoted at the work place (compare Table A1 in appendix). Moreover, the still lively tradition that the groom's family provides the house for the newly married couple means that men usually bring higher assets into marriage.

19 Individuals were asked in the following way: "Please specify the time you allocated to the following activities during the past week in weekdays and the weekend. (Please respond in no. of hours.)". Market work adds up time spent on the three categories "Main work activities (all activities related to work of an employed person, such as work activities, commuting)", "Second job (income-earning activities in addition to the main job)“, and „Job-seeking activities (writing resumes, visiting job placement agencies, Internet searching, interview, etc.)". Housework is defined as "Household work (cooking, laundry, cleaning, grocery shopping, bank and public services, family caretaking, etc.)". 
was similar to that in the US between 1983 and 1992, the data used by Akerlof and Kranton. Men, when contributing 90 to 100 percent to the couple's total market work, have a share of about 10 percent in total housework. If, however, women contribute the major part to total market work (70-100 percent), then they still need to deal with about 70 percent of total housework. Nevertheless, dynamic improvements in gender roles cannot be denied when splitting the sample into a younger (20 to 39 years of age) and an elder generation (40 to 64 years). While relatively elder men don't engage too much in housework, younger men contribute more time to this domain. This might reflect both changes in gender identity as well as relatively stronger bargaining of younger wives.

Table 1.6: Reported Increased Activities After Reduction of Working Hours (in percent)

\begin{tabular}{lcccccc}
\hline & $\begin{array}{c}\text { Wst } \\
\text { choice }\end{array}$ & $\begin{array}{c}\text { 2nd } \\
\text { choice }\end{array}$ & $\begin{array}{c}\text { 3rd } \\
\text { choice }\end{array}$ & $\begin{array}{c}\text { 1st } \\
\text { choice }\end{array}$ & $\begin{array}{c}\text { Men } \\
\text { choice }\end{array}$ & $\begin{array}{c}\text { 3rd } \\
\text { choice }\end{array}$ \\
\hline Income-earning activi- & & & & & & \\
ties & 3.4 & 1.6 & 1.5 & 2.0 & 1.5 & 0.7 \\
Household work & 55.2 & 11.7 & 8.4 & 9.3 & 6.2 & 8.5 \\
Self-development & 7.8 & 9.8 & 9.4 & 16.7 & 11.1 & 12.3 \\
Rest (sleep, etc.) & 13.4 & 38.7 & 21.3 & 28.0 & 21.9 & 16.6 \\
Watch TV & 0.8 & 6.6 & 17.3 & 2.9 & 15.0 & 16.6 \\
Travel/tour & 11.9 & 12.5 & 17.3 & 15.4 & 15.4 & 17.1 \\
Sports/excercise & 3.4 & 10.2 & 10.4 & 20.5 & 17.3 & 11.6 \\
Games & 0 & 0 & 0.5 & 0.9 & 2.5 & 3.7 \\
Social/group activities & 1.9 & 5.5 & 8.4 & 2.5 & 6.8 & 9.9 \\
Civil/volunteer activities & 0.4 & 1.6 & 2.0 & 0.4 & 0.9 & 1.8 \\
Religious activities & 1.1 & 1.2 & 3.5 & 0.6 & 0.9 & 0.7 \\
Other & 0.8 & 0.8 & 0 & 0.9 & 0.4 & 0.4 \\
\hline Total & 100 & 100 & 100 & 100 & 100 & 100 \\
$\mathrm{~N}$ & 268 & 256 & 202 & 689 & 675 & 543 \\
\hline
\end{tabular}

Source: KLIPS, 2004-2008. Statistics are pooled over time.

Table 1.6 shows gender specific responses to reductions in working hours. Related questions were asked from wave 7 to 11 (2004-2008) after the introduction of the 5-day working week in 2004. Respondents were asked to choose up to three out of twelve possible categories of increased time allocation (in the order of their relative importance) after they experienced a reduction in working hours. Results strongly differ between men and women. With 55.2 percent, most women report "household work" as their major increased activity. "Rest (sleep, etc.)" and "travel/tour" follow as further important increases for women. In contrast, men responded to a reduction in working hours primarily with increased 
"rest (sleep, etc.)", followed by "sports/exercise", "self-development", and "travel/tour". This clearly reflects women's on-going double burden and men's substantial freedom from household tasks.

\subsection{Concluding Remarks}

This paper finds that the change in the distribution of working hours, and particularly the reduction in average working hours between 1998 and 2008 has led to increased satisfaction with life, job, and working hours among Korean families. Nevertheless, large gender-specific differences exist in how labor market decisions translate into individual and family happiness. Different fixed-effects estimation techniques are applied throughout the analysis, including the recently suggested BUC estimator. The main results are confirmed by all three estimators. Facing an almost exclusive female responsibility for housework and child care, Korean married women are indifferent in terms of life satisfaction between being a housewife or participating in the labor market when family income is controlled for. Men, in contrast, are still strongly considered main breadwinners and thus exhibit highest satisfaction levels when being full-time employed between 31 and 50 hours a week. While overtime work does not seem to lower men's life satisfaction compared to normal full-time work, it significantly reduces hours and job satisfaction. Particularly working hours beyond 50 hours weekly exponentially reduce the two latter satisfaction measures. Employed women are most satisfied with their jobs when working 31 to 40 hours, which can be explained by incompatibility of long working hours with family duties on the one hand and the lack of part-time options beyond the low-skilled service sector on the other hand. Moreover, unemployment seems to be a major psychological concern for men, but not for women. Strong cross-partner effects in the sample indicate that working hours not only affect individual, but also family happiness. For both sexes, cross-partner effects are strongly significant and often equivalent to the partner's own preferences. Especially woman's life satisfaction strongly responds to her husband's working status. Forty-five percent of all married couples follow the traditional gender model, i.e. the husband works full- or overtime, and the woman takes care of the household and children. This combination is still associated with very high satisfaction levels among Korean families. It is in line with Akerlof and Kranton's gender identity hypothesis, and confirms that traditional gender roles are still strongly at work in Korea.

Labor force participation of women in their prime family years increased from 55.8 percent in 1998 to 61.5 percent in 2006 . However, since then rates are stagnating (2010: 62.3 percent), placing the Korean rate among the lowest in the 
OECD. Therefore, a lot more has to be done in order to provide a familyfriendly working environment. As further hours of work reductions seem to be one important dimension of future policy, equality of chances at the work place, a rethinking of gender identities, as well as flexible job and child care solutions all need to be considered. As Akerlof and Kranton point out, individuals and firms tend to underinvest in unilateral action to change gender identities, since they would be facing the costs alone while being unable to internalize potential benefits of such action; thus further government action is required to escape from a potential prisoner's dilemma. 
Robert Rudolf - 978-3-631-75352-1

Downloaded from PubFactory at 01/11/2019 06:01:29AM

via free access 


\title{
Essay 2
}

\section{Adaptation under Traditional Gender Roles: Testing the Baseline Hypothesis in South Korea}

\begin{abstract}
Using detailed longitudinal data from the Korean Labor and Income Panel Study (KLIPS) from 1998 to 2008, this paper analyzes gender-specific impacts as well as anticipation and adaptation to major life and labor market events. We focus on six major events: marriage, divorce, widowhood, unemployment, first job entry, and introduction of the 5-day-working-week. While our results indicate full adaptation after some events, and more so for women, after others we see no or only partial habituation. Yet, the results show striking gender-specific differences particularly regarding the impact of events related to marital status change. Husbands remain on a higher happiness level throughout marriage. They also suffer more from, and show less rapid or even no adaptation to widowhood and divorce. Women return to their baseline level of happiness relatively quick after marriage and divorce. Surprisingly, widowhood is not associated with negative effects for women. If anything, moderate positive effects can be found here. Husbands' additional long-run happiness gain during marriage is equivalent to an (husband-only) increase of annual per-capita household income of approximately US\$17,800. We show that the intra-marriage happiness gap between husband and wife is strongly related to the intra-couple earnings difference, providing evidence for both intra-household bargaining and the gender identity hypothesis. The studied labor market events point to a gendersegregated labor market. The evidence shows that more effort is needed if Korea wants to achieve higher gender equity.
\end{abstract}

Based on joint work with Sung-jin Kang.

\subsection{Introduction}

Recent work in subjective well-being has shown that individuals' perception of happiness tends to adapt to most life and labor market events (e.g. Gardner and Oswald, 2006; Stutzer and Frey, 2006; Clark et al., 2008; Clark and Georgellis, 2010; Frijters, Johnston, and Shields, 2008; Oswald and Powdthavee, 2008). These papers argue that individuals are equipped with a certain form of baseline happiness which can be mainly explained by quasi-fix factors like genes, early childhood education, and persistent psychological traits. Only a small share of 
an individual's happiness is attributed to demographic and socio-economic factors and these rather short-term variables are assumed to induce fluctuation around the baseline level. ${ }^{20}$ The argument is that changes in most demographic and socio-economic variables have no long-run effect on an individual's level of happiness or life satisfaction, and so individuals rather experience both anticipation and adaptation to most life events. This has recently changed our understanding on the intertemporal dimension of well-being and requires further research. How do shocks, positive or negative, effect individuals over time? Do people fully recuperate after a particular shock, or is there a lasting shift of happiness levels? And if so, which are the factors that do not only temporarily, but permanently shift an individual's well-being? Do differences exist in the impact of and adaptation to shocks between women and men?

Looking at major life events like marriage, or labor market events like unemployment calls for an in-depth study of gender differences in life satisfaction responses over time. Particularly in countries with rather traditional gender roles, both the magnitude of a certain event's impact on individual well-being as well as adaptation to it might differ significantly between women and men. While some related studies have found that women are more likely to adapt to unemployment than men, to the best of our knowledge no study has ever found significant gender differences for a number of events yet. This might be due to the spatially selective nature of happiness research in the past. Most studies in this field concentrate on "Western" OECD countries with comparatively low levels of gender inequality. In their study of German panel data (GSOEP), Clark et al. (2008) estimate intertemporal changes in life satisfaction due to marriage, divorce, widowhood, birth of child, unemployment and layoff separately for the two sexes. They find full or partial adaptation to most events and conclude that the anticipation and adaptation patterns due to life events are "remarkably similar between men and women". In a follow-up paper, Clark and Georgellis (2010) confirm these findings for British panel data (BHPS) and conclude that adaptation might be a "general phenomenon". Frijters, Johnston and Shields (2008) use quarterly life event data from the Household, Income and Labour Dynamics in Australia (HILDA) survey for the study of ten events, where they mainly show that life events are not randomly distributed and thus stress the importance of fixed-effects estimation.

20 Lykken and Tellegen (1996) show that demographic and socio-economic factors account for only a small part of the variance in subjective well-being measures. They estimate the contribution of the stable component of subjective well-being, which they ascribe to genes and persistent psychological traits, to explain as much as 80 percent. 
In this study, we will perform a similar analysis, yet with a country with still stronger traditional gender roles. Within such a society, intra-marriage bargaining might be skewed in the form that women's financial dependence might lead to a gender gap in decision-making and eventual utility outcomes. Thus, we are interested in the main determinants of this potential gap. Psychology literature suggests that the wife's absolute and relative earnings play important roles for intra-marriage well-being. Higher female employment and income can have positive effects for married women if other roles such as being a housewife are less satisfying (Ross, Mirowsky and Goldsteen, 1990). For men, the effect mainly depends on prevailing gender roles and the level of economic hardship. In case of more liberal roles or more severe economic hardship, men will appreciate wives' higher contributions in broadening household's total economic resources. In contrast, if gender roles are rather traditional and the family does not necessarily depend on the wife's earnings, then a higher share of female earnings might imply that the man is unable to fulfill the breadwinner role and this can have negative effects on husband's well-being (Hochschild, 1989; Rogers and DeBoer, 2001). Higher wife's earnings improve female bargaining in the household, and thus can lead to changes in the household division of labor, and in spousal roles more generally. This can have beneficial effects for the couple if more liberal roles are prevalent. However, it may also increase the risk of female-sided marital breakup.

There are two related theoretical threads of literature in the economics field. First, there is an established literature on intra-household bargaining and decision-making (e.g. Haddad, Hoddinott and Alderman, 1997). These studies basically argue against income pooling within a household (Becker's (1981) altruistic dictator) and rather claim that it is important for intra-household decisionmaking who earns the money. It has been shown in several studies that the higher the relative share of income earned by a woman (alternatively share of assets brought into marriage), the higher her relative bargaining power (e.g. Phipps and Burton, 1998; Brown, 2009; Lise and Seitz, 2011). Related to higher female income is an increase in credibility of her potential divorce threat, equipping a woman with a viable alternative in case of unsatisfying marriage. Women who are financially more dependent might not have this alternative at hand, since expected income after divorce will be rather low. In this paper, we will extend this idea by looking at happiness outcomes related to female earnings shares in a society in which traditional gender roles still prevail.

For our analysis, we use eleven waves of the Korean Labor and Income Panel Study (KLIPS) from 1998 to 2008 to study gender-specific impacts as well as anticipation and adaptation patterns in Korea. We will explicitly focus six major life and labor market events on individual happiness: marriage, di- 
vorce, widowhood, unemployment, first job entry, and working day reduction/introduction of the 5-day-working-week. Determinants of gender differences, such as different bargaining variables, will then be analyzed in detail.

We contribute to the literature in the following way. First, we will expand the reach of happiness studies to East Asia. Only few studies have recently started to analyze subjective well-being questions in the East Asian context (e.g. Kang, 2010; Rudolf, 2011). Second, by choosing Korea this will be the first study to examine gender differences in the impact of, and adaptation to major events in an environment of strong traditional gender roles.

Third, this study will then link the adaptation literature with that of intrahousehold bargaining and Akerlof and Kranton (2000)'s concept of identity. Fourth, we will make use of state-of-the art fixed-effects ordered logit estimators which allow to control for unobserved factors and to account for an ordinal dependent variable at the same time. While our main estimation technique will be linear fixed-effects for the benefit of assigning monetary values to the coefficients, we will check the consistency of the estimates using most recent fixedeffects ordered-logit estimators by Ferrer-i-Carbonell and Frijters (2004) and Baetschmann, Staub, and Winkelmann (2011).

Our findings provide evidence for partial and full adaptation to most events. Results suggest a somewhat faster and more complete adjustment for women. Moreover, the results indicate strong gender-specific impacts of various events, particularly of changes in marital status. While marriage has a strong and lasting positive effect on male happiness, female's happiness gain is limited to not more than two years. Men suffer stronger than women from divorce and widowhood, while women show no negative effects in the case of their spouse's death. Concerning labor market events, our findings point towards a gender-segregated working culture.

The paper is organized as follows: Section 2.2 discusses gender inequality in Korea more in detail. Section 2.3 introduces the data set and methodology used for the analysis. Section 2.4 then discusses regression results. While the first subsection treats marriage-related events, the second discusses labor market events. Finally, intra-marriage gender gap is analyzed more in detail in the last subsection. Section 2.5 concludes.

\subsection{Gender Gap in Korea}

The Republic of Korea presents a very interesting case of economic and sociocultural change. The Korean economy has shown spectacular growth rates over the past fifty years. Related rapid socio-economic development allowed the 
country to join the group of high-income OECD countries in $1996 .{ }^{21}$ Since then, Korea can claim to be a part of the developed world. However, traditional gender roles show themselves to be much more resistant to change than political or economic variables. Until today, Korea has maintained strong traditional values, particularly when social and family relations are concerned. ${ }^{22}$ In 2010 , Korea has the third lowest female labor force participation rate (25-54 years of age) among 35 OECD countries. Lower rates were only observed in Turkey and Mexico. In 2005, the UNDP dedicated a whole report to the issue. The "Korean Human Development Report on Gender" points out that "women's participation in political and economic sectors, especially in decision-ranking positions is very low in Korea, despite marked growth in the country's economy over the past decades". While Korean women, when compared internationally, are highly educated, they still face a number of obstacles in order to engage in the labor market in a similar manner as men do. The most prominent of these are strong gender gaps in earnings, very long working hours, the absence of part-time work options beyond the low-skilled service sector, and deficits in child care supply. Table 2.1 presents the gender gap in Korea in a cross-country comparison. Korea ranks particularly low in indicators that strictly focus on the gender gap measured in terms of female-to-male ratios of education, health, economic and political empowerment (Gender Empowerment Measure (GEM) and Global Gender Gap Index (GGG)). The probably most comprehensive attempt to measure the gender gap in a society is the GGG index which is published since 2006 by the World Economic Forum. According to this index, Korea ranks only $104^{\text {th }}$ out of 134 countries in 2010, suggesting very high levels of gender inequality in Korea. Korea's low rank is not at last due to low female-to-male ratios in the following sub-indexes: "wage inequality for similar work", "professional and technical workers", "legislators, senior officials, and managers", "tertiary enrolment ratio" and "seats in parliament". Traditional gender roles in Korea have been further acknowledges in a recent OECD "Society at a Glance" report (2011) comparing male and female shares in housework across OECD countries. While according to the OECD country average, women do 2.13 times the housework that men do, in Korea this ratio amounts to 5.05. For comparison, this ratio is 1.48 in Norway, 2.75 in Spain, and 3.24 in Turkey. Moreover, comparing Korea to Singapore, another Asian growth miracle, further suggests that high gender inequality is not inevitable in countries with Chinese cultural heri-

21 In terms of GDP per-capita in purchasing-power parity units, Korea is expected to reach the level of Germany within the next decade.

22 For an introduction to Korean gender relations, see e.g. Kim (2007) or Clasen and Moon (2010). 
Table 2.1: Gender Gap in Korea in Cross-Country Comparison

\begin{tabular}{|c|c|c|c|c|c|c|c|c|}
\hline & Norway & Germany & Korea & Spain & UK & Singapore & Mexico & Turkey \\
\hline \multicolumn{9}{|l|}{ Ranking by indicator } \\
\hline HDI rank 2010 (out of 169 countries) & 1 & 10 & 12 & 20 & 26 & 27 & 56 & 83 \\
\hline GNI per capita (PPP $2008 \$)$ & 58,810 & 35,308 & 29,518 & 29,661 & 35,087 & 48,893 & 13,971 & 13,359 \\
\hline GII rank 2008 (of 169) & 5 & 7 & 20 & 14 & 32 & 10 & 68 & 77 \\
\hline GEM rank 2009 (of 109) & 1 & 9 & 61 & 11 & 15 & 16 & 39 & 101 \\
\hline GGG rank 2010 (of 134) & 2 & 13 & 104 & 11 & 15 & 56 & 91 & 126 \\
\hline Average rank of three gender indicators & 2.67 & 9.7 & 61.7 & 12 & 20.7 & 27.3 & 66 & 101.3 \\
\hline \multicolumn{9}{|l|}{ Ratio female to male (2010 data) } \\
\hline Population with at least secondary education ( 25 or older) & 1.00 & .98 & .87 & .94 & 1.01 & .88 & .91 & .58 \\
\hline Tertiary enrollment rate & 1.62 & 1 & .69 & 1.24 & 1.40 & - & .98 & .78 \\
\hline Labor force participation rate & .94 & .87 & .73 & .77 & .84 & .74 & .55 & .35 \\
\hline Wage equality for similar work & .75 & .61 & .52 & .52 & .67 & .80 & .54 & .57 \\
\hline Legislators, senior officials, and managers & .46 & .61 & .11 & .48 & .53 & .46 & .44 & .11 \\
\hline Professional and technical workers & 1.06 & 1.01 & .69 & .98 & .90 & .82 & .70 & .54 \\
\hline Seats in parliament & .66 & .49 & .17 & .58 & .28 & .31 & .36 & .10 \\
\hline Time spent in housework & 1.48 & 1.64 & 5.05 & 2.75 & 1.82 & - & 3.31 & 3.24 \\
\hline
\end{tabular}

Sources: WEF 2010; UNDP 2009, 2010; OECD 2011. 
tage. ${ }^{23}$ Whereas Korea and Singapore employ similar ranks in the human development index (HDI), Korea ranks much lower in gender gap measures. Rudolf and Cho (2011) show for married Korean couples that even if a woman is doing most of the market work, she still takes care of about 70 percent of the housework. The same article also argues that very long working hours and the absence of high-skilled part-time work are important restrictions to further female engagement in the labor market. Lee (1998) argues that many Korean girls only strive for higher education in order to increase the likelihood to find a welleducated husband. This might be a rational strategy under the present circumstances, given that marital sorting is relatively high in Korea (Lee, 2008). It might thus be a good sign that gender roles are slowly starting to change in Korea and so does marital labor-sharing. Young generations of husbands already show slightly higher engagement in housework and female labor force participation of women in their prime motherhood years has risen from 55.8 to 62.3 percent between 1998 and 2010 (Rudolf, 2011; OECD, 2011). Yet, to sum up, it becomes evident that Korea, in contrast to its economic and human development achievements, is still lacking behind substantially in terms of gender equality.

\subsection{Data and Methodology \\ 2.3.1 Data}

Data for our analysis comes from the Korean Labor and Income Panel Study (KLIPS) for the years 1998 to 2008. KLIPS is a nationally representative longitudinal study of urban Korean households, modeled after the US's National Longitudinal Surveys (NLS) and Panel Study of Income Dynamics (PSID). It is conducted annually by the Korea Labor Institute, a government-sponsored research institute. The study started in 1998 with 5,000 households and 13,783 individuals aged 15 years or older. KLIPS collects a wide range of information on individuals, such as earnings, family, education, employment backgrounds, and demographic characteristics. In addition, it offers broad information on various indicators of life and job satisfaction.

The data quality KLIPS provides satisfies highest international standards. The panel maintains $76.5 \%$ of the original sample throughout all waves, which is comparable to the US PSID (78\%); the German Socio-economic Panel

23 Chinese cultural understanding of a proper female life is mainly influenced by Confucian and Daoist thought. Both philosophies suggest gender segregation of work, yet Confucianism stresses even stronger the subordination of wives under their husband (Adler, 2006). 
(GSOEP, 79\%); and the British Household Panel Survey (BHPS 77\%). Kang (2010) shows that potential bias produced by attrition is negligible in KLIPS data.

We restrict our sample to the age group of 16 to 60 year olds which yields a total number of 55,447 person-year observations for females and 57,574 for males. For the analysis of widowhood, we extend the upper age limit to 80 years, resulting in a sample of 66,592 person-year observations for females and 65,986 for males. The panel is unbalanced in that not all individuals are present in all waves. Thus, our minimal requirement is that an individual was observed at least once before and after the event, thus excluding left-censored spells.

The central variable for our analysis is overall life satisfaction. In KLIPS' individual questionnaire, the overall life satisfaction question follows a set of detailed questions on the satisfaction with different aspects of life: household income, leisure life, housing environment, family relations, relations with relatives, and social relations. The exact wording of the overall life satisfaction question is then: "Overall, how satisfied or dissatisfied are you with your life?" Individuals are asked to respond on a scale ranging from 1 ("very satisfied") to 5 ("very dissatisfied"). For the sake of easier interpretation, we recoded the scale so that higher numbers correspond to higher levels of satisfaction.

Table 2.2: Distribution of Life Satisfaction by Sex

\begin{tabular}{lccccc}
\hline & \multicolumn{2}{c}{ Females } & & \multicolumn{2}{c}{ Males } \\
& \# of obs & Percentage & & \# of obs & Percentage \\
\cline { 2 - 3 } \cline { 6 - 6 } 1 (very dissatisfied) & 798 & 1.5 & & 867 & 1.7 \\
2 (dissatisfied) & 6,281 & 11.9 & & 6,197 & 12.0 \\
3 (neither satisfied nor dissatisfied) & 29,572 & 55.8 & & 29,243 & 56.5 \\
4 (satisfied) & 15,928 & 30.1 & & 15,070 & 29.1 \\
5 (very satisfied) & 426 & .8 & & 429 & .8 \\
\hline Total & 53,005 & 100 & & 51,806 & 100 \\
Mean & 3.17 & & & 3.15 & \\
S.D. & .70 & & & .70 & \\
\hline
\end{tabular}

Note: Statistics calculated for those aged 16-60. Data: KLIPS 1998-2008

Table 2.2 shows the distribution of life satisfaction for the sample of 16-60 year olds separately for men and women. About half of all women and men report to be "neither satisfied nor dissatisfied". More people report to be "satisfied" than "dissatisfied". It might be a cultural particularity that Koreans tend to avoid the extreme categories "very satisfied" or "very dissatisfied". This is in contrast to studies on e.g. Germany or Great Britain, were usually around 10 
percent of the sample chooses the highest category of satisfaction. ${ }^{24}$ Compared to their male counterparts, females report about the same if not a slightly higher average life satisfaction.

In order to examine the intertemporal change in satisfaction levels due to major life and labor market events and potential gender differences that might arise, we will analyze the following six major events: marriage, divorce, widowhood, unemployment, first job entry, and introduction of the 5-day-workingweek. Since we would like to avoid potential bias through habituation to events, we only take into consideration the first event of its kind for each individual during the sample period. Thus, observations are right-censored in case of e.g. second unemployment spells or remarriages.

For changes in marital status and first job entry, the questionnaire explicitly asks for the exact year and month when the change/entry happened. This allows us to calculate for each person-year observation the years passed since the event happened or the years from a particular wave until the event is going to happen. ${ }^{25}$ Compared to just looking at marital status changes between two interviews, it has the advantage to be able to identify "quick remarriages", where individuals become divorced or widowed and then directly remarry between only two survey waves. Moreover, we can better identify the exact date of change in case there is a gap of two or more years between two interviews. We then coded lead and lag dummies for each year starting with " 3 to 4 years before the event" and until " 5 or more years after the event". For example, the latter dummy in the case of the event "marriage" would take the value 1 if at least five years have passed since a person's first marriage and if she has not had a change in marital status in the meantime. It would take the value 0 otherwise.

For unemployment we use a similar methodology as Clark et al. (2008) who use the occupational status of individual $i$ in each $t=1$ to $T$ to calculate if and for how long an individual is currently unemployed. And if currently working but unemployed in the future, how far she is away from future unemployment. In 2004, following a change in national legislation, the official 6-day-working week was replaced by a 5-day-working-week. To model this empirically, we

24 Compare Clark et al., 2008; Clark and Georgellis, 2010. It is rather unlikely that so few "very satisfied" people exist in Korea compared to Western European countries. We rather believe that this has to do with cultural-specific behavior: a modest and humble use of language is often required by Korean social norms. Especially when talking to an unknown interviewer about your personal happiness, Koreans might be inclined to respond in a more reserved way.

25 A few observations only reported the year of the event, but not the exact month. Here, the middle of the year is used to calculate the length from the event (e.g. 1998+0.5 years). Additionally, we check for the person's marital status around the event. 
observe the date of the first change from above five to five days for each individual. We request that an individual was working during two years on average at least 5.5 days a week, and then changed to a five-day-working-week (4.5 $\leq$ average weekly working days $<5.5$ ) for also at least two periods.

Table 2.3 shows average satisfaction of leads and lags by event and sex. We can see that for almost all events there was a considerable upward or downward change in life satisfaction after the event took place. Most yet not all effects go into the expected direction. In the case of marriage we see the expected increase in average satisfaction by .35 for females and .34 for males in the year following the wedding as compared to the year preceding the wedding. Looking only at descriptive data, both manage to stay on a higher average level of life satisfaction even after more than five years. While women after two years then seem to return partially to their baseline level of happiness, it looks as if men slightly better manage to stay on a higher level after marriage. In the case of divorce, both women and men are already relatively unhappy before the event. Relative to their baseline level, women experience a short drop and a fast recovery while men seem to suffer a long-lasting negative effect of being and staying divorced. Surprising are the gender-specific results for widowhood. In this on average elder generation age cohort, we would expect that gender roles are still the most traditional (compare Rudolf 2011). Men are already happier than women by about .3 units in the years preceding the event. After then eventually becoming widowed, women's life satisfaction increases while that of men suffers a short drop but seems to recover rather fast. Thus, we don't observe serious negative effects, and if so, only for men.

Next we are interested in labor market events. Considering unemployment effects, it seems that there is some anticipation of unemployment in the preceding year both for women and men. Compared to 1-2 years before, when getting unemployed average life satisfaction of women drops by .15 and that of men by .27. Women seem to quickly adapt to unemployment, returning to the old level when being one or more years unemployed. On the other hand, men only partially recover even after two or more years of consecutive unemployment. ${ }^{26}$ The next two columns examine the time around a graduate's first job entry. In the case of females we see a gradual increase in life satisfaction after leaving school, college or university and entering their first job. Growing experience, a better standing in the company, and higher income might be potential explanations. Males' increase is comparable, however, their initial happiness increase in the year of starting the first job is stronger which might be due to higher perform-

26 Extremely low levels of general and also long-term unemployment restrict the analysis of long-term unemployment on life satisfaction in our data. 
Table 2.3: Average Life Satisfaction of Leads and Lags by Event and Sex

\begin{tabular}{|c|c|c|c|c|c|c|c|c|c|c|c|c|}
\hline & \multicolumn{2}{|c|}{ Marriage } & \multicolumn{2}{|c|}{ Divorce } & \multicolumn{2}{|c|}{ Widowhood } & \multicolumn{2}{|c|}{ Unemployment } & \multicolumn{2}{|c|}{ First Job Entry } & \multicolumn{2}{|c|}{ 5-Day-Working } \\
\hline & Females & Males & Females & Males & Females & Males & Females & Males & Females & Males & Females & Males \\
\hline \multicolumn{13}{|l|}{ Leads } \\
\hline $3-4$ years hence & $3.21(314)$ & $3.08(289)$ & $2.96(69)$ & $2.89(72)$ & $2.76(180)$ & 3.05 (39) & $2.98(119)$ & $3.00(211)$ & $3.19(253)$ & $3.08(150)$ & $3.31(96)$ & $3.41(345)$ \\
\hline $2-3$ years hence & $3.21(373)$ & $3.17(331)$ & $2.94(83)$ & $3.04(81)$ & $2.81(187)$ & $3.23(53)$ & $3.00(153)$ & $2.98(285)$ & $3.22(318)$ & $3.13(208)$ & $3.38(112)$ & 3.45 (399) \\
\hline 1-2 years hence & 3.20 (427) & $3.16(372)$ & $2.85(82)$ & $2.93(85)$ & $2.84(237)$ & $3.02(60)$ & $2.97(201)$ & $2.99(400)$ & $3.19(374)$ & $3.13(249)$ & $3.32(157)$ & $3.46(493)$ \\
\hline Within the next year & $3.21(519)$ & $3.19(462)$ & $2.84(103)$ & $2.97(99)$ & $2.78(255)$ & $3.08(62)$ & $2.88(283)$ & $2.89(589)$ & $3.20(461)$ & $3.12(364)$ & $3.36(159)$ & $3.49(503)$ \\
\hline \multicolumn{13}{|l|}{ Lags } \\
\hline 0.1 years & $3.56(316)$ & $3.53(341)$ & $2.67(72)$ & $2.65(66)$ & $2.90(236)$ & $2.89(62)$ & $2.82(285)$ & $2.72(601)$ & $3.26(457)$ & $3.27(356)$ & $3.44(167)$ & $3.54(497)$ \\
\hline $1-2$ years & $3.52(396)$ & $3.43(383)$ & $2.81(70)$ & $2.86(73)$ & $3.03(230)$ & $3.07(46)$ & & $2.69(65)$ & $3.31(238)$ & $3.36(166)$ & $3.51(164)$ & $3.51(502)$ \\
\hline $2-3$ years & $3.40(385)$ & $3.44(337)$ & $2.88(66)$ & $2.72(69)$ & 3.05 (193) & $2.93(45)$ & & & 3.37 (138) & $3.36(122)$ & $3.60(111)$ & $3.62(342)$ \\
\hline $3-4$ years & $3.37(342)$ & $3.48(297)$ & $2.90(58)$ & $2.91(54)$ & 3.07 (163) & $3.14(36)$ & & & $3.40(121)$ & $3.40(97)$ & $3.62(76)$ & $3.67(240)$ \\
\hline $4-5$ years & $3.36(310)$ & $3.48(275)$ & $2.94(48)$ & $2.73(40)$ & $3.08(130)$ & $3.11(35)$ & & & $3.45(77)$ & $3.43(80)$ & $3.57(37)$ & 3.65 (135) \\
\hline 5 or more years & $3.40(790)$ & $3.50(613)$ & $3.01(73)$ & $2.76(68)$ & $3.10(262)$ & $3.22(55)$ & & & $3.44(108)$ & $3.51(105)$ & $3.50(38)$ & $3.67(85)$ \\
\hline 1 or more years & & & & & & & $3.00(12)$ & & & & & \\
\hline 2 or more years & & & & & & & & $2.87(15)$ & & & & \\
\hline
\end{tabular}

Notes: Numbers of observations are calculated for individuals aged 16-60 (except for widowhood 16-80) and displayed In brackets. Data: KLIPS 1998-2008. 
ance expectations and related social pressure towards men as future main breadwinners. $^{27}$

The last two columns of the table show the effect of the reduction in working days on satisfaction with working hours. We see that while there is a general upward trend in hours satisfaction due to gradual working hours reductions that took place in Korea during the time of our study, there is a particularly strong effect when working days are reduced from above five to five days a week. ${ }^{28}$

\subsubsection{Anticipation and Adaptation Model}

In order to capture the intertemporal effects of the discussed events in a multivariate regression framework, we estimate the following empirical model. We use life and hours satisfaction as our main response variables. As Ferrer-i-Carbonnel and Frijters (2004) point out, assuming cardinality or ordinality of the satisfaction measure does produce very similar results. In order to be able to better interpret the magnitude of impact and adaptation of the events followed in this study, and to assign monetary values, we will use linear fixed-effects estimation as our main technique and use fixed-effects ordered logit estimators for consistency checks. Controlling for fixed-effects is essential in satisfaction models since unobserved personality traits are likely to be correlated with certain decisions that appear on the right hand side of the equation, such as employment and marital status (Clark, 2003; Stutzer and Frey, 2006).

Satisfaction $S$ of individual $i$ in period $t$ is modeled as follows:

$S_{i t}=L E_{i t} \beta+X_{i t} \gamma+u_{i}+\eta_{t}+\varepsilon_{i t}, \quad i=1, \ldots, N \quad t=1, \ldots, T$

where $L E_{i t}$ is a vector containing a set of binary lead and lag variables to control for the intertemporal effect of a certain life or labor market event.

$L E_{i t}=\left(L E_{-4, i t}, L E_{-3, i t}, L E_{-2, i t}, L E_{-1, i t}, L E_{0, i t}, L E_{1, i t}, L E_{2, i t}, L E_{3, i t}, L E_{4, i t}, L E_{5, i t}\right)^{\prime}$

$X_{i t}$ is a vector of standard control variables in satisfaction models, including individual and household demographic and socio-economic variables. $u_{i}$ is individual $i$ 's fixed effect, $\eta_{t}$ controls for year effects, and $\varepsilon_{i t}$ is an i.i.d. error term. Since it is very likely that $E\left(u_{i}, X_{i t}\right) \neq 0$ and $E\left(u_{i}, L E_{i t}\right) \neq 0$, we should estimate this model using a fixed-effects estimator in order to yield consistent estimates of the model parameters $\beta$ and $\gamma$. In order to yield gender-specific estimates we will run the regressions separately for men and women.

27 While young men are supposed to have a secure job and income before being able to marry, women often have to give up their career for family duties after marriage (Lee et al., 2008).

28 For more information on working hours reduction see Rudolf and Cho (2011). 
While the basic model is estimated by linear fixed-effects, for consistency checks we will then also use the FF-estimator (Ferrer-i-Carbonell and Frijters, 2004) and the BUC-estimator (Baetschmann, Staub and Winkelmann, 2011) which estimate fixed-effects in the presence of an ordinal dependent variable. The FF-estimator was recently used by Booth and van Ours $(2008 ; 2009)$ for their study of working hours and life satisfaction in Germany and Australia. We will use the "mean version" of the estimator in our analysis. Very recently, Baetschmann, Staub and Winkelmann (2011) proposed the BUC-estimator and they show in Monte-Carlo simulations that it performs best among a set of fixed-effects ordered logit estimators.

\subsubsection{Intra-Marriage Gender Happiness Gap Model}

In order to look closer at the drivers of a potential gender-specific impact of marriage, we use an intra-household bargaining model as a methodological starting point. According to these models, women are able to increase their relative bargaining power within the household as soon as their share in total earnings rises (Haddad, Hoddinott, and Alderman, 1997). Related to higher female income is a more credible divorce threat, leaving a woman with a viable alternative in case of unsatisfying marriage.

Thus we would expect the utility difference $U$ diff $f_{j}$ between husband and wife of couple $j$ to decrease with the wife's share $\tau_{j}$ in total couple earnings:

$$
\frac{\partial \text { diff }_{j}}{\partial \tau_{j}}<0 \text {. }
$$

Another related hypothesis is that of Akerlof and Kranton (2000) who introduce the psychological-sociological concept of "identity" into an economic model of behavior. In their model, individual $i$ 's identity or self image $I_{i}$ depends on own actions $a_{i}$, other's actions $a_{-i}$, the assigned gender $\operatorname{sex} x_{i}$, own given characteristics $\varepsilon_{i}$, and the social ideal of the assigned gender (gender prescription) $P$.

$$
I_{i}=I_{i}\left(a_{i}, a_{-i}, \operatorname{sex}_{i}, \varepsilon_{i}, P\right)
$$

Individual well-being $U_{i}$ then depends on own actions $a_{i}$, other's actions $a_{-i}$ and own identity. $U_{i}=U_{i}\left(a_{i}, a_{-i}, I_{i}\right)$

Complying with expected gender behavior is rewarded, while noncompliance has a negative effect on own utility. This leads us to the following regression model where we regress satisfaction of wife, husband, the sum of the two and their difference in separate regressions on own occupation, spouse's occupation, as well as a set of bargaining variables bargain $_{i t}$, namely the share of women in total couple earnings, as well as the husband-wife age and educa- 
tion (years of schooling) differences. We add a number of standard household demographic and socio-economic controls. We would expect social prescriptions to reward men relatively more when being main breadwinners and having a higher share of earnings. ${ }^{29}$ The regression model for the life satisfaction husband-wife difference of partner $i$ is denoted as follows:

$S_{\text {diff }, i t}=$ ownocc $_{i t} \beta+$ spouseocc $_{i t} \gamma+$ bargain $_{i t} \delta+X_{i t} \lambda+u_{i}+\eta_{t}+\varepsilon_{i t}$

where ownocc $_{i t}$ and spouseocc $_{i t}$ are own and spouse's occupation of partner $i$ in period $t$ and $X_{i t}$ is a vector of further controls. The model in equation (2.3) will be estimated separately for wives, husbands, and for joint couple happiness using linear fixed-effects estimation.

\subsection{Regression Results}

Table 2.4 shows the results of the linear fixed-effects regressions by event and sex. Anticipation only plays a minor role in most events. It is only seen significant in the case of both male and female unemployment and female transition to the 5-day-working-week. Concerning impact and adaptation, our data produces interesting findings. Most events show substantial gender-specific impacts on life satisfaction. The estimates indicate full adaptation after some events, and more so for women. However, after others we see no or only partial habituation. Table 2.5 presents determinants of the observed intra-marriage gender happiness gap.

\subsubsection{Marriage-Status-Related Events}

Columns (1) to (6) of Table 2.4 show the results of different changes in marital status on life satisfaction. ${ }^{30}$ Females experience a strong positive significant effect in the first year after marriage. Yet, this positive effect halves one year later and disappears completely after two years from marriage shifting women back to their baseline level of happiness. In comparison, males also experience the strongest positive effect in the year of marriage and this effect more than halves in the second year.

29 Further research should also include the effect of assets brought into marriage on the gender happiness differential. Traditional practice in Korea requests the groom's parents to provide the house for the new couple, while the bride's parents should provide the necessary house equipment. As the relative price of housing has been constantly on the rise, this usually means a higher share of assets brought into marriage by the groom.

Results are graphically displayed in Figure 2.1. 
Table 2.4: Effect of Life and Labor Market Events on Life Satisfaction ${ }^{36}$

\begin{tabular}{|c|c|c|c|c|c|c|c|c|c|c|c|c|}
\hline & \multicolumn{2}{|c|}{ Marriage } & \multicolumn{2}{|c|}{ Divorce } & \multicolumn{2}{|c|}{ Widowhood } & \multicolumn{2}{|c|}{ Unemployment } & \multicolumn{2}{|c|}{ First Job Entry } & \multicolumn{2}{|c|}{ 5-Day-Working } \\
\hline & Females & Males & Females & Males & Females & Males & Females & Males & Females & Males & Females & Males \\
\hline & (1) & (2) & (3) & (4) & (5) & (6) & (7) & (8) & (9) & (10) & (11) & (12) \\
\hline \multicolumn{13}{|l|}{ Leads } \\
\hline $3-4$ years hence & .054 & $-.077^{*}$ & .111 & -.046 & .004 & .051 & -.002 & .045 & -.034 & -.063 & -.067 & .020 \\
\hline $2-3$ years hence & .023 & .019 & .102 & .016 & .053 & $.159 *$ & .007 & -.005 & -.010 & -.015 & -.041 & .034 \\
\hline $1-2$ years hence & .007 & .008 & .020 & -.085 & .058 & -.067 & -.027 & -.011 & -.038 & -.028 & $-.118^{* *}$ & .019 \\
\hline Within the next year & -.012 & .028 & -.057 & -.068 & -.064 & -.022 & $-.096 * *$ & $-.058^{* *}$ & -.024 & -.006 & -.092 & .031 \\
\hline \multicolumn{13}{|l|}{ Lags } \\
\hline $0-1$ years & $.264^{* * *}$ & $.332^{* * *}$ & $-.286^{* * *}$ & $-.507^{* * *}$ & -.003 & $-.264^{* * *}$ & $-.190 * * *$ & $-.278^{* * *}$ & -.050 & .032 & -.051 & $.060^{*}$ \\
\hline $1-2$ years & $.138^{* * *}$ & $.121^{* * *}$ & -.128 & $-.228 * * *$ & $.098^{*}$ & -.136 & & $-.249 * * *$ & -.041 & .051 & -.024 & .012 \\
\hline 2-3 years & .025 & $.120^{* * *}$ & -.082 & $-.375^{* * *}$ & $.113^{*}$ & $-.274^{* *}$ & & & -.033 & -.011 & .039 & $.067^{*}$ \\
\hline $3-4$ years & -.007 & $.168^{* * *}$ & $-.166^{*}$ & $-.254^{* * *}$ & $.106^{*}$ & -.105 & & & -.039 & .066 & -.009 & .069 \\
\hline $4-5$ years & -.004 & $.162^{* * *}$ & -.052 & $-.326^{* * *}$ & .092 & -.115 & & & -.056 & .044 & -.067 & .061 \\
\hline 5 or more years & -.001 & $.197 * * *$ & .014 & $-.291^{* * *}$ & .070 & -.024 & & & $-.186 * * *$ & .122 & -.051 & .005 \\
\hline 1 or more years & & & & & & & -.103 & & & & & \\
\hline 2 or more years & & & & & & & & $-.314^{*}$ & & & & \\
\hline Observations & 45,049 & 43,953 & 50,014 & 48,799 & 59,282 & 56,639 & 49,953 & 46,284 & 42,633 & 41,527 & 11,046 & 24,923 \\
\hline Individuals & 5,923 & 6,087 & 6,798 & 6,946 & 7,609 & 7,637 & 6,823 & 6,619 & 6,703 & 6,836 & 2,156 & 3,902 \\
\hline
\end{tabular}

Notes: Linear fixed-effects estimator. Other control variables include 5-year-age-cohorts, dummies for household head and spouse, years of schooling, household size, number of young (0-14 years) and old (15-

du

dumntes, 10 year dunmies, dununies controlling for current occupation status. $* * * / * * *$ indicate a parameter estimate is significant at the 1\%/5\%/10\% level. Data: KLIPS $1998-2008$. 
However, they somehow manage to increase the positive effect again three years after marriage and are then able to sustain it in the long-run. The results suggest that men might benefit more from marriage than women.

Full results for the event "marriage" including all covariates can be seen in Table A1 in the appendix. Here, the main findings are confirmed for the two ordered logit estimators (FF and BUC). The results provide additional evidence for the fact that life events are not randomly distributed (Stutzer and Frey, 2006). Comparing lead effects of simple ordered logit estimates in columns (1) and (5) with the fixed-effects estimates, it can be seen that among all never married individuals of the same age cohort those that eventually get married are already happier several years before marriage. Thus, happier personality traits are more likely to marry. ${ }^{31}$ While this once more confirms the importance to control for fixed effects to avoid potential selection bias, the comparison of different estimators also indicates that the choice of the fixed-effects estimator does not change the main results.

Bearing in mind additional marital benefits for men, results for divorce and widowhood can be better understood. In general, results suggest that men suffer much more from marital dissolution. When getting divorced, women experience a short negative effect in the first year following divorce but quickly manage to recover. ${ }^{32}$ Men experience a twice as strong negative initial effect, and when staying divorced never return to their marital level of happiness within the observed time frame. Results on widowhood also diverge between men and women. While widowed men show a transient negative effect and full adaptation thereafter, widowed women on average show no negative effect after their spouses pass away. They experience, if anything, small positive effects between the second and the fourth year after the event. ${ }^{33}$

31 Full results of all events except marriage are not displayed in the paper because of space limitations. They can be obtained from the authors on request. Examining potential selection effects for the case of divorce, we find that unhappier female personality traits are more likely to get divorced, a finding that does not hold for men in our data.

32 Note that if the woman was a housewife, she is entitled to receive 30 percent of the wealth accumulated during marriage when divorce takes place within the first 10 years, and 40-50 percent thereafter. Wealth that was already formed before marriage goes to the partner who brought it into marriage. In the case of female widowhood, she is treated with a factor of 1.5 , and each child of 1 . Thus the woman receives about 43 percent of total inheritance in the case of one daughter and one son.

33 Of course, the latter results of widowhood focus on the eldest generation and cannot be generalized for younger marriages. Gender inequality is likely to be highest in the eldest generation (see also Rudolf and Cho, 2011). 
These results are particularly interesting when comparing them to the findings of Clark et al. (2008) and Clark and Georgellis (2010) for German and British women and men. In their analyses of more gender-equal societies, they do not find significant differences in adaptation to marriage-related events by sex. Both women and men adjust to the positive (negative) effects of marriage (widowhood) rather quickly and return to their baseline happiness within a similar time horizon than that of our paper. Only in the long run (5 or more years), they find significant negative effects for women. In the case of divorce, German and British women and men show strong negative effects before getting divorced and then increase their happiness gradually after. Here also, no specific gender effects could be traced out. Therefore, Korean results do significantly differ from what has been found so far in the literature.

In a further step we want to visualize the magnitude of the gender happiness gap. Thus, we assign monetary values to the effect, as has been done, for example, by Oswald and Powdthavee (2008) in the case of calculating compensation payments for disabled people. When looking at column (8) of Table A1 in the appendix, we see that the average long-run happiness shift for men is around .15. This conservative calculation is almost double the effect of living in one's own house (.083), and it is equivalent to approximately a 300 percent increase in per-capita household income (assuming that we could raise only male per-capita household income). Since the mean of log annual household per-capita income in our sample is equivalent to 6.08 million Korean Won (KRW) in real 2005 value, an increase of 300 percent is equivalent to an increase of about 18.2 Million KRW. Applying a yearly average exchange rate of $1,024 \mathrm{KRW} / \$ \mathrm{US}$ in 2005 , this is equivalent to the happiness effect (exclusively for the husband) of raising per-capita yearly household income by approximately US $\$ 17,800$.

\subsubsection{Labor Market Events}

Columns (7) to (12) of Table 2.4 show estimation results of effects of unemployment, first job entry, and the introduction of the 5-day-working-week on happiness. Unemployment and its long-run effects can only partially be analyzed with the help of Korean data. The dynamic nature of Korea's labor market and the near absence of public unemployment insurance both result in a very low number of long-term unemployed. Thus we had to reduce the number of lag categories in our model. Still, the results suggest partial adjustment for women already after more than one year of unemployment. Men seem to not adjust over the limited time horizon. Their negative satisfaction respond does not diminish in size after two or more years of continuous unemployment, it rather slightly 
increases. This is in line with Jang et al. (2009) who show that Korean men suffer much more from depressive symptoms than their female counterparts when unemployed, early retired or out-of-labor-force.

Entering one's first job does not show significant effects on happiness, once we control for income effects. If anything, one might notice that men have rather positive coefficients and women merely negative ones following first job entry. In the long-run we can see a negative effect for women who stay in their first job. $^{34}$

Finally we look at what happens when individuals move from a 6-to-7-dayto a 5-day-working-week. Effects on life satisfaction are in general rather weak. The estimates suggest slight positive effects for men in the years after the reduction in working days. Women do not show significant effects after the reduction. Table A2 in the appendix examines this satisfaction response more in detail. It reports the results of the same model, but now additionally estimated with hours and job satisfaction as dependent variables. ${ }^{35}$ The results show that while women experience no effect on either of the three satisfaction measures, men show positive responses in both their satisfaction with working hours and their overall job satisfaction. The latter indicators show positive, significant effects starting 1 to 2 years before the actual reduction and then lasting in the long-run. Thus, we cannot reject non-adaptation to the observed working days reduction for men. ${ }^{36}$ It seems that men, who have on average higher labor force participation and work more days and hours than women, benefited more from the newly introduced two leisure days per week.

To sum up, the findings on labor market events show that men are both harder hit by unemployment and benefit more from a reduction in working days.

34 Direct gender discrimination in the Korean labor market manifests not only through significant gender wage differentials but also through unequal promotion chances (Lee et al., 2008).

35 The job satisfaction question is "Overall, how satisfied or dissatisfied are you with your main job?", while hours satisfaction is the answer given to the aspect "Working hours" following the question "How satisfied or dissatisfied are you with regard to your main job on the following aspects?". Both variables use the same scale as life satisfaction, i.e. from 1 ("very dissatisfied") to 5 ("very satisfied") in our analysis.

36 Note that the result of no adaptation does not change after introducing working hours controls. Thus, the mere effect of shifting working time from six or seven days to only five days a week appears to have lasting positive effects. 

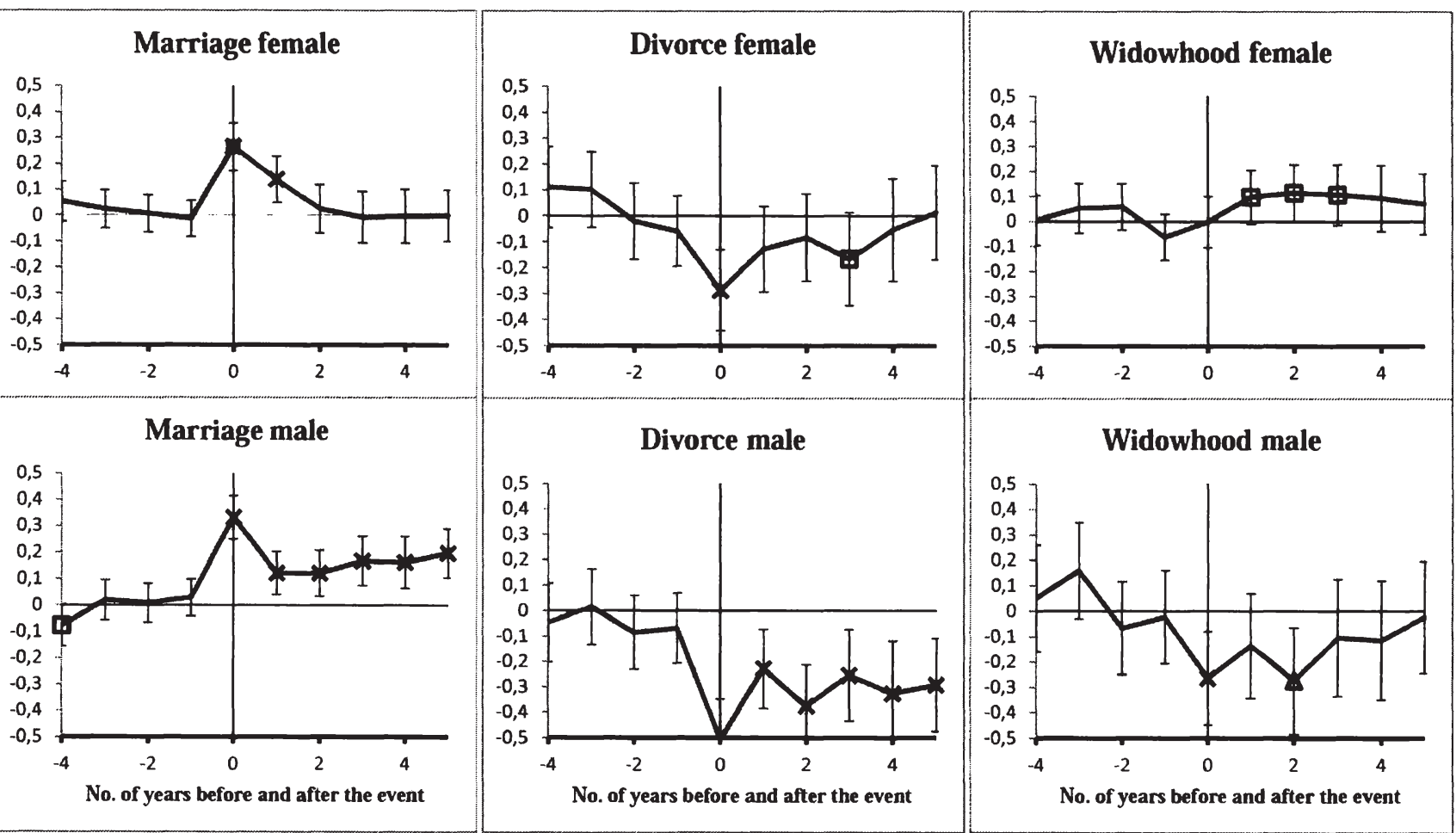

( $\times \ldots$ significant at the $1 \%$ level; $\Delta \ldots$ significant at the $5 \%$ level; $0 . .$. significant at the $10 \%$ level) 

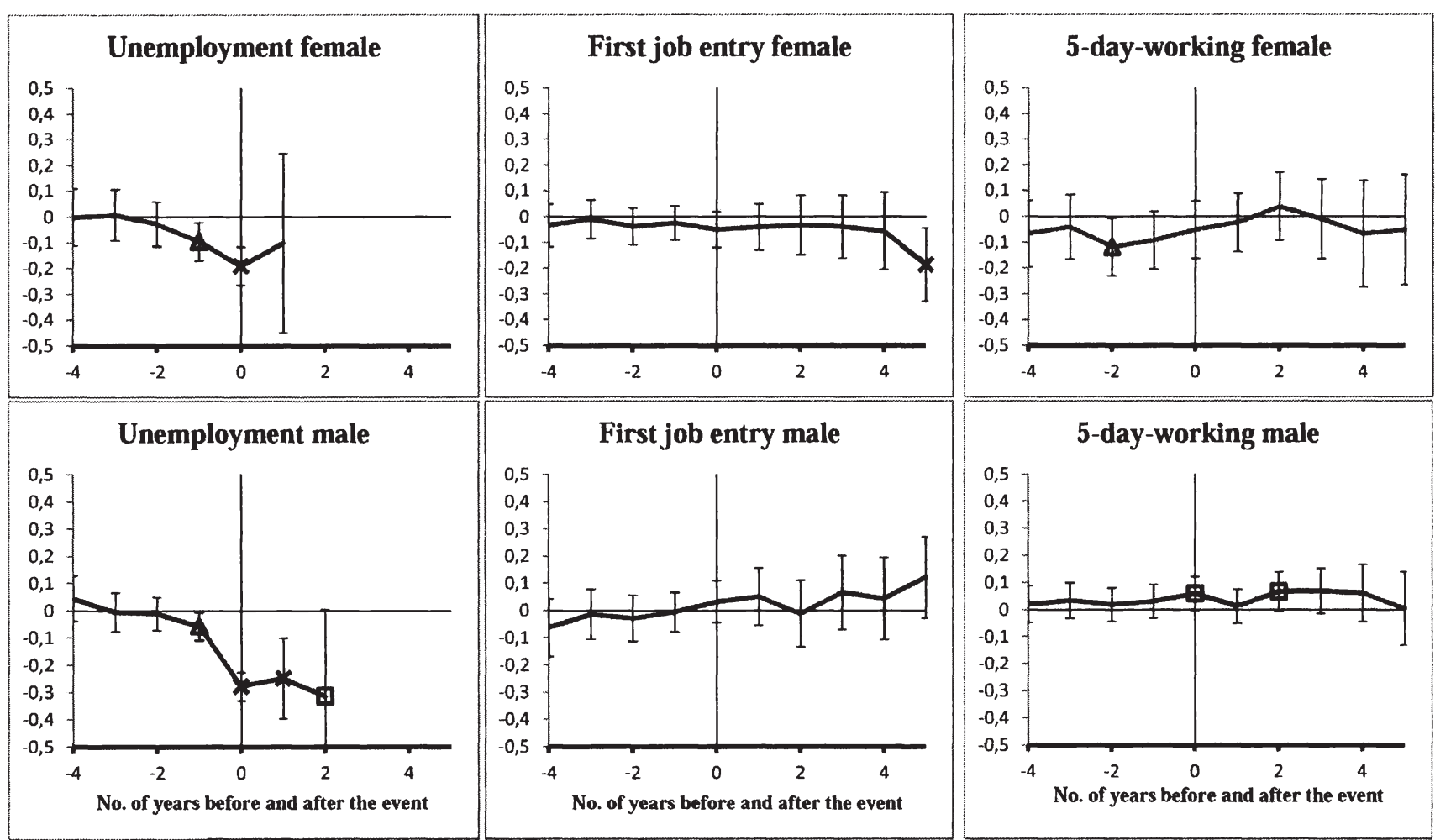

Fig. 2.1: Adaptation to life and labor market events

( $\times \ldots$ significant at the $1 \%$ level; $\Delta . .$. significant at the $5 \%$ level; $\square . .$. significant at the $10 \%$ level) 


\subsubsection{Determinants of Intra-Marriage Gender Happiness Gap}

The finding of a significant intra-marriage gender happiness gap in the preceding subsections leads to the analysis of the determinants of this gap. The results are presented in Table 2.5. The female share in earnings has the expected negative significant effect on the husband-wife happiness gap. ${ }^{37}$ When women increase their relative bargaining position in the household, they also increase their happiness relative to their husbands (column (1)). However, does this effect work through an increase of female happiness or through a decrease in male happiness? As the last three columns show, the latter is the case. When female shares in earnings rise, husband's happiness falls (column (4)). Since for the wife there is no effect (column (3)), the sum of husband's and wife's happiness is negatively affected by a relative increase in female earnings (column (2)). This result can be interpreted in two ways: On the one side it could be used as evidence supporting intra-household bargaining theories. Husband's happiness might have decreased because of a decrease in relative bargaining power. On the other side, it could also provide evidence for the gender identity hypothesis. He might suffer a negative utility effect due to his non-fulfillment of societal expectations. While it is not possible with our data to disentangle the relative importance of the two effects, we do believe that both effects play a role. Further support for the identity effect can be seen when comparing the effect that unemployment has on female versus male happiness. Husband's unemployment has not only a strong effect on male happiness, but also on female happiness. In fact, women are affected even stronger by male unemployment. Being confronted with wife's unemployment has a much smaller effect on the household's combined happiness. Thus, gendered role prescriptions are likely to influence utility. Another interesting finding is that women seem to compare themselves more with others than men, as indicated by a much stronger negative effect of log regional per-capita income on women's happiness. Interestingly, men seem to prefer their wives not to stay at home as a housewife, but to work instead. Thus, while working women increase male happiness compared to housewives, a higher female earnings share is detrimental for male well-being. Women themselves seem to be indifferent between working and being a housewife.

37 Note that the female share in married couple earnings in our sample rose from 1998 (.17) to $1999(.22)$, but then stagnated until $2008(.23)$. 
Table 2.5: Intra-Marriage Happiness Inequality

Dep. Variable: Life satisfaction -

\begin{tabular}{cccc}
$\begin{array}{c}\text { Difference } \\
\text { (husb-wife) }\end{array}$ & $\begin{array}{c}\text { Sum } \\
\text { (husb+wife) }\end{array}$ & Wife & Husband \\
\hline
\end{tabular}

Relation (husband to wife)

Female share earnings

Age difference

$-.163 * * * \quad-.144 * *$

Years of schooling difference

$-.036^{*}$

.042

.009

$-.154 * * *$

$-.005$

.002

$.039 * *$

.003

Wife's occupation

Hours 1-30

$-.020$

$-.072^{* *}$

$-.026$

$-.046^{* *}$

Hours 31-40

$-.005$

.016

.011

.005

Hours 51-60

.022

.020

$-.036^{*}$

$-.008$

$-.001$

.021

Hours 60+

Housewife

Unemployed

Retired

$-.069 * * *$

$-.072^{* *}$

.014

$-.022$

$-.045$

$-.394 * * *$

$-.001$

$-.071 * * *$

$-.066$

.082

$-.175^{* * *}$

$-.220 * * *$

In education

$-.288^{* * *}$

.206

.074

.008

Illness

Other occup

$-.028$

$-.266^{* * *}$

$.247^{* *}$

$-.041$

$-.022$

$-.124 * *$

$-.119 * *$

$-.147 * * *$

Husband's occupation

Hours 1-30

Hours 31-40

$-.005$

$.181 * * *$

$-.051$

$-.073^{* *}$

Hours 51-60

$-.020$

$-.013$

$-.088^{* * *}$

$-.093 * * *$

$-.001$

$-.066^{* * *}$

$-.017$

Hours 60+

Houseman

Unemployed

$-.018$

$-.022$

$-.033^{* * * *}$

.124

$-.095$

$-.002$

$-.020$

.060

$-.712^{* * *}$

$-.109$

.015

Retired

$143 * * *$

$-.113$

$-.386^{* * *}$

$-.326^{* * *}$

In education

Illness

$-.012$

$-.098$

$-.128 * * *$

.015

.034

$-.352 * * *$

$-.043$

$-.055$

Other occup

.006

$-.294 * * *$

$-.193 * * *$

$-.159 * * *$

Other controls

No of children 0-14

No of children 15-30

Years of schooling wife

Log per-capita hh income

Log per-capita reg income

Own house

.012

$-.041 * *$

$-.150^{* * *}$

$-.144^{* * *}$

Constant

.009

$-.035^{* *}$

$-.027 * * *$

$-.014$

$-.012$

.007

$-.022^{* * *}$

$-.013$

$-.006$

$.103 * * *$

.009

$-.003$

-

$-.246 * * *$

$.055^{* * *}$

$.048^{* * *}$

$-.151^{* * * *}$

$-.095 *$

004

$.136^{* * *}$

$.066^{* * *}$

$.070 * * *$

Observations

.026

$7.016 * * *$

$3.674^{* * *}$

$3.342 * *$

Individuals

4,977

27,559

27,559

27,559

Notes: Linear fixed-effects estimation. Other control variables include 5-year-age-cohorts, 14 regional dummies and 10 year dummies. $* * * / * * / *$ indicate a parameter estimate is significant at the $1 \% / 5 \% / 10 \%$ level. Reference category for occupation status: Working $41-50$ hours a week. Data: KLIPS 1998-2008. 


\subsection{Conclusion}

The main aim of this paper was to provide evidence for the baseline hypothesis from a society with relatively strong traditional gender roles. Korea presents an ideal case study, since compared to its economic and human development achievements, the country still ranks very low in terms of gender equity. Our analysis revealed that the inter-temporal nature of major life and labor market events matters. While partial and full adaptation can be seen to most events, anticipation only plays a minor role. We find important gender-related differences in both impact and adaptation to major events. All events have a lower absolute initial impact on women's happiness. This can partly explain why women then return to their baseline happiness more quickly than men. Moreover, particularly the events related to a change in marital status provide evidence for a significant gender gap during marriage in Korea. While marriage has a strong and lasting positive effect on male happiness, female's happiness gain is limited to not more than the first two years after marriage. We find that the long-run male happiness shift due to marriage is equivalent of twice the effect of living in one's own house and to an increase of per-capita yearly household income by approximately US\$17,800. Men suffer relatively more than women from divorce and widowhood. Female widows do not show any negative effects after their partner passes away. If anything, rather small positive effects can be observed. Examining potential determinants of the intra-marriage gender happiness gap closer revealed that low female earnings shares provide an important explanation for the happiness gap. Two theoretical explanations can be thought of. First, financial dependence lowers relative female bargaining power in the household, which might have impacts on the intra-marital happiness distribution. Second, if societal prescriptions are such that men should have the dominant earnings share, and if social comparison matters for utility, then higher female earnings might induce lower male happiness.

With respect to unemployment, our findings suggest partial adaptation for women but no adaptation for men to unemployment in the short-run. The reduction of working days and the move towards a 5-day working week shows positive effects only for men. Thus, labor market events also point towards the importance of gendered roles. Men's role as the main breadwinner might explain stronger male responses to labor market events.

Although gender roles are changing in Korea today, the fact that married women's share in couple earnings has stagnated between 1999 (.22) and 2008 (.23) indicates that past reforms have not led to significant improvements for married women yet. As traditional gender roles and a highly male-dominated labor market continue to be major obstacles to the pursuit of gender equity in 
happiness in Korea, reforms in this area should be continued and require critical evaluation. Future reforms should ensure equal pay and equal promotion chances for women, as well as the creation of family friendly job opportunities, particularly in high-skilled employment. In order to better separate effects of gender-specific impacts of the event from gender-specific adaptation patterns, further research is needed. 


\title{
Essay 3
}

\section{Rural Reforms, Agricultural Productivity, and the Biological Standard of Living in South Korea, 1941-1974}

\begin{abstract}
This paper analyzes effects of the Republic of Korea's two major rural reforms in 1950 and 1962/63 on agricultural productivity and individual well-being. The 1950 Land Reform resulted in a large-scale redistribution of land while 'green revolution'-type reforms in 1962/63 pushed forward the application of modern agricultural technologies and improved rural infrastructure. This study's findings indicate that both reforms had significant positive impacts on agricultural productivity. Using the link between final height outcomes and early childhood nutrition further allows an assessment of the interventions on the biological standard of living using adult height outcomes. Korean mean adult height grew by a remarkable $8.1-12 \mathrm{~cm}$ for women and 7 to $9.6 \mathrm{~cm}$ for men born between 1920 and 1987. Two thirds of this growth took place after the 1950 reform, and about $40-50$ percent after the 1962/63 reforms. Structural break analyses of height trends reveal significant upward shifts in trend around the years of the reforms. While Korea can be considered a case of successful land reform, the years between the two major reforms can be considered as Korea's lost decade.
\end{abstract}

\subsection{Introduction}

The World Development Report 2008 once again redirected the focus for development policy and poverty reduction efforts on the rural economy, accruing from the fact that the majority of the world's poor at the beginning of the $21 \mathrm{st}$ century still resides in rural areas. It argues that sustainable rural income growth and poverty reduction requires improvements in agricultural productivity, a general empirical finding in the literature (e.g. Datt and Ravallion, 1998b; Ravallion and Chen, 2007; Deininger, 2003; Grimm, Klasen and McKay, 2007; Minten and Barrett, 2008). It goes on to state that both an equitable land distribution and agricultural production technologies are key factors for attaining sustainable growth in the rural economy. Moreover, they can lay the basis for industrialization and equitable growth of the whole economy, as has been seen in the extraordinarily successful East Asian NICs. 
In the short run, a more equal land distribution translates into both lower average farm size and higher rates of ownership. By redistributing land to the actual tillers, strong incentive effects can be set free. As long as feudal or semifeudal land structures pertain, with few landlords who own most of the land and many landless and land-poor wage laborers or tenants, cultivation is often less efficient and land productivity remains low. Usual contracts of hired farm labor or sharecropping are associated with lack of supervision and thus result in lack of incentive and static inefficiencies (Otsuka, Chuma and Hayami, 1992). ${ }^{38}$ Moreover, empirical findings suggest that in low-productivity agricultural sectors, farm sizes are often inversely related to agricultural productivity (see e.g. Deolalikar, 1981; Fan Chan-Kang, 2005). In addition to efficiency considerations, ownership rights further enable farmers to access credit, and to raise investment in education and physical capital (e.g. Feder and Feeny, 1991; Deininger, 2003).

That initial asset inequality matters for long-run growth has been shown in the academic literature in several studies (Alesina and Rodrik, 1994; Persson and Tabellini, 1994; Deininger and Squire, 1998; Rodrik et al., 1995; Galor et al., 2009). Theoretical explanations put forward two main channels: On the one hand, credit rationing in the presence of indivisible, economically profitable investment opportunities in education or agricultural technology may lead to underinvestment of the asset-poor. On the other hand, political bargaining power of the asset-poor might be limited and thus also the ability or preference to participate in a democratic process. Therefore, creating low levels of asset inequality can foster broad-scale investment into human and physical capital not only on the individual but also on the government level, and therefore significantly enhance long-run growth. Rising overall human capital combined with low social pressure for redistributive policies furthermore facilitates efficient governance and political stability. For all the above mentioned reasons and the undeniable success of the East Asian low-initial-inequality growth examples, the formerly widely believed equity-efficiency trade-off which assumes that inequality is good for growth, is nowadays increasingly put into question.

Besides delivering lower growth, asset inequality does also lead to persistent income inequality even if the country manages to industrialize. In the process of development and structural change of an initially agriculture-based economy, traditional patterns of land holding are often translated into distributions of in-

38 Already in 1975, the World Bank stressed the desirability of owner-operated family farms and the importance of an egalitarian asset distribution as two of its three strategic principles for its land reform policy. Until today, these strategies have not been changed (Deininger and Binswanger, 1999). 
dustrial productive assets including financial, physical and human capital. That is, in the absence of an initially equitable rural asset base, a limited number of initially wealthy families are those who will then easily maintain their relative political and economic predominance under the new circumstances perpetuating the country's unequal income distribution.

Therefore, a redistributive land reform at an early stage of development can be a crucial means to lay the basis for agricultural productivity gains in the short run while enhancing long-run equitable growth and poverty reduction prospects. Such government interventions can lead to both equity and efficiency gains. However, history has also taught us that implementing successful land reforms is not a simple task. First, success depends on earlier land structures, whether hacienda like systems prevailed with mainly wage contracts, or tenancy systems with sharecroppers used to run their own businesses. It has often shown advantageous if land was distributed to tenants rather than landless laborers, who might find it particularly difficult to become successful farmers. Second, most successful land reforms took place in times of grand political change and were government-led. In many cases, the class of rural landless and near landless found powerful allies in other sectors of society, and sometimes even from abroad (Barraclough, 1999). Third, land reforms might yield only limited success if land redistribution is not flanked by productivity enhancing complementary reforms. Such complementary reforms might include improvements in general public infrastructure, better access to credit, improved inputs like new seed varieties, increased supply of fertilizer, extension services, and agricultural R\&D. An extensive empirical literature exists that focuses on the effects of agricultural technology adoption and productivity improvements during the Green Revolution. Strong positive effects on agricultural productivity are usually found from the increased use of fertilizer, improved seeds, pesticides, and related technical education (e.g. Feder and Umali, 1993). Effective agricultural technology adoption requires government effort and can have pro-poor effects, thus reducing the relative income gap between the rich and the poor (De Janvry and Sadoulet, 2002; Minten and Barrett, 2008). ${ }^{39}$

South Korea represents an interesting case of land reform since land redistribution and 'green-revolution'-type reforms can be studied rather separately due to the fact that they were not enacted at the same time but the latter followed a decade after land redistributions had been completed. Since the government's

39 However, the so-called 'green-revolution' technologies do also have their negative sides, for example when exposure to pesticides like DDT lead to increased rates of breast cancer (Clapp et al., 2008) or when monoculture and an overuse of chemicals result in soil degradation (Singh, 2000). 
objective of the 1950 reform was not the improvement of agricultural productivity but rather the restoration of political stability after turbulent years following liberation, it is possible to isolate relative effects of land redistribution and technology enhancing reforms in Korea (Pak, 1968; Jeon and Kim, 2000). The Korean case is particularly interesting since it represented one of the least developed countries in 1950 with a per-capita GDP level of around the average of the African continent and an almost complete agriculture-based economy. ${ }^{40}$ During the following six decades it then went through its well-known growth miracle which lifted the country up to the level of high-income, high-technological OECD economies. In the meantime, Korea managed to hold income inequality at very low levels, with Gini coefficients of income always within the range of .3 to .4 , initially rising but lately falling again (World Bank, 2004).

The aim of this paper is to shed new light on the still understudied effects of Korean rural reforms on agricultural productivity and individual living standards. Only few papers have estimated the impact of the reforms on the former, making use of macro data, which are scarce particularly during the 1940s and early 1950s. To the best of the author's knowledge no paper has yet analyzed effects of the reforms on individual well-being using national micro data. This paper takes advantage of the fact that current anthropometric data, or more precisely adult height data sets, can provide good proxies for Korean individual living standards during the midst of the $20^{\text {th }}$ century for which no national-level survey data exists (Komlos, 1993; Komlos and Baten, 1998; Steckel, 1995; 2009; Deaton, 2008; Hoddinot et al., 2008). This paper tries to find if and to what extent land redistribution around 1950 and intensification reforms in 1962/63 positively affected agricultural productivity and individual well-being. The findings indicate that both the lowering of land inequality/increase in ownership cultivation and later technology-enhancing reforms had positive significant effects on productivity. Moreover, structural break analyses of time series of adult average height outcomes reveal positive shifts in trends around the years of the rural reforms. Thus, there seems to be evidence for improved food availability resulting from the reforms and an improved standard of living.

The paper is organized as follows: Section 3.2 gives the reader an overview over background, process and implications of the rural reforms in the Republic of Korea (ROK). Section 3.3 then analyses the effect of the reforms on agricultural productivity while section 3.4 examines the effect on individual well-being using anthropometric data. Section 3.5 summarizes and concludes.

40 Maddison (2003) estimates a level of per-capita GDP for 1950 (in 1990 International Geary-Khamis dollar) for South Korea of $\$ 854$ while the average of 57 African countries is $\$ 889$. 


\subsection{Rural Reforms in 1950 and $1962 / 63$}

South Korea's government-led land redistribution put into law by the Agricultural Land Reform Amendment Act (ALRAA) in March 1950 is considered in the literature one of the most successful cases of land reform. Before 1950, the Korean rural economy was characterized by a landlord estate system, where few land owners rented out their land to tenants in exchange for a fixed share of their harvest. ${ }^{41}$ By transferring large amounts of farm land from the rich to the poor as direct or indirect consequences of ALRAA, rural social relations changed and former landless and land-poor tenants were empowered both economically and politically (Oh, 2008). Equity and democratization gains resulting from the reform are viewed as one of the keys to the country's later economic miracle (World Bank, 2004; Rodrik et al., 1995; Boyce et al., 2007). Vested Japanese land had been distributed as early as 1948 under the US military government. After the formation of the ROK Government in August 1948, earlier discussed land reform ideas further progressed and led to voluntary land sales of many Korean landlords already before the actual Land Reform Law (ALRAA). According to the ALRAA scheme, excess land from Korean landlords was then purchased in order to provide it to former tenants and workers. A three hectare ceiling on land holding was established for each farm household. Excess land was distributed among tenants. Korean landlords received land securities in the beginning, and were later compensated in cash at the government's regulated rice price, which was much lower than the going market price of rice. In this way, the government managed to redistribute income from the rich to the poor while at the same time overcoming own capital shortages and enhancing investment

41 In the case of Korea the share rent was on average about 50 percent of "standard production", depending on the quality of land it could be between 30 and 70 percent (Pak et al., 1966). "Standard production" meant that a tenant had to pay a fixed share of standard production each year rather than weighing the crop each year. This was partly due to the phenomenon of absent landlords, who preferred to live in the cities and thus were not able to continuously monitor farm production. De facto this was coming close to a fixed-rent contract. Thus tenants were rather bad off in poor crop years and better off in years of good harvest. Contract choice theory tells us that fixed-rent contracts are more efficient than sharecropping contracts in terms of providing maximal incentives. However, poor tenants might often prefer sharecropping arrangements if they are risk-averse and prefer to ensure themselves against bad harvest. In the case of Korea, an additional uncertainty that tenants faced was, as mentioned, the unpredictability of landlords' visits to evaluate "standard production". Thus, some tenants would even thin out the stand of newly headed out rice in good years and cook the heads in a stew. It was to their advantage to hold down rice yields to not encourage the landlord to raise the standard production figure (Morrow and Sherper, 1970). 
into agricultural and industrial infrastructure (Jeon and Kim, 2000). Tenancy became legally prohibited. The reform which was implemented with the assistance of US military forces led to a sharp increase in ownership and reduction in average farm size. The percentage of tenants among all rural households decreased from 45.8 in 1949 to practically zero in 1952, only to increase slightly again afterwards (6.8\% (1960), 9.7\% (1970)). Average farm sizes decreased from 2.06 ha per rural household in 1950 to .88 ha in 1960 and .93 ha in 1970 (Fan and Chan-Kang, 2005). While land was fully redistributed by 1952 (Morrow and Sherper, 1970), compensation payments to landlords and tenants' payments to the government were practically finalized by the beginning of the 1960 s.

As a result of the reform 1.29 million hectare of land changed ownership. Of this total amount, 21 percent was confiscated land from Japanese landlords, 23 percent was land redistributed by the government through the ALRAA scheme, while as much as 55 percent was land targeted by the reform freely sold in the market in anticipation of ALRAA (KAERI, 1989, pp. 1030-31).

Korea had been under Japanese colonial rule and was then occupied after the Second World War by US troops who governed the country between 1945 and 1948. Several developments led to the Land Reform Law of 1950 in South Korea. First of all, the South Korean post-war government was anti-colonial and so it confiscated land from the Japanese. Second, rural landless and land-poor had already been organized in protests during colonial times. This facilitated implementation of the reform with a great deal of support and participation by the beneficiaries. Moreover, the weak government after 1945 in comparison with the preceding colonial administration led to a situation in which transaction costs for landlords to enforce tenant's payments saw a sudden sharp increase implying that tenant's rents were de facto reduced already as early as $1945 .^{42}$ Third, especially the US occupants feared that North Korea with the support of the USSR could try to mobilize the class of rural poor in the South to overthrow the Southern government. And fourth, there was always competition between the North and the South with respect to the economic model chosen. Thus, political momentum and increased transaction costs for the rural oligarchy eventually led to large redistributions of land around the years of the official reform in 1950.

42 For the same acreage of sharecropping land, a landlord could collect 1,500 suk of rice during the colonial period. This rent reduced to 100 suk right after August 1945, and 400-500 suk after 1946. One suk equals approximately 180.4 liters. Note that the U.S. military administration had set official rental rates for tenancy at one third of annual crop yields in October 1945, down from on average 50 percent before. 
Even though redistribution of land in Korea succeeded in creating a more equal rural asset base, it failed in establishing a minimum size of land ownership. Due to geographic restriction (most of the country consist of mountainous terrain which does not allow for agricultural production) and high population density, scarce land had to be distributed among a high number of farmers. Thus, a high degree of fractionalization of land was the natural consequence posing a natural limit to economies of scale production. In fact, after land reform in 1953, 41.2 percent of all farm households cultivated less than half a hectare, while 33.3 percent cultivated between .5 and 1 hectare of own land (Pak et al., 1966; Morrow and Sherper, 1970). ${ }^{43}$

The Korean War (1950-53) interfered with the land reform period, particularly with the post-reform period. As mentioned above, three quarters of redistributed land had already changed owners by the time that ALRAA was enacted in March 1950, i.e. three months before the invasion of North Korean forces into South Korea. Enforcement of ALRAA was only slightly delayed (MAFF, 1966). The war led to about one million casualties among the South Korean population. ${ }^{44}$ However, displacement of farmers from their farms is rather negligible since South Korea was merely occupied for about 3 months during 1950 before joint South Korean and US forces pushed back Northern troops. Thus, the major economic impact resulting from the war can be seen in the decline of farm population due to war casualties by about ten percent and through widespread destruction of industrial property and infrastructure. The latter effects led to the imposition of a land tax enacted in September 1951 in order to rebuild industrial structures. This levy on the rural population combined with forced rice sales to the government at below-market prices from February 1950 onwards is likely to lead to an underestimation of individual welfare changes after the land reform (Pak, 1966a).

This paper tries to show that the 1950 Land Reform brought about both equity and efficiency gains in the Korean economy. As Pak (1968) notices it succeeded in changing the rural social framework from a feudalistic two-class society into a much more equal one with nearly equality of opportunities. However, it might be the case that the redistributive change from tenancy to ownership alone might have only modest impacts on agricultural productivity if land results

43 The 1965 Farmland Survey asked people for their preferred and present cropland sizes both including owned and rented land. Farm families with less than 1 hectare of land cultivated on average 0.56 ha and would have preferred a size of 1.2 ha. Families with more than 1 ha cultivated on average 1.6 ha and would have preferred on average 1.97 ha. It is also shown that larger households possessed on average more land but would have preferred also a much higher increase of land than smaller households (Pak, 1968). Compare with Table 3.1 ahead. 
to be highly fragmented and complementary policies remain absent. In fact, Korean agricultural productivity saw stronger growth after 1962 when Park Chunghee's military government issued its first Five-Year Development Plan. It focused likewise on the increase of agricultural output and the creation of heavy industry (Pak, 1966b; Morrow and Sherper, 1970). The agricultural part of the plan which aimed at achieving Korea's food self-sufficiency through increased agricultural productivity, led to a rapid increase in the use of modern technologies and interlocked services such as increased supply of fertilizer, pesticides, improved seeds, improved irrigation, and access to credit and extension services. Japanese colonial officials had pushed modern technologies and agricultural services forward already in a first wave of agricultural reforms throughout the 1920 s and early 1930 s. ${ }^{45}$ However, the years after liberation had seen technology and service provision in Korea at a low with the Korean War (1950-53) and weak governments. Besides that the Five-Year Plan of 1962 issued several policies supporting small-scale farmers and the agricultural sector as a whole. Financial strain on the rural population was relaxed by a re-arrangement of terms of farm debt, provision of farm management funds, establishment of fair prices for farm products ${ }^{46}$, consolidation of agricultural credit institutions, improvement of commodity loans on the farm crops, as well as the establishment of a bank for small business. Moreover, unjustly-acquired properties were confiscated by the government and the government took the control over the supply of commercial fertilizers (Pak, 1966b).

\subsection{Effect of Rural Reforms on Agricultural Productivity}

In order to identify the effect of the two waves of agricultural reforms on agricultural productivity and individual height outcomes this study proceeds as

45 Major institutions involved in this process were (1) the Korean Agricultural Associations (KAA) which was responsible for seeds, fertilizer and farm equipment and had 15,000 employees nation-wide, (2) the Federation of Financial Associations (FFA) which was responsible for credit supply, and (3) the national and local government administrative units which laid out exact agricultural programs and watched over their implementation (Morrow and Sherper, 1970). Besides that, an Agricultural Experiment Station had been installed under the Japanese in Suwon. A 1954 UN Report concludes that the interlocking services were simple, direct and enforced.

46 The law of crop control from February 1950 led to a two-price system in Korea which might have been considered 'unfair' by Korean farmers. Farmers were obliged to sell between 10 and 24 percent of their output (depending on farm size) to the government at below-market prices (approximately 50-60 percent of the going market price). 
follows. This section presents the estimation of an agricultural productivity model using farm output per capita and per farm capita ${ }^{47}$ as the relevant productivity measures and including relevant controls to proxy for the rural reforms. Since agricultural production was almost completely devoted to domestic food consumption, this should be a valid proxy for Korean household's food availability around the time of the reforms. In section 4, height and agricultural productivity time series will be examined for the presence of structural breaks around the years of the reforms 1950 and 1963.

\subsubsection{Historical Farm Data}

This study uses various macro sources to access national-level farm variables from 1941 onwards. Data on total farm production, farm households, farm population, and land inequality comes from Keidel (1981), while farm land comes from both Cheong (1975) and Keidel (1981). Tenancy rates are taken from Bank of Chosun (1948) and KAERI (1989) as cited in Jeon and Kim (2000). The fertilizer index is constructed using annual growth rates of chemical fertilizer production from UNKRA (1954) as reported in Morrow and Sherper (1970) for the period 1941 to 1952 and of chemical fertilizer sales from Keidel (1981) for the period 1952 to 1974 . Irrigation data comes from various editions of the Ministry of Agriculture, Forestry and Fishery's (MAFF) Yearbooks of Agriculture as reported in Morrow and Sherper (1970). Data on farm credit employees is also taken from Morrow and Sherper (1970). GDP and population data are from Kim (2009) and CPI data from Kim and Park (2007). Note that all values until 1945 represent only the values for the provinces that nowadays form part of South Korea and not the North Korean part, the only exception being the share of irrigated paddy land. ${ }^{48}$

47 Farm output divided by farm population.

48 While some series are complete, missing values needed to be adjusted for in some cases. Thus, six years of the farm land and three years of the tenancy rate variable were filled up using linear interpolation. For irrigation and land inequality, usually there is only one observation every five years. Here, too, linear interpolation was used to fill the gaps. Moreover, in the land inequality variable the years around the land reform were coded such that a linear decrease took place between 1947 and 1952 as observed in the qualitative literature. 


\subsubsection{Land Reform and Trends of Agricultural Input and Output}

Korea's rural economy went through continuous change over the $20^{\text {th }}$ century, as it developed from a traditional labor-intensive semi-feudal system at the end of the Joseon Dynasty to a post-modern, capital-intensive sector today. The main advances certainly took place during the 25 years after liberation in 1945. Table 3.1 shows important agricultural input and output variables from 1941 to 1974. Total farm output decreased during the first 3 years following liberation but then increased again from 1948 onwards, during the time when the government started the distribution of confiscated Japanese land and Korean landlords started selling their land. State-led land redistributions around 1950 totally changed rural social and economic composition, as can be seen by a large drop in tenancy rates and land inequality. While 58.5 percent of all farmers in 1941 were tenants, this number had dropped to practically zero around 1950 . The redistribution brought down the Theil measure of land inequality from .925 in 1946 to .255 in 1955. Compared to the end of the Japanese occupation period, a strong increase in the share of irrigated paddy fields can be seen around the time of the land reform. Partly this can be assigned to government investments resulting from surpluses generated through the ALRAA scheme. At the same time, as theory suggests higher ownership leads to increased investment in the cultivated land. Thus, between 1945 and 1955 the share of irrigated paddy rose from about 20 to almost 50 percent. After the Korean War came to a halt in 1953, growth in agricultural inputs was rather slow throughout the 1950s which then also translated into slow growth of the whole agricultural sector. Tenancy rates as well as land inequality were slowly on the rise again, but remaining on relatively low levels. After the Park Chung-hee administration then took power and started the first Five-Year Development Plan, the application of modern agricultural technology inputs strongly increased, as can be seen in a 75 percent increase of fertilizer sales and a 263 percent increase in pesticide sales between 1962 and 1963. Interestingly, farm output did not increase directly, yet it did in the following years by about 20 to 40 percent. The reforms were flanked by an increase in the number of crop varieties, an increase in agricultural research and development, and a broader supply of farm credit. The number of farm credit employees had risen by 150 percent between 1958 and 1965. Population figures show how the beginning of massive rural-urban migration was supported by the agricultural sector: Rising agricultural productivity was setting free rural labor for the emerging industrial sector during the 1960 s. Thus, while total population was strongly increasing, farm population as well as the number of farm households reached their maximum in 1967 and decline thereafter. 
Table 3.1: Agricultural input and output summary statistics

\begin{tabular}{|c|c|c|c|c|c|c|c|c|c|c|c|}
\hline Year & $\begin{array}{c}\text { Total farm } \\
\text { output }\end{array}$ & $\begin{array}{c}\text { Farm } \\
\text { population }\end{array}$ & $\begin{array}{c}\text { Farm } \\
\text { households }\end{array}$ & $\begin{array}{c}\text { Total } \\
\text { population }\end{array}$ & $\begin{array}{c}\text { Farm } \\
\text { land }\end{array}$ & $\begin{array}{c}\text { Irrigated } \\
\text { paddy }\end{array}$ & $\begin{array}{c}\text { Fertilizer } \\
\text { sales (chem.) }\end{array}$ & $\begin{array}{c}\text { Pesticide } \\
\text { sales }\end{array}$ & $\begin{array}{l}\text { Farm credit } \\
\text { employees }\end{array}$ & $\begin{array}{c}\text { Tenancy } \\
\text { rate }\end{array}$ & $\begin{array}{c}\text { Land } \\
\text { inequality }\end{array}$ \\
\hline & (billions 1970 Won) & (million) & (million) & (million) & $\begin{array}{c}\text { (million } \\
\text { ha) }\end{array}$ & (share of total) & (Index: 1952=100) & ( 100,000 met. tons) & & & (Theil measure) \\
\hline 1941 & 340 & 12.2 & 2.13 & 15.6 & 2.14 & & 154.5 & & & .585 & \\
\hline 1942 & 285 & 12.2 & 2.12 & 15.9 & 2.13 & & 125.9 & & 6,226 & .588 & \\
\hline 1943 & 341 & 13.3 & 2.31 & 16.1 & & & 111.4 & & & .546 & \\
\hline 1944 & 367 & 12.9 & 2.24 & 16.3 & & & 93.0 & & 6,638 & .524 & \\
\hline 1945 & 306 & 11.4 & 2.02 & 16.6 & & .206 & 68.8 & & & .502 & .854 \\
\hline 1946 & 316 & 12.6 & 2.1 & 18.4 & & & 68.7 & & 4,709 & .463 & .925 \\
\hline 1947 & 341 & 13.7 & 2.17 & 19.2 & & & 68.4 & & & .425 & \\
\hline 1948 & 398 & 14.1 & 2.32 & 19.8 & & & 153.6 & & 4.110 & & \\
\hline 1949 & 411 & 14.4 & 2.47 & 20.2 & 2.07 & & 181.4 & & & .458 & \\
\hline 1950 & 364 & 12.9 & 2.26 & 20.4 & 1.97 & .466 & 286.6 & & & & \\
\hline 1951 & 264 & 12.9 & 2.25 & 19.8 & 1.96 & & 22.6 & & & & \\
\hline 1952 & 306 & 12.9 & 2.23 & 20.2 & 1.96 & & 100 & 6.8 & & $0^{1}$ & $.200^{\prime}$ \\
\hline 1953 & 394 & 13.1 & 2.25 & 20.2 & 1.95 & & 102 & 7.8 & & & \\
\hline 1954 & 431 & 13.2 & 2.23 & 20.8 & 1.97 & & 113 & 16.8 & & & \\
\hline 1955 & 445 & 13.3 & 2.22 & 21.4 & 2.01 & .494 & 124 & 40.2 & & .052 & .225 \\
\hline 1956 & 398 & 13.4 & 2.2 & 22.0 & 2.00 & & 133 & 48.2 & & .055 & \\
\hline 1957 & 442 & 13.6 & 2.21 & 22.7 & 2.01 & & 142 & 67.6 & & .058 & \\
\hline 1958 & 473 & 13.7 & 2.22 & 23.3 & 2.02 & & 144 & 51.1 & 4,320 & .061 & \\
\hline 1959 & 479 & 14.1 & 2.23 & 24.0 & 2.03 & & 142 & 55.7 & & .065 & \\
\hline 1960 & 465 & 14.6 & 2.35 & 25.0 & 2.04 & .55 & 141 & 58.8 & & .068 & .248 \\
\hline 1961 & 544 & 14.5 & 2.33 & 25.8 & 2.05 & & 178 & 55.7 & & .064 & \\
\hline 1962 & 529 & 15.1 & 2.47 & 26.5 & 2.08 & & 198 & 51.8 & 7,519 & .06 & \\
\hline 1963 & 508 & 15.3 & 2.41 & 27.3 & 2.08 & & 347 & 188 & & .056 & \\
\hline 1964 & 617 & 15.6 & 2.45 & 28.0 & 2.18 & & 372 & 234 & & .052 & \\
\hline 1965 & 607 & 15.8 & 2.51 & 28.7 & 2.26 & .574 & 393 & 127 & 10,810 & .07 & .243 \\
\hline 1966 & 699 & 15.8 & 2.54 & 29.4 & 2.30 & & 423 & 126 & & .075 & \\
\hline 1967 & 662 & 16.1 & 2.59 & 30.1 & 2.32 & & 486 & 100 & & .081 & \\
\hline 1968 & 679 & 15.9 & 2.58 & 30.8 & 2.32 & & 478 & 100 & & .086 & \\
\hline 1969 & 746 & 15.6 & 2.55 & 31.5 & 2.31 & .762 & 535 & 175 & 9,451 & .092 & \\
\hline 1970 & 723 & 15.2 & 2.51 & 32.2 & 2.29 & & 563 & 250 & & .097 & .267 \\
\hline 1971 & 752 & 14.7 & 2.48 & 32.9 & 2.27 & & 605 & 300 & & .089 & \\
\hline 1972 & 760 & 14.7 & 2.45 & 33.5 & 2.25 & & 648 & 332 & & .081 & \\
\hline 1973 & 786 & 14.6 & 2.45 & 34.1 & 2.24 & & 793 & 364 & & .073 & \\
\hline 1974 & 819 & 13.5 & 2.38 & 34.7 & 2.25 & & 837 & 626 & & .077 & \\
\hline
\end{tabular}




\subsubsection{Econometric Model}

In order to assess the relative importance of individual production factors for total agricultural production a World Bank study by Ahn, Singh and Squire (1981) can be used. The authors analyze a simultaneous consumption and production model for 443 Korean farm households surveyed in 1970. Averaged over the households surveyed, total production costs split up into 28 percent variable input costs (fertilizer, irrigation, pesticides, seeds, salt), 66 percent labor costs (family plus hired labor), 2 percent draft animals costs, and 4 percent interest charges. Thus, in 1970 after modernization was launched, approximately two thirds of production costs account for labor and one third for variable inputs. In order to evaluate the effect of the two rural reforms on agricultural productivity, an agricultural production model of the following form will be estimated:

$Q_{t}=\alpha+\beta_{1}$ fland $_{t}+\beta_{2}$ fpop $_{t}+\beta_{3}$ fert $_{t}+\beta_{4}$ irrig $_{t}+\beta_{5}$ landine $_{t}+$ $\beta_{6}$ kwar $_{t}+\varepsilon_{t}$

$Q_{t}$ denotes agricultural production per capita or per farm capita in year $t$, fland la $_{t}$ and fpop $_{t}$ denote total farm land and total farm population in $t$. The variables fert $_{t}$ and irrig $_{t}$ represent an index of fertilizer use and the share of irrigated paddy land, respectively, where the former will be the main proxy for intensification reforms in 1963. Increased use of commercial fertilizers has been found as the most important factor in the reforms after 1962/63 in many studies (see e.g. Pak et al., 1966, p. 106). ${ }^{49}$ The land reform in 1950 enters the model through the variable landinequ $u_{t}$, which will be measured in two alternative ways: (1) decreased land inequality as measured by a Theil index for land, and (2) increased land ownership as measured by the tenancy rate. ${ }^{50}$ The variable irrig $_{t}$ controls for the share of irrigated paddy land, while $k_{w a r}$ controls for particular effects of the Korean War. ${ }^{51}$

It can be safely argued that the rural reform variables are exogenous. Land redistribution had mainly political reasons strongly related to weak governments unable to sustain the old social and political order after the departure of the Japanese (Jeon and Kim, 2000). At the same time, land redistributions in the North put further pressure on the US military government in the South since they fac-

49 Morrow and Sherper (1970) argue that the breakdown of the KAA and limited resources of the FFA led to a general slack in the supply of farm inputs after liberation which then only recovered following the reforms in the early 1960 s.

50 Since the tenancy rate time series is more complete, and the Theil land inequality measure requires substantial interpolation, the annual variation of the tenancy measure is likely to be more reliable.

51 For effects of war on heights see also Moradi (2005). 
ing Communist tendencies among Southern farmers. Agricultural technology reforms in the 1960s were then designed by the Park Chung-hee administration in order to lay the foundation for future industrial growth allowing industrial sectors to absorb agricultural surplus labor. Therefore, it is plausible to assume one-way causality in both cases.

In order to estimate equation (3.1) time series properties of all series have to be taken into account. Standard unit root tests (ADF, Phillips-Perron) indicate that all agricultural series in the model are integrated of order one. Thus, taking first differences and adding lagged values on the right hand side of the model allows the use of least squares estimation to consistently estimate an autoregressive distributed lag model (Greene, 2003) of the form:

$d(Q)_{t}=\sum_{i=1}^{k} \gamma_{i} d(Q)_{t-i}+\sum_{j=0}^{l} X_{t-l}^{\prime} \beta_{t-l}+\varepsilon_{t}$

where $X_{t}$ is a vector containing all explanatory variables from equation (3.1). Estimation of a very general model with $i=3$ and $j=3$ strongly decreases the number of degrees of freedom in the estimation. Thus, I apply Hendry's generalto-specific method and stepwise exclude right-hand side variables which show the lowest $t$-values. The results can be seen in Table 3.2. The dependent variable enters the final model with two lags. Farm population, farm land, fertilizer index, and the share of irrigated paddy only have a contemporaneous effect on agricultural output which is in line with the theory. Land inequality and tenancy rate however, do not have a direct effect on agricultural output, but one that is lagged three periods. Adaptation to ownership, initial uncertainty about land rights in the war period and thus resulting reduced investment and cultivation effort might be possible explanations. Columns (1) and (2) of Table 3.2 show the determinants of agricultural production per farm capita (farm output divided by farm population), while columns (3) and (4) show the models with agricultural production per capita (farm output divided by total population). Negative significant coefficients for the lagged dependent variables indicate a tendency towards mean reversion of the series. Farm land and share of irrigated paddy are positively linked with agricultural productivity, while the Korean War decreased farm output. The 1950 Land Reform seems to have increased agricultural productivity with a three years time lag: Both land inequality and tenancy rate show negative significant coefficients in all regressions. Moreover, results also suggest a positive effect of the 1962/63 reforms: The fertilizer index is positive and significant in all specifications. For all regressions, respective LM-tests indicate no presence of serial correlation in the residuals. 
Table 3.2: Determinants of Agricultural Output (1944-1974)

\begin{tabular}{|c|c|c|c|c|}
\hline & $\mathrm{d}($ Ypfarmc $)$ & $\mathrm{d}($ Ypfarmc $)$ & $\mathrm{d}(\mathrm{Ypc})$ & $\mathrm{d}(\mathrm{Ypc})$ \\
\hline & (1) & (2) & (3) & (4) \\
\hline \multirow[t]{2}{*}{ Dep. Var. $(-1)$} & $-.576 * * *$ & $-.470 * * *$ & $-.333 * *$ & $-.286^{*}$ \\
\hline & $(.135)$ & $(.148)$ & $(.158)$ & $(.158)$ \\
\hline \multirow[t]{2}{*}{ Dep. Var. (-2) } & $-.494 * * *$ & $-.287^{*}$ & $-.471 * * *$ & $-.347^{* *}$ \\
\hline & $(.122)$ & $(.151)$ & $(.138)$ & $(.149)$ \\
\hline \multirow[t]{2}{*}{ d(Farm population) } & $-3.623 * * *$ & $-3.321 * * *$ & -.663 & -.514 \\
\hline & $(.796)$ & $(.898)$ & $(.617)$ & $(.624)$ \\
\hline \multirow[t]{2}{*}{ d(Farm land) } & $34.02 * *$ & $53.29 * * *$ & 11.76 & $21.67 * *$ \\
\hline & $(13.87)$ & $(15.55)$ & $(10.16)$ & $(10.16)$ \\
\hline \multirow[t]{2}{*}{$\mathrm{d}($ Fertilizer index $)$} & $.018^{* * *}$ & $.015^{*}$ & $.010^{* *}$ & $.009^{*}$ \\
\hline & $(.006)$ & $(.007)$ & $(.004)$ & $(.005)$ \\
\hline \multirow[t]{2}{*}{ d(Share of irrigated paddy) } & $68.06 * * *$ & $50.53 * *$ & 4.058 & -1.173 \\
\hline & $(16.50)$ & $(18.61)$ & $(10.92)$ & $(11.16)$ \\
\hline \multirow{2}{*}{$\mathrm{d}($ Land inequality, Theil) $(-3)$} & $-31.54 * * *$ & & $-14.48 * *$ & \\
\hline & $(8.30)$ & & $(6.00)$ & \\
\hline \multirow[t]{2}{*}{ d(Tenancy rate) $(-3)$} & & $-14.37 * *$ & & $-8.013^{* *}$ \\
\hline & & $(5.96)$ & & $(3.76)$ \\
\hline \multirow[t]{2}{*}{ Korean war } & $-7.162 * * *$ & $-2.965^{*}$ & $-3.583 * *$ & -1.589 \\
\hline & $(1.85)$ & $(1.67)$ & $(1.38)$ & $(1.13)$ \\
\hline $\mathrm{N}$ & 31 & 31 & 31 & 31 \\
\hline Adj. R-squared & .624 & .512 & .424 & .397 \\
\hline F-statistic & 8.13 & 5.50 & 4.15 & 3.82 \\
\hline
\end{tabular}

Notes: Standards errors in parentheses. ${ }^{* * *}$ significant at $1 \%,{ }^{* *}$ significant at $5 \%, *$ significant at $10 \%$. LM tests indicate no serial correlation in residuals.

For various sources of national-level farm data see data section 3.3.

\subsection{Effect of Rural Reforms on Individual Well-being 3.4.1 Body Height and Individual Welfare}

The method of the biological standard of living (BSoL) uses individual height data as a proxy for individual welfare during historical periods for which no household income or consumption data is available. The strong relationship between early childhood household economic conditions and heights has been frequently documented (Komlos, 1993; Komlos and Baten, 1998; Steckel, 1995; 2009; Hoddinot et al., 2008; Deaton, 2008). Final height outcomes are correlated with nutritional intake during the first three years of a person's life, and here 
particularly during the first 12 months after birth..$^{52}$ Nutritional conditions in turn highly depend on relative food prices and a household's income situation. In the case of agricultural self-production, ownership of productive assets is crucial. Thus, welfare trends of a large enough sample of a particular population can be inferred from height data. In the context of the rural economy Kopczynski (2007) uses height data and finds stagnating mean heights for the birth cohorts 1882-1892 in the Kingdom of Poland resulting from an agrarian crisis whereas those born in the adjacent province of Galicia which carried out far-reaching agrarian reforms and closed the border for trade instead, continued to grow in mean height.

When working with height data it is important to deal appropriately with the issue of shrinking of old-age cohorts. While individuals usually reach their final height around the age of 20 to 30, shrinking usually starts from the age of 40 to 50 and then accelerates in later periods of life. Cline et al. (1989) as well as Chandler and Bock (1991) provide gender-specific formulas to adjust for shrinking. These formulas have been applied in the East Asian context by, among others, Pak et al. (2010) on Korean data, and Morgan (2008) on Chinese data. Both adjustment methods will be applied in the following. ${ }^{53}$ Using height data, the problem of "age-heaping" might bias estimates when especially less educated individuals misreport their exact age and thus tend to report rounded years. This would then lead to biased sample mean height trends in the data. However, this does not present a problem for the used Korean data. Due to initially high literacy already in the first half of the $20^{\text {th }}$ century as well as the cultural importance of the 12-year animal cycle of the Chinese zodiac, birth years are generally well known and thus age-heaping is not seen in the data set. ${ }^{54}$

Korea in the $20^{\text {th }}$ century has gone through one of the fastest anthropometric growth spurts ever seen in human history. While the second half of the century has been certainly more successful than the first half, even under Japanese colonial rule Korean average heights show a positive trend. Choi and Schwekendiek (2009), pooling various height series, estimate an increase of approximately $2 \mathrm{~cm}$ in average male adult heights during the colonial period from 1910 to 1945. While representing one of the darkest chapters in Korean history, the oc-

52 Of special importance is the availability of proteins. To a lesser degree, also vitamins A, $\mathrm{D}$ as well as minerals play a role for height (Silventoinen, 2003).

53 While Chandler and Bock's method only controls for old-age shrinking and thus should only be applied to those aged 40 and above, adjustment according to Cline et al. additionally corrects for not fully reached final height of the young age cohorts.

54 Besides that, Korea has a long history of detailed administrative record keeping. Regressing heights on age-heeping dummies shows no problems with age-heeping in the data. 
cupation period brought Korea important advances in education, health, and other basic infrastructure. The Japanese moreover modernized agricultural technologies in a first reform period during the 1920s and early 1930s. However, a gradual increase in forced rice collections from Korean farmers to sustain Japanese wars in the Pacific beginning with the Japanese invasion of Manchuria in 1931 and lasting until the end of World War II in 1945 led to a worsening of the nutritional situation in the later colonial years. ${ }^{55}$

Individual height data used in this paper comes from Korea's National Health and Nutrition Surveys (KNHS) which have been collected regularly by the Korean Institute of Health and Social Affairs since 1995. Four nationally representative cross-sections collected in 1998, 2001, 2005 and 2007/08 have been published. The data offers for the purpose of this paper basic demographic and anthropometric information for between 3,051 and 5,333 randomly selected households per cross-section. KNHS data reports measured heights at the first decimal. Excluding ages below 20 and extreme heights below $120 \mathrm{~cm}$ and above $200 \mathrm{~cm}$ the final data set comprises 16,580 females and 12,705 males, respectively. The number of observations per five-year birth cohort can be seen in Table 3.3.

Table 3.3: Observations per birth cohort (of variable height)

\begin{tabular}{lcc}
\hline & No. of females & No. of males \\
\cline { 2 - 3 } $1920-1924$ & 301 & 177 \\
$1925-1929$ & 594 & 320 \\
$1930-1934$ & 888 & 624 \\
$1935-1939$ & 1209 & 946 \\
$1940-1944$ & 1297 & 1014 \\
$1945-1949$ & 1269 & 1053 \\
$1950-1954$ & 1335 & 1116 \\
$1955-1959$ & 1820 & 1515 \\
$1960-1964$ & 1895 & 1564 \\
$1965-1969$ & 1964 & 1473 \\
$1970-1974$ & 1851 & 1407 \\
$1975-1979$ & 1290 & 891 \\
$1980-1984$ & 674 & 480 \\
$1985-1987$ & 193 & 125 \\
\hline Total & 16580 & 12705 \\
\hline \hline
\end{tabular}

Data: National Korean Health Surveys (KNHS) 1998, 2001, 2005, 2007/08;

55 For further evidence on development of average heights during the first half of the $20^{\text {th }}$ century see e.g. Kimura (1993). 
Figure 3.1 shows the trend in average height of Korean female and male adults from 1920 to 1987. Depending on the method of shrinking-adjustment, the trend lines show that average female heights increased over this 67-year time span by between 8.1 and $12 \mathrm{~cm}$. Average male heights grew a little slower, but still by a strong 7 to $9.6 \mathrm{~cm}$. This stronger female growth might reflect decreasing gender inequality in education and consumption which took place over the $20^{\text {th }}$ century. It is remarkable that for both men and women about two thirds of this growth took place after the land reform in 1950, and even about $40-50$ percent of the growth took place after 1962. Data quality might be compromised by survivor bias which has been found in past studies (Waaler, 1984; Steckel, 1995).

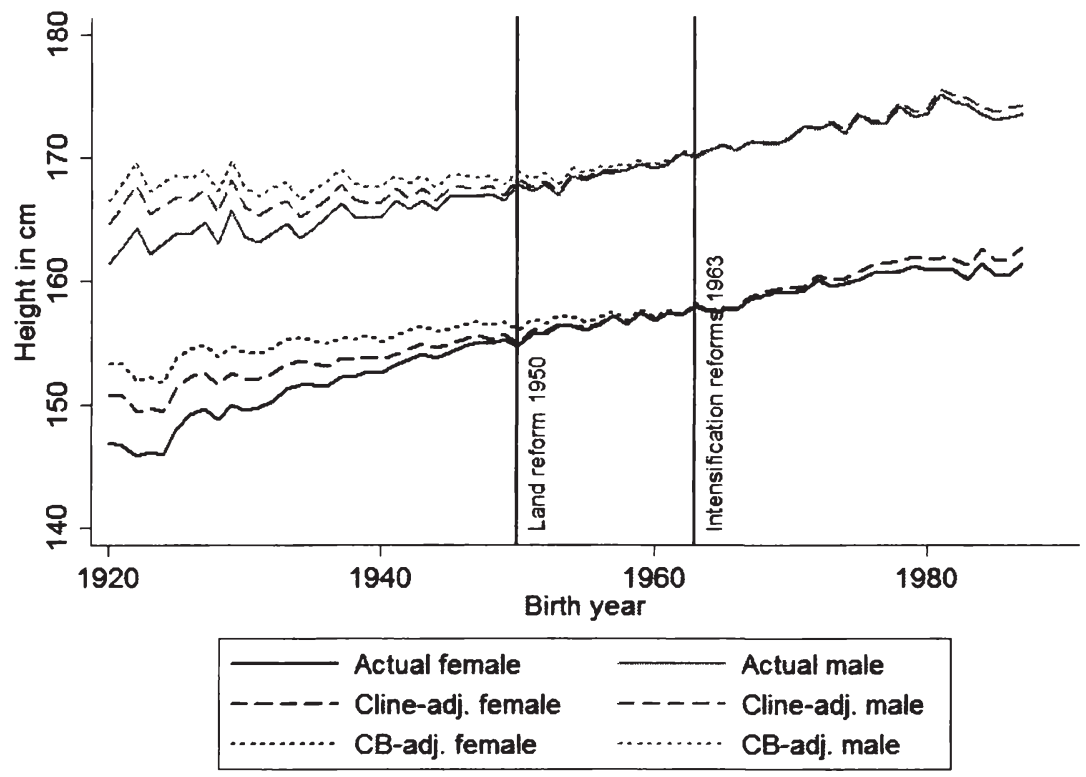

Fig. 3.1: $\quad$ Korean female and male heights, 1920-1987. Data: National Korean Health Surveys 1998, 2001, 2005, 2007/08. Age-adjustments based on Cline et al. (1989) and Chandler and Bock (1991).

According to these studies, there is a bias in older age cohorts in that taller people are on average more likely to survive a certain age than shorter people. Thus, estimating the mean of elder birth cohorts might lead to an upward bias in the estimated mean. This would then lead to an underestimation of growth over 
the whole period. However, as the bias would decrease in a gradual manner when moving to younger cohorts, this should not pose a problem for the following structural breaks analysis. The survivor bias is rather unlikely to produce abrupt breaks in the height series. ${ }^{56}$

\subsubsection{Testing for Structural Breaks in Time Series}

Human body growth theory suggests that a person's final height outcome depends on both genetic and environmental factors. While the parent's heights play the major role in determining final height outcomes in the developed world, in nutrition and health constrained developing countries, environmental factors are still of high relative importance. The foremost environmental factor is a child's postnatal nutritional situation and thus this will be the basis of this study's main line of argumentation. In Korea, food expenditures had a very high share in total farm household expenditures during the time of this study. While the Engel coefficient, the share of total household expenditures spent on food, was as high as 73.6 percent in 1954, by 1964 it had slightly reduced but still represented 59.3 percent (Pak et al., 1966). Second in rank is the postnatal disease environment of the newborn. ${ }^{57}$ Geographic and climatic conditions play further roles in explaining final height outcomes but are more important in the analysis of large countries or cross-country height comparisons (Silventoinen, 2003; Komlos, 1993; Komlos and Baten, 1998).

In order to identify potential effects of the two rural reforms in 1950 and 1963 on average individual welfare, I will examine the height time series for women and men for potential structural breaks around the years of the reforms. Following the theory of the Biological Standard of Living and assuming nutritional improvements through the rural reforms, one should expect increases in intercepts or trends of final height outcomes of those born after the reforms.

Running standard unit root tests (ADF, Phillips-Perron) for the height series without allowing for structural breaks results in no-rejection of a unit root. However, as Perron (1989) points out, the power to reject the null of a unit root decreases if the stationarity alternative is true, but structural breaks are ignored.

56 One might argue that the survivor bias might produce breaks in height series in the case of the Korean War, if soldiers were more likely to be recruited among poorer parts of the population. However, this should then lead to a bias around the age cohorts 1930 to 1935 , a period that is excluded from the following time series analysis.

57 Data on health indicators would also be interesting to study. However, there is a serious lack of data on health indicators between 1942 and 1955 for Korea. Since nutrition is a strong determinant of health, these two are likely to be highly correlated. 
Thus he suggests a modification of the ADF test allowing for a known structural break. The break can be in the intercept, in the trend, or in both. Zivot and Andrews (1992) argue that break points (BP) might not be exogenous in some cases and thus selecting exogenous break points when the data is already known could lead to an over-rejection of the null hypothesis of a unit root. In the case of the Korean rural reforms, structural breaks could be determined exogenously as has been argued earlier. However, in order to check for validity of these breaks, first successive Zivot-Andrews(ZA)-tests are run in order to account for two endogenous breaks in the series. The ZA-model specification with shift only in trend for time series $y_{t}$ can be written as follows:

$y_{t}=\mu^{A}+\alpha^{A} y_{t-1}+\beta^{A} t+\gamma^{A} D T_{t}+\sum_{l=1}^{m} \delta_{l}^{A} \Delta y_{t-j}+\varepsilon_{t}$

The ZA-model with both shift in intercept and slope is then:

$y_{t}=\mu^{B}+\alpha^{B} y_{t-1}+\beta^{B} t+\theta^{B} D C_{t}+\gamma^{B} D T_{t}+\sum_{l=1}^{m} \delta_{l}^{B} \Delta y_{t-j}+\varepsilon_{t}$

Here DT indicates an additional trend and DC a shift in the intercept such that

$D T_{t}=\left\{\begin{array}{c}t-B P \text { if } t>B P \\ 0 \text { otherwise }\end{array}\right.$

and

$D C_{t}=\left\{\begin{array}{l}1 \text { if } t>B P \\ 0 \text { otherwise }\end{array}\right.$

The model with only a change in intercept can be omitted since this does not seem to be relevant for the shape of this study's time series. The models in equation (3.3) and (3.4) on the series of heights for women and men are run separately for the two methods of shrinking-adjustments. Moreover, they are also run for agricultural productivity. Being interested in determining two break points, I estimate two successive ZA-tests on the series. The first test is estimated over the whole series. After obtaining the first break point $B P 1, \mathrm{I}$ then run the second test over the series $\left[t_{1}\right.$ to $\left.(B P 1-1)\right]$ if $\left|t_{1}-B P 1\right|>\left|B P 1-t_{T}\right|$ or over $\left[(B P 1+1)\right.$ to $\left.t_{T}\right]$ if $\left|t_{1}-B P 1\right|<\left|B P 1-t_{T}\right|$.

Table 3.4 shows the results of the endogenous detection of the break points. Column (1) and (2) show results from the estimation of equation (3.3) for a mere shift in trend. While the first break in trends is detected between 1948 and 1957, the second break is determined between 1961 and 1965. This does support the existence of break points around the rural reforms. Columns (3) and (4) result from estimating equation (3.4) for shifts both in intercept and in trend. 
Table 3.4: Endogenous detection of structural breaks (successive Zivot-Andrews tests) 
Table 3.5: Regression estimations with exogenous structural breaks in 1950 and 1963, data for 1941-1974

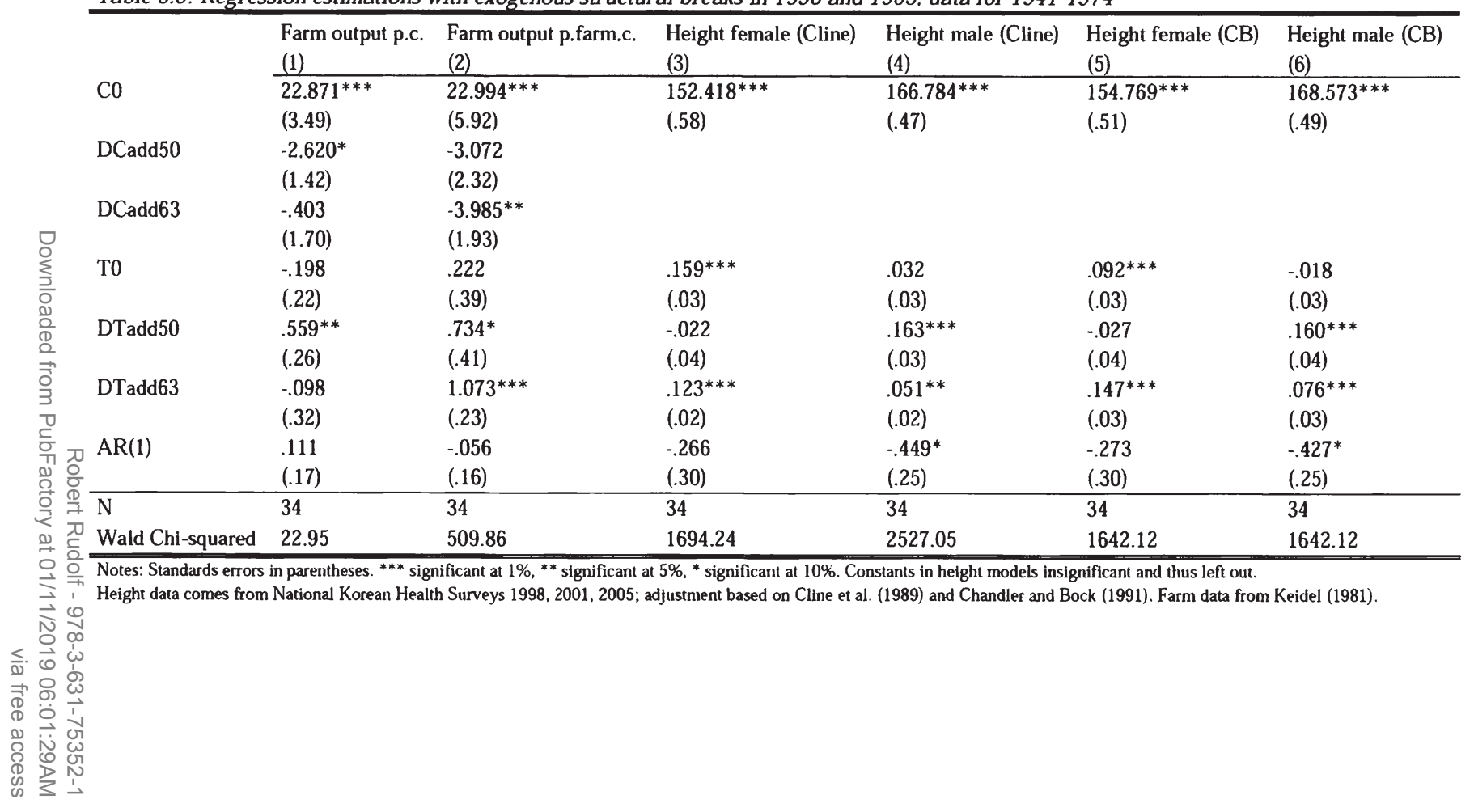


Here, the first significant change in male heights and farm productivity happened between 1951 and 1954, while the model fails to detect a significant break of female heights during that period. The second break is detected between 1964 and 1971. Thus, except for the last column, results from this exercise support the hypothesis of structural breaks around 1950 and 1963.

In a further step the structural break points are assumed to be known and to be located in 1950 and 1963. Thus a model of the following form is estimated:

$$
y_{t}=C 0+\beta_{1} D C_{a d d 50, t}+\beta_{2} D C_{a d d 63, t}+\beta_{3} T 0+\beta_{4} D T_{a d d 50, t}+\beta_{5} D T_{a d d 63, t}+\varepsilon_{t}
$$

where $\varepsilon_{t}=\varphi \varepsilon_{t-1}+\eta_{t}$ follows an $\mathrm{AR}(1)$ process with idiosyncratic error term $\eta_{t}$. In (3.7) $c 0$ and $T 0$ represent the general intercept and general linear trend, while $D C_{a d d 50}$ and $D C_{a d d 63}$ are shifts in intercept and $D T_{a d d 50}$ and $D T_{a d d 63}$ are shifts in trend which are defined as in equation (3.5). Equation (3.7) can be estimated for height and agricultural productivity series using least squares. Results are displayed in Table 3.5.

From column (1) in can be seen that farm output per capita experienced a structural change in 1950. Before 1950, agricultural productivity stagnated. Then in 1950 short-run dynamics probably related to the outbreak of the Korean War decreased agricultural productivity as can be seen in the significant downward move of the intercept. Yet, agricultural per-capita output entered a stable long-run growth after 1950. Looking at farm output per farm capita one can observe short-run decreases both in 1950 and 1963, yet only the latter shows up significant. The trend behavior indicates that productivity experienced an acceleration of growth rates both 1950 and 1963. This confirms findings in Table 3.2 that both rural reforms had positive long-run impacts on agricultural productivity.

Is there evidence for an improvement of the nutritional situation in the Korean population? Columns (3) to (6) try to answer this question. Here shifts in intercept were left out since they turned out to be insignificant in all models. Female heights grew at a steady absolute rate already between 1941 and 1949 (.16 cm Cline-adjusted (.09 cm CB-adjusted)). This growth rate then continued after 1950 and eventually experienced an upward shift to $.28(.24) \mathrm{cm}$ annual growth from 1963 onwards. Male heights did not grow in the pre-1950 period, yet reached an average annual growth of $.16 \mathrm{~cm}$ from 1950 to 1962 which then further increased to an annual $.21(.24) \mathrm{cm}$ between 1963 and 1974. Thus while male heights show a structural break in form of an upward shift in trend both in 1950 and 1963, women only show a break point in 1963. 
Farm output per capita

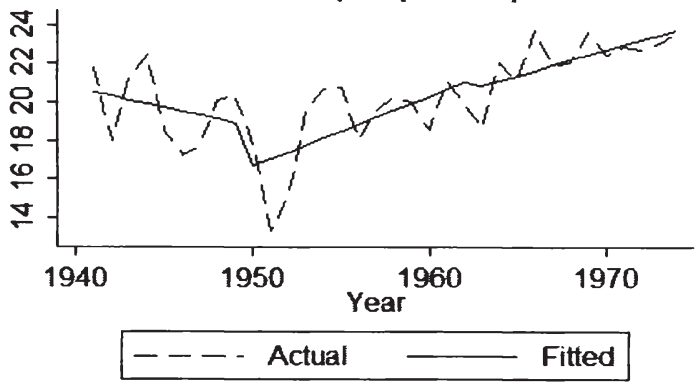

\section{Height female}

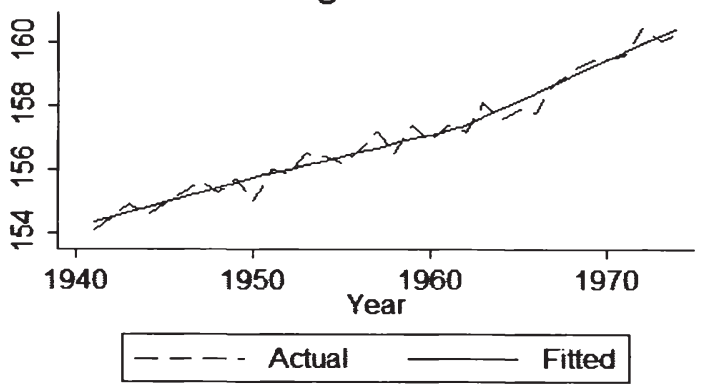

Farm output per farm capita

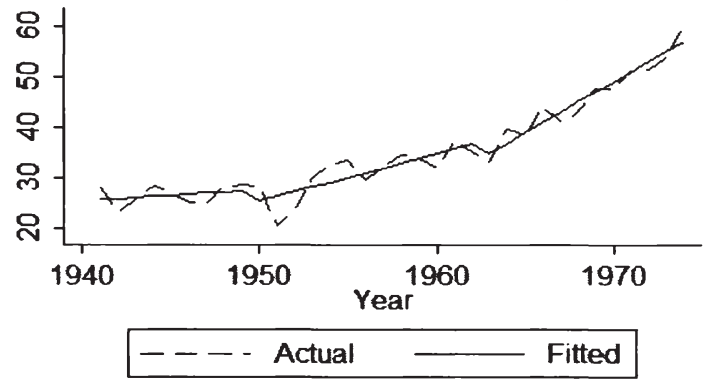

Height male

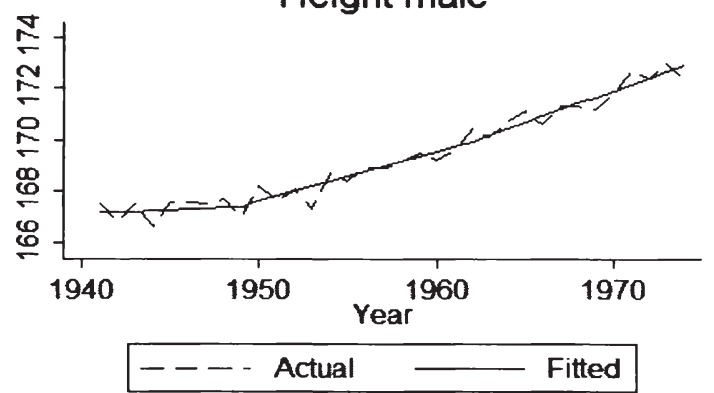

Fig 3.2: Estimation of trends in farm output and heights with structural breaks in 1950 and 1963, data for 1941-1974. Height data from National Korean Health Surveys 1998, 2001, 2005, 2007/08. Adjustments based on Cline et al. (1989). Farm data from Keidel (1981). 
Figure 3.2 graphically displays the results of columns (1) to (4) of Table $3.5 .^{58}$ Actual series as well as fitted trend lines containing structural breaks in 1950 and 1963 are shown. Note that in the figure I exclude the AR-dynamic of the residuals included in the econometric model to illustrate more clearly break points and deviations of the time series from the estimated trend.

Strong negative effects around the Korean War as well as a significant upward trend can be observed in all four series.

\subsection{Concluding Remarks}

The Korean Land Reform in 1950 is often taken as a textbook example for successful land reform (Ray, 1998). From an equity point of view massive land redistribution resulted in tremendous democratization of rural areas providing a more equal distribution of productive assets, income and political power within the Korean population. The resulting long-run effects for growth and development cannot be estimated high enough. It is remarkable, that even with a high fragmentation of land after the reform, increased ownership still led to significant efficiency and productivity gains as found in this paper. In a rural generation which struggled from war, a large influx of migration from urban areas, as well as bad governance until the early 1960s, increased ownership of land secured nutrition and stabilized individual welfare.

Without doubt, land reform effects could have been even stronger in 1950 if directly combined with rural technology and infrastructure reforms in the first place. However, Korean farmers had to wait more than a decade until in 1962/63 Green-Revolution type reforms were implemented by the Park Chung-hee administration leading to strong agricultural productivity growth in the following.

Individual welfare measured with the help of anthropometric data shows strong growth over the $20^{\text {th }}$ century in Korea. Between the birth cohorts of 1920 to 1987 average adult heights grew by 8.1 to $12 \mathrm{~cm}$ for women and 7 to $9.6 \mathrm{~cm}$ for men, respectively. Two thirds of this growth took place after the land reform in 1950, and about 40-50 percent after the 1962/63 reforms. Structural break analyses of height trends reveal significant upward shifts in trend around the years of the reforms. Effects of the 1950 reform might even be underestimated due to the costs of the Korean War which were widely paid for by the farm population in form of additional 'reconstruction taxes' during the 1950s.

58 Results in columns (5) and (6) are very similar to those in (3) and (4) and are thus not displayed graphically. 
Korean rural reforms thus not only increased equity, but also efficiency of the rural economy and the economy as a whole. The Korean case might hold important lessons for agricultural-based economies still marked with high rural asset inequality and low productivity in less developed economies in Africa, Latin America and Asia. The design of rural reforms in a holistic way that combines both land redistribution and productivity enhancing policies should be given particular importance. 
Robert Rudolf - 978-3-631-75352-1

Downloaded from PubFactory at 01/11/2019 06:01:29AM

via free access 


\title{
Essay 4
}

\section{Cash Crop Choice and Income Dynamics in Rural Areas: Evidence for Post-Crisis Indonesia}

\begin{abstract}
In this paper we investigate the factors affecting income levels and income growth in rural Indonesia following the crisis of 1997/98. In particular, we investigate the relative roles of non-farm incomes and productivity improvements achieved via changes in crops versus improvements on the same crops on income dynamics. Drawing on unique household panel data from Central Sulawesi and using advanced panel econometric methods, we find that local innovations related to the adoption and intensification of new cash crop varieties, more specifically the shift from coffee to cocoa production, can explain a substantial part of the observed post-crisis developments. Causal estimates of the effect of growing cocoa suggest that households were on average able to achieve about 14 percent higher income levels during the post-crisis period compared to the planting of other crops most notably coffee. Also, our results demonstrate the importance of engagement in non-farm activities for household income growth. Comparative analyses using a nationally representative survey suggest that similar processes are at play in other parts of Indonesia.
\end{abstract}

Based on joint work with Jan Priebe and Stephan Klasen.

\subsection{Introduction}

In the years 1997/98 Indonesia experienced a major economic, financial and political crisis. Within one year real GDP per capita fell by about 15 percent and real wages in the urban formal sector declined by 40 percent in 1998 (Frankenberg et al., 2003). Although urban areas were hit hardest during the crisis in economic terms, rural areas which represent approximately 60 percent of the population and 80 percent of the poor in Indonesia were severely affected too. Moreover, droughts and fires associated with El Niño in 1997/98 depressed agricultural output in many parts of the country and thereby exacerbated the situation of rural households. Since then the recovery of the Indonesian economy has been comparatively stable with annual GDP growth rates of about 5 percent between 1999 and 2010. Poverty rates at the national level declined substantially 
from 24.2 to 13.3 percent between 1998 and 2010 and in rural Indonesia from 25.7 to 16.6 percent (BPS, 2010).

However, despite poverty in Indonesia being largely a rural phenomenon, little is known about the underlying factors that determine rural incomes and that have contributed to the observed income growth in the post-crisis period.

Clearly, agricultural output and household incomes in Indonesia are likely to have increased as a result of forest conversion and land use changes related to the planting of rubber or palm oil across the country (Sunderlin et al., 2001; Dewi et al., 2005). However, no empirical study currently exists that investigates to what extent increases in agricultural productivity, in contrast to increases in the area under cultivation, have contributed to the observed growth in agricultural incomes. Improvement in agricultural productivity has been found to be crucial to raise rural incomes in many other parts of the world (Datt and Ravallian, 1998a; Fan et al., 2008; Dercon et al., 2009). However, nearly all of these studies have focused on the analysis of the impact of large public interventions such as cash transfer programs, provision of infrastructure, land titling policies or the provision of improved seeds on improvements in agricultural productivity and the resulting growth in incomes.

In contrast to these studies and given the absence of large public interventions in rural areas in the post-crisis period we focus our analysis on the impact of local innovation, more precisely the shift of cropping patterns among cash crops, as an explanatory factor for the observed income growth in rural Indonesia. For our analysis we make use of the large restructuring efforts across Indonesian rural households to switch from coffee to cocoa production. Coffee had been Indonesia's major export crop until the mid 1980s. However, due to falling world market prices for coffee during the 1990s it had been replaced by cocoa in many areas of the country. As a consequence, by the early 2000s Indonesia has become the second largest cocoa producer in the world after Cote d' Ivoire (FAOSTAT, 2011).

Furthermore, we investigate whether income growth has been influenced by more longer-term trends away from agriculture. Particularly, engagement in high-productivity, non-agricultural activities has been found to be conducive towards income growth, especially in the presence of poor physical infrastructure and human capital constraints (Datt and Ravallion, 1998b; Ravallion and Datt, 2002; Lanjouw and Lanjouw, 2001; Micevska and Rahut, 2008).

This article's principal objective is to therefore examine the sources of income growth in rural Indonesia. Notably, the following research questions are of paramount interest to us: (a) What have been the main sources of observed income growth in the post-crisis period in rural Indonesia? (b) What has been the relative importance of productivity improvements of the same crops versus 
shifts to more lucrative crops in explaining agricultural productivity improvements? (c) How has income diversification, in particular into the non-agricultural sector, helped households to increase incomes?

Several contributions set this article apart from others in the literature. First, we use a unique data set based on a household panel survey (STORMA) collected at three different points in time $(2001,2004,2006)$. To the best of our knowledge these are the most detailed surveys conducted to investigate the livelihoods of rural households in Indonesia. Second, this article is the first to investigate panel-based household income dynamics related to cropping patterns and the role of income diversification for Indonesia. In particular, the panel structure allows us to address endogeneity issues so that we are able to derive causal estimates for our key variables of interest. Third, in contrast to other studies that use small scale rural household surveys, we directly compare our findings to those obtained from analyzing the national socio-economic household survey (SUSENAS), which is used to calculate official poverty rates in Indonesia. Therefore, we are able to separate between effects that hold for all of rural Indonesia and those that might be particular to the study area.

Controlling for endogeneity issues and using a large set of control variables, our analysis reveals that household incomes increased substantially in the postcrisis period. We show that the growth in household incomes can be primarily attributed to increases in the value of agricultural production (both in terms of output and yields) which is caused largely by shifts in cropping patterns related to cash crop production, namely the switch from coffee to cocoa, and much less to an increase in the efficiency of agricultural production for a particular crop; poorer households have particularly benefited from these increases in agricultural self-employment incomes. In addition, in the context of the nationwide economic recovery, the growth in agricultural incomes was complemented by steady increases in non-agricultural incomes which have become the principal source of income for a rising number of households, with richer households benefitting particularly from these opportunities. These results seem to be robust to different econometric specifications. Furthermore, when comparing our results to SUSENAS we obtain very similar findings when extending our analysis to all of rural Indonesia except the heavily populated island of Java.

The remainder of this article is organized as follows. Section 4.2 briefly discusses the relevant literature on cropping patterns and the determinants of income dynamics in rural Indonesia. Section 4.3 presents details about the data sets and main variables used. Moreover, this section provides the descriptive analysis of the data. In section 4.4 the empirical identification strategy is outlined and causal effects from panel regressions are presented and discussed. Sec- 
tion 4.5 analyzes the results from a comparison of our data with national household data from SUSENAS while section 4.6 summarizes and concludes.

\subsection{Literature Review}

Most rural households in Indonesia are engaged in small-scale farming activities deriving a substantial share of their income from the cultivation of subsistence crops such as rice and cash crops. However, the cropping pattern has changed significantly over time due to government interventions, trade patterns and world market prices (Rosegrant et al. 1998).

In the 1960s and 1970s Indonesia's primary focus was to become selfsufficient on rice which was finally achieved in the mid 1980s. To accomplish this objective the government provided farmers with new rice varieties and substantial subsidies on agricultural input factors that aimed at increasing the production of rice. In addition, the producer price of rice was controlled to ensure attractive conditions to producers and stable prices for consumers (Timmer, 2007). Since the end of the 1970s Indonesia has complemented its rice policy by promoting the adoption and intensification of cash crops such as rubber, sugar, coffee, tea and particularly palm oil in order to increase earnings from non-oil exports (Barbier, 1989).

Since the mid 1980s Indonesia experienced strong growth in the production of its major cash crops. Likewise, the area under cultivation has significantly increased over this period mostly due to deforestation (Sunderlin et al., 2001). One of the most important cash crops over the last three decades has been coffee. In the mid 1980s coffee was the main export crop from Indonesia. Only in the late 1980s coffee was gradually replaced by palm oil and rubber as major export crop of the country. In the wake of the economic crisis in 1997/1998 which coincided with a substantial decline in world coffee prices farmers started to either plant cocoa on new plots or to gradually switch from coffee production into the production of cocoa (Sunderlin et al., 2001). While the ratio of cocoa to coffee exports, all in volume (tons), value (US\$), and area under cultivation was about $1 / 10$ in 1986 and $2 / 5$ in 1996, cocoa has replaced coffee as the third major export crop by the early 2000s (FAOSTAT, 2011). At the same time Indonesia has become the world's second largest producer of cocoa after Cote d'Ivoire.

Therefore, in contrast to experience from other main coffee exporting countries such as Uganda (Bussolo et al., 2007; Hill, 2010), rural households in Indonesia did not only respond to the coffee price shock of the late 1990s by replacing old coffee trees with new coffee trees, as observed in Uganda, but as well by starting to produce and intensifying the production of cocoa. One reason 
for the ready adoption of cocoa was the already prevailing knowledge on cocoa production and its distribution channels in some areas of the countries so that the widely documented risk of adopting new crop varieties (Ashraf et al., 2009; Dercon, 1996; Fafchamps, 1992) was mitigated by already existing experience in other parts of the country.

Interestingly, despite the importance of income from agriculture, either through wage or self-employment or through the production of subsistence and cash crops, for the majority of rural households, no study currently exists that evaluates the importance of agricultural income and its different sources on the observed income growth in rural areas over recent years. In contrast, several descriptive studies recently emerged that analyze the role of the non-agricultural sector on incomes of rural Indonesian households (Dewi et al., 2005; World Bank, 2006; Suryahadi et al., 2009; Gibson and Olivia, 2010). Consistent with findings from Latin American (Lanjouw and Lanjouw, 2001) and various Southeast Asian countries (Estudillo et al., 2006; Cherdchuchai and Otsuka, 2006; Nargis and Hossain, 2006) these studies confirm the growing importance of non-agricultural activities as a means for rural households to generate income. Moreover, most of these studies point to a common set of obstacles for the development of non-agricultural activities related to poor infrastructure such as bad roads or unstable electric power supply. However, all of these studies only present descriptive evidence on the importance of non-farm activities and therefore require caution in the interpretation of its results.

In this paper we will examine the respective roles of crop switching, productivity improvements on existing crops, and non-farm incomes on rural income growth in Indonesia. By using panel data and explicitly controlling for endogeneity, we are able to move beyond the existing more descriptive analyses.

\subsection{Data and Setting}

The data comes from three household surveys generated as part of the so-called STORMA project and conducted in the second half of 2001, 2004, and 2006 in the rural areas of the province of Central Sulawesi (CS). Compared to most other provinces in Indonesia CS shows a relatively low GDP per capita level which is partly attributable to its low level of urbanization and industrialization. During the economic crisis of 1998 the province was hit hard but was not as much affected as most other provinces (Ravallion and Lokshin, 2007). CS itself is largely agrarian, based on traditional farming methods and terraced slopes. Most production comes from ownership-cultivation on small farms with an average size of two hectare. The main staple crop in the area is rice while the main cash crop 
in the 1990s was coffee. At the end of the 1990s the majority of rural households, due to the decline of world coffee prices, began switching to the production of cocoa.

The study area comprises about 110 villages in four sub-districts (kecama$\tan )$. Out of these 110 villages 12 were chosen randomly for the inclusion into the household surveys. The sample size in each village was determined with respect to the share of the village population in the overall population. ${ }^{59}$ In 2001 , 294 households in 12 villages were interviewed. Due to financial and technical problems, only 258 households were interviewed in the 2004 round. In the 2006 round still 271 of the original 294 households could be re-interviewed. Since we are primarily interested in income dynamics, we restrict the analysis to those households that were interviewed in all three rounds which gives a total number of 257 households per round. ${ }^{60}$ The surveys themselves provide detailed information on agricultural and non-agricultural activities, demographic status, asset and land holdings, and further socio-economic household and individual characteristics.

An important geographical feature of the study area is its close proximity to the rain forest area of the Lore Lindu National Park. Although enforcement of the borders of the park is occasionally difficult in practice, little deforestation of rain forest areas was observed in the study area during that time period (Schwarze et al., 2009). This circumstance provides us with the empirical advantage that our causal estimates will not be confounded by income effects that result from economies of scale in the production process due to the increase in the land area used for agricultural production.

\subsubsection{Variables of Interest}

In the subsequent analyses we distinguish between four types of income sources following Barrett and Aboud (2001) who classify income sources according to sectors (agriculture and non-agriculture) and employment status (wage and selfemployment). Concerning the construction of a measure of agricultural selfemployed income, we add the implicit income from subsistence production imputed at local prices to the value of crops and animal products marketed in the last year. From the total value of agricultural production, we subtract the costs of seed, fertilizer, livestock, repairs of machinery, hired labor, and the like. Agri-

59 A detailed description of the sampling procedure is provided in Zeller et al. (2002).

60 The comparison of characteristics between households that could not be interviewed again and those that remained in the sample between the first and third round showed that no statistically significant differences exist. 
cultural and non-agricultural wage incomes include payments in kind, while non-agricultural self-employed income is net of business costs, such as expenditures on raw materials, energy, hired labor, and equipment maintenance. Based on the amount of income received from these four income categories, we classify households into five types. If a household's income from one of these four categories exceeds 50 percent of total household income, a household is classified as agricultural self-employed, agricultural wage, non-agricultural selfemployed or non-agricultural wage, respectively. In case a household does not receive an income of more than 50 percent from one of the four sources, the household is classified as mixed.

The level of education of a household can be measured and incorporated in different ways. Since cultural factors in Indonesia often lead to the situation that the oldest person in the household will be considered the head, we follow Basu et al. (2001) to take the highest educational level of an adult in working age, as the educational information most relevant for a household. This way we circumvent the problem that some of the household heads do not contribute to the income generating process of the household anymore.

In most studies, the area of land a household owns is included in the analysis. Instead we use the area of arable land a household uses for agricultural production since this is the relevant measure for land being an input into the household's production process. Also, the land variable excludes the area dedicated to the housing area of the household since this land cannot be used for agricultural production. In addition, we construct a variable referring to the area of agricultural land devoted to the production of cocoa and one variable referring to the area of land under coffee production. Both, the cocoa and the coffee variables are meant to capture the ability of households to diversify into more economically rewarding agricultural activities compared to subsistence agriculture. In the multivariate analysis all three variables are included whereby the inclusion of the area of agriculturally suitable land has in this context the additional role to control for mere size effects in the cocoa and coffee variables.

Clearly, the wealth of households determines their ability to invest, to obtain access to the formal credit market, and to participate in high-productive nonagricultural activities. We include the value of assets a household owns as a proxy for household wealth. The variable comprises productive, consumer and financial assets. Taking sample size limitations into account we decided to focus on this aggregate measure instead of incorporating asset variables for each of the three components.

In our empirical analysis we further control for locational characteristics. Ease of access to infrastructure and proximity to markets is proxied by travel time of households to the next paved road. Given the hilly terrain of the region 
and the sometimes poor condition of roads, mileage is not an appropriate measure. Instead we rely on time measured in minutes. In line with a recent study from Dercon et al. (2009) who find a positive causal effect of improvements in access to roads and agricultural extension services on consumption growth in rural Ethiopia we include a control variable that indicates whether a household was visited by an extension officer during the year preceding the survey. However, in contrast to Dercon et al. (2009) we do not observe any major expansion in road networks, changes in the quality of roads or an expansion in agricultural extension services. Since travel time to the next paved road and access to extension services remains rather constant over time we do not expect these variables to be responsible for the observed growth in incomes over time. Furthermore, we control for whether a household has access to electricity or not. Interregional disparities are captured by grouping villages into the four sub-districts (kecama$\tan$ ) they belong to and using kecamatan-fixed effects. ${ }^{61}$

\subsubsection{Descriptive Analysis}

In 2001, the first year of our panel data, recovery from the crisis of 1997/98 was already under way in rural Sulawesi. Furthermore, income growth continued substantially between 2001 and 2006 as depicted in Table 4.1 below.

Table 4.1: Summary Statistics (Means) on STORMA households

\begin{tabular}{llll}
\hline & STORMA '01 & STORMA '04 & STORMA '06 \\
\hline Household Size & 5.42 & 5.19 & 4.56 \\
& $(2.00)$ & $(1.96)$ & $(1.93)$ \\
\hline Age of HH Head & 43.8 & 46.5 & 48.1 \\
& $(14.0)$ & $(14.1)$ & $(13.6)$ \\
\hline Sex of HH Head & .95 & .93 & .91 \\
& $(.21)$ & $(.26)$ & $(.29)$ \\
\hline Dependency Ratio & .70 & .75 & .74 \\
& $(.58)$ & $(.60)$ & $(.70)$ \\
\hline Number of Men & 1.85 & 1.86 & 1.37 \\
& $(1.03)$ & $(1.10)$ & $(.87)$ \\
\hline Years of Schooling of HH Head & 6.77 & 6.79 & 6.78 \\
& $(3.36)$ & $(3.37)$ & $(3.35)$ \\
\hline Max. Years of Schooling of a HH Member & 8.68 & 8.67 & 8.43 \\
& $(2.87)$ & $(2.89)$ & $(2.87)$ \\
& & & \\
\hline
\end{tabular}

61 A detailed overview on the definition and coding of variables is provided in Table A1 in the appendix. 


\begin{tabular}{|c|c|c|c|}
\hline Total Per-Capita Income & $\begin{array}{l}95,076 \\
(106,003)\end{array}$ & $\begin{array}{l}93,187 \\
(131,061)\end{array}$ & $\begin{array}{l}119,586 \\
(123,391)\end{array}$ \\
\hline Agricultural Self-employed Income, p.c. & $\begin{array}{l}60,266 \\
(68,679)\end{array}$ & $\begin{array}{l}52,751 \\
(77,544)\end{array}$ & $\begin{array}{l}68,005 \\
(81,073)\end{array}$ \\
\hline Agricultural Wage Income, p.c. & $\begin{array}{l}8,319 \\
(17,016)\end{array}$ & $\begin{array}{l}4,820 \\
(11,164)\end{array}$ & $\begin{array}{l}8,200 \\
(18,353)\end{array}$ \\
\hline Non-Agricultural Self-employed Income, p.c. & $\begin{array}{l}10,906 \\
(64,371)\end{array}$ & $\begin{array}{l}11,062 \\
(40,068)\end{array}$ & $\begin{array}{l}19,678 \\
(68,299)\end{array}$ \\
\hline Non-Agricultural Wage Income, p.c. & $\begin{array}{l}15,583 \\
(46,465)\end{array}$ & $\begin{array}{l}23,652 \\
(102,055)\end{array}$ & $\begin{array}{l}22,659 \\
(63,891)\end{array}$ \\
\hline Gini Index (income, p.c.) & .49 & .54 & .48 \\
\hline Area Owned (are) & $\begin{array}{l}202.40 \\
(215.16)\end{array}$ & $\begin{array}{l}195.55 \\
(205.23) \\
\end{array}$ & $\begin{array}{l}208.26 \\
(204.13) \\
\end{array}$ \\
\hline Area Cocoa (are) & $\begin{array}{l}50.57 \\
(91.70) \\
\end{array}$ & $\begin{array}{l}77.12 \\
(103.25) \\
\end{array}$ & $\begin{array}{l}81.43 \\
(99.37) \\
\end{array}$ \\
\hline Area Coffee (are) & $\begin{array}{l}43.30 \\
(75.94)\end{array}$ & $\begin{array}{l}19.55 \\
(50.22) \\
\end{array}$ & $\begin{array}{l}13.88 \\
(37.40) \\
\end{array}$ \\
\hline Access to electricity & $\begin{array}{l}.66 \\
(.48) \\
\end{array}$ & $\begin{array}{l}.66 \\
(.48) \\
\end{array}$ & $\begin{array}{l}.71 \\
(.45) \\
\end{array}$ \\
\hline Distance to paved road (hours) & $\begin{array}{l}.95 \\
(2.76) \\
\end{array}$ & $\begin{array}{l}.85 \\
(2.65) \\
\end{array}$ & $\begin{array}{l}.73 \\
(2.46) \\
\end{array}$ \\
\hline Access to agricultural extension service & $\begin{array}{l}.34 \\
(.48) \\
\end{array}$ & $\begin{array}{l}.39 \\
(.49) \\
\end{array}$ & $\begin{array}{l}.25 \\
(.25) \\
\end{array}$ \\
\hline Expenditures on fertilizer/pesticides & $\begin{array}{l}12,333 \\
(24,072) \\
\end{array}$ & $\begin{array}{l}12,590 \\
(36,434) \\
\end{array}$ & $\begin{array}{l}9,975 \\
(19,474)\end{array}$ \\
\hline Share of rice fields without irrigation & $\begin{array}{l}.57 \\
(.63) \\
\end{array}$ & $\begin{array}{l}.57 \\
(.63) \\
\end{array}$ & $\begin{array}{l}.57 \\
(.63) \\
\end{array}$ \\
\hline $\begin{array}{l}\text { Share of rice fields with simple or } \\
\text { Semi-technical irrigation }\end{array}$ & $\begin{array}{l}.32 \\
(.46) \\
\end{array}$ & $\begin{array}{l}.32 \\
(.46) \\
\end{array}$ & $\begin{array}{l}.32 \\
(.46) \\
\end{array}$ \\
\hline Share of rice fields with technical irrigation & $\begin{array}{l}.11 \\
(.32) \\
\end{array}$ & $\begin{array}{l}.11 \\
(.32) \\
\end{array}$ & $\begin{array}{l}.11 \\
(.32) \\
\end{array}$ \\
\hline Value of assets & $\begin{array}{l}2,540,766 \\
(6,793,056)\end{array}$ & $\begin{array}{l}2,711,764 \\
(10,000,000) \\
\end{array}$ & $\begin{array}{l}4,014,757 \\
(8,533,662)\end{array}$ \\
\hline Value of livestock & $\begin{array}{l}1,375,301 \\
(2,571,215)\end{array}$ & $\begin{array}{l}1,331,491 \\
(5,738,906)\end{array}$ & $\begin{array}{l}1,259,397 \\
(2,491,986) \\
\end{array}$ \\
\hline $\mathrm{N}$ & 257 & 257 & 257 \\
\hline
\end{tabular}

All monetary values are real in Indonesian Rupiahs with base year 2001 and use regional CPIs provided by BPS. Incomes are monthly. Standard deviations in parentheses. Local land units are measured in are. One are is equal to $100 \mathrm{~m}^{2}$.

While in 2001 monthly per capita household income was at 95,076 Rupiah, it increased about 25 percent to 119,586 Rupiah in real terms in 2006. Nonetheless, income growth was not continuous during this period. From 2001 to 2004 
households experienced even a decline in per capita income attributable to the restructuring of cropping patterns. In the context of the economic crisis and strong declines in world coffee prices in the late 1990s, households in the STORMA region gradually switched their main cash crop production from coffee to cocoa. In 2004 households were still in the middle of this transformation process. In particular, cocoa trees had not reached full maturity for production in most cases. Consequently, income from agricultural self-employment rose only moderately during this period while income from agricultural wage labor from 2001 to 2004 fell. After 2004 agricultural production increased significantly and in 2006 both agricultural self-employment and agricultural wage incomes show peak values for the whole study period.

The shift to cocoa was highly rewarding for rural households. As Table 4.2 shows, households harvest more physical output per area $\left(\mathrm{kg} / \mathrm{are}^{62}\right)$ with cocoa compared to coffee, while at the same time mean farm gate prices per $\mathrm{kg}$ of cocoa are clearly above those for coffee. These two things together lead to cocoa yields (in value terms) that are about 90 percent above those from coffee. ${ }^{63}$

Table 4.2: Cocoa and coffee production

\begin{tabular}{lllllll}
\hline & $\begin{array}{l}\text { STORMA } \\
\text { 01 }\end{array}$ & $\begin{array}{l}\text { \# of } \\
\text { obs. }\end{array}$ & $\begin{array}{l}\text { STORMA } \\
\text { '04 }\end{array}$ & $\begin{array}{l}\text { \# of } \\
\text { obs. }\end{array}$ & $\begin{array}{l}\text { STORMA } \\
\text { '06 }\end{array}$ & $\begin{array}{l}\text { \# of } \\
\text { obs. }\end{array}$ \\
\hline Cocoa & & & & & & \\
Output (kg/are) & 2.28 & 115 & 2.40 & 132 & 3.60 & 174 \\
Price (per kg) & 5,000 & 115 & 6,254 & 132 & 5,307 & 174 \\
Yield (IDR/are) & 9,777 & 115 & 14,454 & 132 & 18,978 & 174 \\
Area cocoa (are) & 50.57 & 257 & 77.12 & 257 & 81.43 & 257 \\
Coffee & & & & & & \\
Output (kg/are) & 1.68 & 97 & 1.56 & 60 & 2.40 & 45 \\
Price (per kg) & 4,500 & 97 & 2,779 & 60 & 4,189 & 45 \\
Yield (IDR/are) & 6,500 & 97 & 3,474 & 60 & 9,553 & 45 \\
Area coffee (are) & 47.07 & 257 & 21.00 & 257 & 14.68 & 257 \\
\hline
\end{tabular}

Monetary values are real Indonesian Rupiahs with base year 2001 and use the provincial CPI for Palu provided by BPS. Output, price and yields are median values per year based on all farmers active in the particular crop. Local land units are measured in are. One are is equal to $100 \mathrm{~m}^{2}$.

Moreover, Table 4.2 demonstrates that increases in real incomes from cocoa between 2001 and 2006 are primarily due to increases in the scale of production

62 An are comprises 100 square meters, i.e. 100 ares make up one hectare.

63 The true difference in terms of outputs is likely to be even larger since only productive coffee plants were still left on the plots, while cocoa plants were sometimes not yet ready for full production. 
(area under cultivation and output per are). In 2001, 115 out of the 257 households were engaged in cocoa cultivation while in 2006 already 174 households derived agricultural self-employed income from cocoa. Accordingly the average area of agricultural land devoted to cocoa cultivation increased by about 60 percent. In addition, it is important to note that the growth in the area of cocoa mirrors the reduction in the area devoted to coffee production. Hence, we do not observe much change in the average area devoted to the production of cash crops or in the total area of arable land. Accordingly, we observe no difference in the area devoted to rice which is the main perennial crop in the study area. Furthermore, output of cocoa per are increased due to the circumstance that more cocoa trees reached its production stage. While price effects partly explain the increase in income from cocoa in the period 2001-2004, the price difference of cocoa between 2001 and 2006 is rather small and therefore does not explain much of the observed increase in cocoa income.

One can decompose the increase in incomes of farmers working on perennial crops into gains due to shifts from coffee to cocoa and increases in yields. Such decomposition suggests that about half of the increase in incomes is due to the shift of farmers from coffee to cocoa, while the other half is due to increases in yields in both coffee and cocoa. But the latter is likely to greatly overestimate the impact of improved agricultural productivity in the two crops. In the case of cocoa, much of the increase in yields is, as discussed above, due to the fact that households planted these cocoa trees in the early 2000 s and they only started to yield the returns by the third round in 2006. Similarly, it is likely that the much reduced acreage in coffee was limited to the most productive plots so that the increase in yields is actually not primarily due to increases in agricultural productivity. Moreover, this development seems not to be caused by improvements in the agricultural production technology. As shown in Table 4.1 the values of all three of our proxies (share of rice fields with technical irrigation systems, expenditures on fertilizer/pesticides and access to agricultural extension services) remain largely unchanged over the entire period. Thus this descriptive evidence suggests that the primary driver of income growth for farmers with perennial crops was due to the shift to cocoa.

A closer look at the composition of incomes from agricultural self-employment reveals that rural households derive incomes mainly from crops with a minor part coming from other sources like livestock and gathering. ${ }^{64}$ Moreover, households derive incomes from perennial and annual crops rather equally.

64 The decline in incomes from gathering follows from the improvement in economic conditions. Gathering forest products like rattan is time-intensive and dangerous. It is only done by households in times of greatest needs. 
While the income from annual crops, like rice and maize, reflects household preferences for food security, it becomes clear from Table 4.3 that particularly the growth in incomes from perennial crops helps in explaining the growth of agricultural self-employment income with cocoa constituting about 85 percent of perennial crop income in 2004 and 2006 (2001: 58 percent).

Table 4.3: Agricultural Diversification - Mean Incomes of Self-employment

\begin{tabular}{llll}
\hline Sector & STORMA '01 & STORMA '04 & STORMA '06 \\
\hline Livestock & 6,190 & 3,350 & 5,026 \\
Gathering & 10,527 & 4,249 & 2,931 \\
Cropping & 44,752 & 46,549 & 60,048 \\
-Annual crops & 21,859 & 18,588 & 26,146 \\
-Perennial Crops & 22,892 & 27,961 & 33,901 \\
$\quad$-Cocoa & 13,278 & 24,280 & 28,307 \\
-Coffee & 5,405 & 1,752 & 2,861 \\
\hline $\mathrm{N}$ & 257 & 257 & 257 \\
\hline
\end{tabular}

All values are monthly in per-capita terms and real Indonesian Rupiahs with base year 2001 . Provincial CPIs for Palu were provided by BPS.

In contrast to agricultural incomes, non-agricultural incomes do not seem to have been affected much by the shift from coffee to cocoa and grew steadily in accordance with the growing national economy of the post-crisis period. As shown in Table 4.1 non-agricultural self-employed income nearly doubled between 2001 and 2006 and non-agricultural wage income increased by about 50 percent in the same period. In this context, non-agricultural income has become the principal income source for several households in the region. The income source transition matrix in Table 4.4 shows that the number of households who receive more than half of their income from non-agricultural activities rose from 41 to 54 between 2001 and 2006. Meanwhile, the number of households that generate most of their income from agriculture decreased from 209 to $189 .{ }^{65}$

65 Non-agricultural self-employment in the STORMA region consists mainly of small trading shops, restaurants (warung) and small-scale handicrafts. Wage employment in the non-agricultural sector is available in terms of work in the construction and public sector. 
Table 4.4: Income Sector Transition Matrix

\begin{tabular}{|c|c|c|c|c|c|c|c|c|c|c|c|c|}
\hline \multirow[b]{2}{*}{$\begin{array}{l}\text { STORMA } \\
2001\end{array}$} & \multirow[b]{2}{*}{$\begin{array}{l}\text { Starting } \\
\text { Income }\end{array}$} & \multirow[b]{2}{*}{$\begin{array}{l}\text { \# of } \\
\text { obs. }\end{array}$} & \multicolumn{4}{|c|}{\begin{tabular}{|l|l}
\multicolumn{2}{|l}{ STORMA 2006} \\
$\begin{array}{l}\text { Agric. Self- } \\
\text { employed }\end{array}$ & $\begin{array}{l}\text { Agricultural } \\
\text { Wage }\end{array}$ \\
\end{tabular}} & \multicolumn{2}{|c|}{$\begin{array}{l}\text { Non-farm } \\
\text { Self- } \\
\text { employed }\end{array}$} & \multicolumn{2}{|c|}{$\begin{array}{l}\text { Non-farm } \\
\text { Wage }\end{array}$} & \multicolumn{2}{|l|}{ Mixed } \\
\hline & & & Income & $\begin{array}{l}\text { \# of } \\
\text { obs. }\end{array}$ & Income & $\begin{array}{l}\text { \# of } \\
\text { obs. }\end{array}$ & Income & $\begin{array}{l}\text { \# of } \\
\text { obs. }\end{array}$ & Income & $\begin{array}{l}\# \text { of } \\
\text { obs. }\end{array}$ & Income & $\begin{array}{l}\text { \# of } \\
\text { obs. }\end{array}$ \\
\hline $\begin{array}{l}\text { Agricultural } \\
\text { Self- } \\
\text { employed }\end{array}$ & 87,580 & 180 & 105,969 & 135 & 65,992 & 14 & 198,022 & 12 & 180,752 & 12 & 87,955 & 7 \\
\hline $\begin{array}{l}\text { Agricultural } \\
\text { Wage }\end{array}$ & 52,744 & 29 & 76,603 & 17 & 52,292 & 4 & 423,417 & 1 & 81,924 & 4 & 72,583 & 3 \\
\hline $\begin{array}{l}\text { Non-farm } \\
\text { Self- } \\
\text { employed }\end{array}$ & 178,477 & 16 & 153,616 & 6 & & 0 & 243,471 & 5 & 142,350 & 5 & & 0 \\
\hline $\begin{array}{l}\text { Non-farm } \\
\text { Wage }\end{array}$ & 129,681 & 26 & 72,397 & 8 & 35,164 & 1 & 224,819 & 2 & 239,930 & 13 & 87,608 & 2 \\
\hline Mixed & 163,616 & 6 & 120,554 & 4 & & 0 & 195,338 & 1 & & 0 & 72,661 & 1 \\
\hline & & 257 & 103,448 & 170 & 61,486 & 19 & 220,927 & 21 & 186,104 & 34 & 83,178 & 13 \\
\hline
\end{tabular}

Incomes are monthly, real Indonesian Rupiahs with base year 2001 and provincial CPI for Palu.

Engagement in non-agricultural activities proved to be strongly beneficial. Table 4.4 shows that already in 2001 households with mainly non-agricultural self-employed incomes were best off, followed by non-agricultural wage, agricultural self-employed and agricultural wage households. Moreover, the income gap between non-agricultural and agricultural households further broadened in the post-crisis period, when non-agricultural self-employed households' mean incomes rose by 23.8 percent, non-agricultural wage households' incomes by 43.5 percent, agricultural self-employed households' incomes by 18.1 percent and agricultural wage households' incomes by 16.6 percent.

Although engagement in non-agricultural activities seems to be highly rewarding in order to raise incomes of rural households, gaining access to highproductivity non-agricultural income sources strongly depends on a household's income and wealth situation. Dividing the 2001 household per capita incomes into quintiles, Table 4.5 shows that in particular households situated in the upper two quintiles receive incomes from non-agricultural sources. 
Table 4.5: Income Quintile Statistics

\begin{tabular}{llllll}
\hline & Quintile 1 & Quintile 2 & Quintile 3 & Quintile 4 & Quintile 5 \\
\hline 2001 & & & & & \\
Av. Total Per-capita income 01 & 13,364 & 40,006 & 67,362 & 108,628 & 249,039 \\
Share Agricultural Wage (AW) 01 & .19 & .19 & .16 & .11 & .046 \\
Share Agricultural Self (AS) 01 & .70 & .61 & .72 & .68 & .63 \\
Share Non-farm Wage (NW) 01 & .043 & .11 & .08 & .17 & .19 \\
Share Non-farm Self (NS) 01 & .06 & .08 & .03 & .03 & .13 \\
\# Households in AW 01 & 23 & 25 & 26 & 22 & 13 \\
\# Households in AS 01 & 48 & 49 & 50 & 50 & 48 \\
\# Households in NW 01 & 5 & 7 & 8 & 15 & 19 \\
\# Households in NS 01 & 4 & 7 & 6 & 5 & 15 \\
& & & & & \\
2006 & 23,769 & 51,381 & 75,717 & 130,600 & 320,400 \\
Av. Total Per-capita income 06 & .14 & .16 & .15 & .11 & .017 \\
Share Agricultural Wage 06 & .77 & .69 & .65 & .63 & .51 \\
Share Agricultural Self 06 & .08 & .08 & .11 & .14 & .26 \\
Share Non-farm Wage 06 & .04 & .04 & .08 & .11 & .21 \\
Share Non-farm Self 06 & 21 & 24 & 27 & 17 & 5 \\
\# Households in AW 06 & 50 & 49 & 45 & 51 & 49 \\
\# Households in AS 06 & 9 & 8 & 15 & 14 & 21 \\
\# Households in NW 06 & 3 & 6 & 9 & 12 & 20 \\
\# Households in NS 06 & 52 & 52 & 51 & 51 & 51 \\
\hline N & S6 & & & & \\
\hline
\end{tabular}

Note: Quintile classification is based on 2001 household per-capita income distribution.

Quintile 1 refers to the poorest quintile.

While the number of households engaged in some sort of non-agricultural activity increased across quintiles from 2001 to 2006, the share of income derived from these sources is much higher for richer households and only increased for households in the richest three quintiles. In contrast, given the increase of average household incomes across all five quintiles, the share of agricultural self-employed income increased remarkably for poorer households, despite a higher number of poor households being engaged in non-agricultural activities. Thus, the principal source of income growth observed between 2001 and 2006 differs between initially poorer and richer households. Income growth among poor households can be primarily attributed to increases in agricultural self-employed income due to increases in crop output, shifting cultivation patterns and favorable price developments, while richer households in addition seem to have benefited from strong increases in non-agricultural incomes. 


\subsection{Model and Results}

The primary focus of this paper is to investigate the impact of agricultural production, in particular the decision to grow cocoa or coffee, and engagement in non-agricultural activities, more precisely non-farm self-employment, on income levels and the growth of incomes in the post-crisis period. To achieve this we adopt a regression framework in which we control for other factors that might determine incomes in the region.

In order to understand the determinants of incomes across households $i$ $(i=1, \ldots, N)$ and time $t(t=1, \ldots, T)$ we adopt an econometric framework that links household per-capita income $\left(y_{i t}\right)$ to a source of income levels that is common to all households $(\delta)$. Furthermore, incomes might be determined by a household specific set of variables $\left(X_{i t}\right)$ such as demographic characteristics, access to infrastructure, wealth level of households, cropping patterns or the economic sector of employment. The main focus of our analysis is on the effect of non-farm self-employment (NSE) and the planting of cocoa (Cocoa) and coffee (Coffee). Although our data set collects very detailed information of a variety of household characteristics there might be additional factors that influence incomes which are specific to each household but that are largely unobserved to the researcher such as ability or motivation $\left(\theta_{i}\right)$. The econometric specification of this model is represented in equation (4.1) in which we assume an error term that is household specific and time-varying.

$\ln \left(y_{i t}\right)=\delta+X_{i t}^{\prime} \beta+\gamma_{1} N S E_{i t}+\gamma_{2} \operatorname{Cocoa}_{i t}+\gamma_{3} \operatorname{Coffee}_{i t}+\theta_{i}+u_{i t}$

Since it is very likely that the unobserved characteristics $\theta_{i}$ are correlated with at least some of our control characteristics $X_{i}$ and more importantly with our main variables of interest, $N S E_{i t}, \operatorname{Cocoa}_{i t}$ and $\operatorname{Coffe}_{i t}$, the coefficients $\gamma_{1}, \gamma_{2}$ and $\gamma_{3}$ might be biased. In order to address this endogeneity problem we make use of our panel structure and implement a Fixed-Effects specification that helps to eliminate the effect of $\theta_{i}$ on the other coefficients so that $\gamma_{1}, \gamma_{2}$ and $\gamma_{3}$ can be estimated consistently (Baltagi, 2008).

Secondly, we want to assess the impact of NSE, Cocoa and Coffee on percapita income growth for the post-crisis period. A natural way of doing so is an empirical growth model that allows for transitional dynamics (Mankiw, 1992). In this model growth rates for household $i\left[\ln \left(y_{i t}\right)-\ln \left(y_{i t-1}\right)\right]$ are related to initial levels of income $\ln \left(y_{i t-1}\right)$. Similar to the static model above we assume that there is source of growth common to all households which we again denote by $\delta$. Other sources of growth from $t-1$ to $t$ are exogenous levels of our socioeconomic control variables $\mathrm{X}$ and our main variables NSE, Cocoa and Coffee, 
each observed at $t-1$. As in model (1) we allow the household specific unobserved effect $\theta_{i}$ to be correlated with the other regressors.

Mindful of the numerous reasons why one should be careful in applying this framework given the theoretical and empirical assumptions implied by this model (Temple, 1999) our basic model is

$\ln \left(y_{i t}\right)-\ln \left(y_{i t-1}\right)=\alpha \ln \left(y_{i t-1}\right)+\delta+X_{i t}^{\prime} \beta+\gamma_{1} N S E_{i t}+\gamma_{2} \operatorname{Cocoa}_{i t}+$ $\gamma_{3}$ Coffee $_{i t}+\theta_{i}+u_{i t}$

In contrast to our model in equation (4.1) using a Fixed Effects approach will provide an inconsistent estimate of $\gamma_{1}, \gamma_{2}$ and $\gamma_{3}$ from equation (4.2) due to the inclusion of $\ln \left(y_{i t-1}\right)$ as regressor. To address the discussed econometric problems we use a Generalized Methods of Moments (GMM) estimator with a twostep Windmeijer (2005) correction so that our estimates of $\gamma_{1}, \gamma_{2}$ and $\gamma_{3}$ are both consistent and efficient (Blundell and Bond, 1998).

Before estimating equations (4.1) and (4.2) there are further empirical issues that require consideration. While we addressed endogeneity issues arising from X, NSE, Cocoa or Coffee being potentially correlated with the householdspecific unobserved effect $\theta_{i}$, there might be further endogeneity problems. In particular our main variables of interest, NSE, Cocoa and Coffee, might be correlated with the household specific and time-varying error component $u_{i t}$ which might lead to biased causal estimates of $\gamma_{1}, \gamma_{2}$ and $\gamma_{3}$. Such a correlation might stem from issues of reversed causality between the dependent variable and the NSE, Cocoa or Coffee variable. For instance, in our context it is likely that those households that achieve a high level of or growth in per-capita incomes are more likely to have the financial resources to be able to diversify into lucrative nonfarm self-employment opportunities. Likewise richer households might be better able to cope with periods of lower agricultural incomes and higher income risks when transiting from the production of coffee to cocoa.

To address the issue of simultaneous causality we adopt an Instrumental Variable (IV) approach to estimate equations (4.1) and (4.2). To instrument NSE, Cocoa and Coffee we use lagged values of these variables as instruments. Estimation of equation (4.1) is done by 2 SLS. In the GMM framework we include in addition the lagged differences of these values as recommended in Blundell and Bond (1998). Since the values of the endogenous variables are only providing moderate variation over time, we include additional instruments that we believe are exogenous to the income generating process.

In the case of non-farm self-employment we make use of an important geographical feature of our study area that can be used to construct a suitable instrument for the panel regressions. All study villages are situated in one of the two valleys (Palolo and Kulawi valley) which extend up to $200 \mathrm{~km}$ south of the 
provincial capital Palu. Both valleys are connected with paved roads to Palu and for each of the villages Palu is by far the nearest city in the area. Palu itself comprises roughly 250,000 inhabitants and contains the main port in CS which is used to import commodities (durables) and to export cocoa and coffee primarily to the USA. The distance to Palu matters for rural households mainly in that Palu offers a variety of non-agricultural employment opportunities. Therefore, households residing closer to the provincial capital are more likely to find or start non-agricultural activities. Thus, distance to Palu proxies the strength of spill-over effects from urban to rural areas. As found in Suryahadi et al. (2009) such spill-over effects are most likely to occur in the rural service sector which in our case is part of the non-agricultural sector. Once we control for asset possession, education, demographic and location characteristics, as well as sector choice in our income regressions, we do not expect that distance to Palu (measured in travel time) exercises any direct influence on household incomes. Furthermore, it is noteworthy that in our case distance to Palu varies on the household level since households usually first need to reach the nearest paved road (which varies from household to household even within a village) in order to get to the main road to Palu.

With respect to our Cocoa and Coffee variables we use the lagged village level prices of cocoa and coffee as additional instruments. Obviously, the decision to grow cocoa depends on the price of cocoa as well as on the price differential between cocoa and coffee. The prices of these two crops can reasonably be assumed to be exogenous to the households in our study region since production of these crops in Central Sulawesi is too small to have an effect on the world market price of these products. Although we have household level data on farm gate prices for cocoa and coffee we instrument by the village level price in order to reduce the presence of measurement error in the price data.

\subsubsection{Basic Results}

Table 4.6 presents the results of our panel regressions (4.1), the determinants of per capita income levels, and (4.2), the determinants of per-capita income changes. The first and third column provide results for the case that NSE, Cocoa and Coffee are assumed to be exogenous determinants of the dependent variable while the second and fourth columns show the IV estimates when NSE, Cocoa and Coffee are instrumented as outlined above. All regressions include a common set of control variables $\mathrm{X}$ that are related to demographic characteristics (age and age $^{2}$ of the household head, gender of the head, household size, number of men in the household and dependency ratio), engagement in a particular eco- 
nomic sector, household wealth variables (wealth in durable consumption and production assets, area of arable land) and infrastructure variables (access to electricity, distance to the next paved road, visit with an extension officer over the last year).

Table 4.6: Determinants of income and income growth

\begin{tabular}{lllll}
\hline & Income & Income & $\begin{array}{l}\text { Income } \\
\text { Growth }\end{array}$ & $\begin{array}{l}\text { Income } \\
\text { Growth }\end{array}$ \\
\cline { 2 - 5 } Controls & FE & FE-IV & GMM & GMM+ \\
\hline Age & (I) & (II) & (III) & (IV) \\
Age & 0.046 & 0.016 & 0.019 & 0.012 \\
Female Head & -0.001 & -0.000 & -0.000 & -0.000 \\
Education & $-0.683^{*}$ & -0.063 & -0.153 & -0.169 \\
HH size & 0.001 & 0.024 & 0.014 & 0.020 \\
Number of Men & $-0.152^{* * *}$ & $-0.167^{* * *}$ & $-0.169 * * *$ & $-0.166^{* * *}$ \\
Dependency ratio & -0.067 & 0.063 & -0.000 & 0.000 \\
Non-farm self. employment & -0.148 & -0.087 & -0.083 & -0.089 \\
Non-farm wage employment & $0.870^{* * *}$ & $0.841^{* * *}$ & $0.687^{* *}$ & $0.599^{* *}$ \\
Agricultural self. employment & $0.887^{* * *}$ & $0.810^{* * *}$ & $0.629 * * *$ & $0.625^{* * *}$ \\
Other & 0.205 & 0.193 & 0.120 & 0.172 \\
Area owned & 0.325 & 0.439 & 0.558 & 0.724 \\
Area cocoa & 0.000 & 0.000 & 0.001 & 0.000 \\
Area coffee & $0.002^{* * *}$ & $0.002^{* * *}$ & $0.001 *$ & $0.002^{* *}$ \\
Ln (value of assets) & 0.001 & 0.000 & 0.001 & 0.000 \\
Access to electricity & -0.007 & $0.068^{* * *}$ & $0.073 * * *$ & $0.064^{* *}$ \\
Distance to road & $0.35^{* *}$ & $0.31^{* *}$ & $0.24 * *$ & $0.17 * *$ \\
Visits from extension officer & -0.000 & $0.001^{* * *}$ & -0.000 & -0.000 \\
Lagged dependent variable & -0.081 & 0.085 & 0.111 & 0.093 \\
\hline N & - & - & $-0.860^{* * *}$ & $-0.771^{* * *}$ \\
F-statistic & 771 & 514 & 257 & 257 \\
Hansen test (p-value) & & 14.52 & 14.20 & 11.83 \\
\hline All & & 0.14 & 0.22 & 0.13 \\
\hline
\end{tabular}

All monetary values were included in real terms with base year 2001. Further controls include sub-district and time dummies. A common intercept is included. Significance levels: $* * * / * * *$ denote $0.01,0.05$ and 0.1 . Robust t-statistics used.

Moreover, time and sub-district dummies were included. ${ }^{66}$

66 In the discussion of our results we focus on the role of NSE, cocoa and coffee on the levels and growth of household per-capita income. The direction, magnitude and significance levels of the control variables, $\mathrm{X}$, are in line with what would be expected from economic theory or what is known from other empirical studies. In particular, the effects of the demographic variables, and the lagged dependent variable are similar to 
The results show that a household's engagement in non-farm self-employment leads to increases in income levels of approximately 139 percent ${ }^{67}$ (column 1) compared to the reference category of agricultural wage employment. Likewise, non-farm self-employment seems to lead to higher income growth of about 69 percent (column 3) compared to the reference category. Both coefficients are statistically significant at a one-percent level. When controlling for the potential endogeneity of NSE using an IV approach we find that the results do not change much. After instrumenting the effect of NSE on per-capita income levels declines slightly to 132 percent while in the growth model we see that the effect of NSE on income growth is about 60 percent. Thus, in both cases we observe that engagement in non-farm self-employment seems to generate strong payoffs in terms of per-capita income levels and income growth during the post-crisis period. Furthermore, the benefits seem to be similar for non-farm wage employment which also generates a high income premium. However, both forms of non-farm employment generate a sizable pay-off compared to agricultural selfemployment.

With respect to the effect of cropping patterns on household incomes we find that growing cocoa boosts incomes by about 0.2 percent per are (column 1 ). Given that households had on average about 70 are under cocoa cultivation across 2001 and 2006 this effect implies that on average households were able to achieve approximately 14 percent higher incomes due to the cultivation of cocoa, holding everything else constant. Moreover, ceteris paribus, an average household having planted all its two hectares with cocoa in 2006 would have had an about 40 percent higher income level. Similarly, households growing cocoa were experiencing higher income growth throughout the period $2001-2006$ of a similar magnitude (column 3). The results in columns 2 and 4 are nearly identical to those in columns 1 and 3 . Therefore, even in the IV set up we still find a substantial economic and statistically significant effect of cocoa on household incomes. In contrast to the growing of cocoa we find a positive but statistically insignificant effect of planting coffee.

those found in other studies (e.g. Woolard and Klasen, 2005; Fields et al., 2003). The insignificant education coefficient is also not unusual. In fact,the sign of the education coefficient on rural incomes have even been found to be negative in some cases, e.g. Adams (1995) on the value of wheat, sugarcane, and rice production in Pakistan or Rosegrant and Evenson (1992) on total factor productivity in India. In our case, the correlation of the education variable with non-agricultural activities and the value of assets, is likely to cause the coefficient to be statistically insignificant.

67 Because the value of $\gamma_{1}$ is relatively large the correct interpretation of the coefficient of a dummy variable in the log-normal model is obtained after using the exponential transformation of $(\exp (0.87)-1)^{*} 100=139$ percent. 


\subsubsection{Robustness Checks}

Table 4.7 shows the results of a series of robustness checks designed to assess whether changes in model specification, estimation, or sample affect the core results. Since the coefficient on our coffee variable is very close to zero and not statistically distinguishable from zero in all of these specifications we decided to not report the coefficient of coffee here in this table (but it is available on request). Row (0) repeats the results from our preferred specification (Table 4.6, columns 2 and 4). Row (1) explores how sensitive results are to the influence of outliers. In particular, the GMM estimates might be vulnerable to the influence of outliers because the optimal weighting matrix that underpins them is a function of fourth moments (Baum et al., 2003). We address this concern by trimming our sample such that we drop the top and bottom 1 percent of observations of income growth in the period 2001 - 2006. Doing so does not have a large effect on our estimates.

Table 4.7: Selected robustness checks on basic results

\begin{tabular}{|c|c|c|c|c|c|}
\hline & \multirow[b]{2}{*}{ Specification } & \multicolumn{2}{|c|}{ Income } & \multicolumn{2}{|c|}{ Income Growth } \\
\hline & & $\begin{array}{l}\text { Non-farm } \\
\text { self. emp. } \\
\text { (I) }\end{array}$ & $\begin{array}{l}\text { Area of } \\
\text { cocoa } \\
\text { (II) }\end{array}$ & $\begin{array}{l}\text { Non-farm } \\
\text { self. emp. } \\
\text { (III) }\end{array}$ & $\begin{array}{l}\text { Area of } \\
\text { cocoa } \\
\text { (IV) }\end{array}$ \\
\hline (0) & Basic results & $0.841^{* * *}$ & $0.002 * * *$ & $0.599 * *$ & $0.002 * * *$ \\
\hline (1) & $1 \%$ trim of dependent variables & $0.840 * * *$ & $0.002 * * *$ & $0.738 * * *$ & $0.002 * *$ \\
\hline (2) & Additional controls & $0.830 * * *$ & $0.002 * * *$ & $0.673 * * *$ & $0.002 * *$ \\
\hline (3) & Village fixed effects & $0.802 * * *$ & $0.002 * * *$ & $0.574 * * *$ & $0.002 * *$ \\
\hline (4) & Instrumenting value of assets & $0.897 * * *$ & $0.002 * * *$ & $0.533 * * *$ & $0.002 * *$ \\
\hline (5) & Excluding value of assets & $0.993 * * *$ & $0.002 * * *$ & $0.607 * * *$ & $0.002 * * *$ \\
\hline (6) & Instrumenting infrastructure & $0.907 * * *$ & $0.003 * * *$ & $0.476 * * *$ & $0.002 * *$ \\
\hline (7) & Excluding infrastructure & $0.786 * * *$ & $0.003 * * *$ & $0.576 * * *$ & $0.002 * * *$ \\
\hline (8) & Random effects IV estimator & $0.832 * * *$ & $0.003 * * *$ & - & - \\
\hline (9) & First difference estimator & $0.723 * * *$ & $0.003 * * *$ & - & - \\
\hline
\end{tabular}

The Basic results specification (0) repeats the results from columns (II) and (IV) from Table 4.5. Specifications (1) to (9) are reported. against specification (0). This means that each row reports results applying exactly only one change compared to the basic specification. Significance levels: $* * * / * * / *$ denote $0.01,0.05$ and 0.1 .

In row (2) we test whether our results are robust to the inclusion of additional covariates. More specifically, we include the share of irrigated rice fields, the usage of pesticides, taking part in formal or informal credit groups and reception of remittances. Again the obtained results are very similar to those from the main specification. Similarly, results do not change much when we use village fixed effects instead of sub-district fixed effects (row (3)). 
Next, we consider the impact of treating the value of durable consumptive and productive assets a household possess as endogenous to the income generating process (row (4)). Similar to the instrumentation of NSE and cocoa we use lagged values of the variable. In addition, we use an external instrument which measures the value of assets brought into marriage of the household head by husband and spouse. When we do so, results from the first stage F statistic indicate that we have strong instruments. Likewise, the p-value from the Hansen $J$ test indicates that instruments used in the model fulfill the necessary exclusion restrictions. Again, the results do not change in a substantial way. Row (5) reports results when we run a sort of reduced form regression by excluding the value of assets from the regressions. As before, the main results seem to be robust to a change in the specification.

Row (6) reports results when taking into account that the three infrastructure variables, access to electricity, distance to next paved road and access to agricultural extension officers might be endogenous. We instrument by using lagged values of these variables. In contrast, in row (7) we adopt again a reduced form regression framework by excluding all three variables compared to the basic specification. In both cases the results seem not be sensitive to the potential endogeneity of these control variables.

To estimate equation (4.1) we adopted a household fixed effects framework that allows the covariates to be correlated with the unobserved effect $\theta_{i}$. However, if $\theta_{i}$ are uncorrelated with NSE or cocoa then a Random Effects (RE) specification might provide more efficient estimates since it draws both on withinand between-household variation. Results for estimating equation (4.1) with a RE estimator while still instrumenting NSE and cocoa (Row (8)) gives roughly the same results as with the FE approach and therefore do not change the main conclusions of the paper. Moreover, the specific Hausman test suggests that the random effects assumption is not valid. A further alternative to estimate equation (4.1) when allowing $\theta_{i}$ to be correlated with NSE or cocoa is to eliminate $\theta_{i}$ by taking first differences (FD) instead of demeaning each variable by its household specific period average as implied by the FE approach. In a static model such as in equation (4.1) FE is typically preferred over FD since FE can have less bias as $N$ goes to infinity. Moreover, the FE estimator is more efficient under the assumption that the error term $u_{i t}$ is serially uncorrelated. However, if the $u_{i t}$ follows a random walk the FD estimator is more efficient (Wooldridge, 2006). As before the results (row (9)) do not change much compared to the main specification when estimation is done by using an FD estimator. ${ }^{68}$ 


\subsection{Extension}

In a last step we explore to what extent the findings obtained from our study region can be generalized to a larger geographical setting covering substantial parts of rural Indonesia. To do this we compare our results to those obtained from large national household surveys called SUSENAS. SUSENAS is conducted by the Indonesian National Statistical Office (BPS) and covers more than 100,000 households annually. Moreover, SUSENAS is Indonesia's principal source for official poverty, consumption, income, and education statistics. For our analysis we make use of the 2002 and 2005 rounds of SUSENAS which are the latest two rounds for which a detailed income and consumption module is available.

Unfortunately, SUSENAS does not capture information on several of the covariates that we used in the previous analysis, e.g. infrastructure variables, value of household assets, and detailed income data from agricultural sources. In particular, SUSENAS does not contain data on type of crops planted, quantity harvested and respective output prices, but simply asks households about their income from agriculture in the respective year. Likewise, the SUSENAS 2002 and 2005 rounds are cross-sectional data so that we cannot apply any of the previous panel techniques. Given this restriction our analysis rests on comparing descriptive but not causal estimates between our study region and other areas of Indonesia. More specifically, we rely on simple cross-sectional OLS regressions using the same set of explanatory variables on our and the SUSENAS data.

In a first step we assess whether households from the study region are similar to households in other regions in Indonesia. In order to compare households we need to guarantee that variables are measured in the same or similar way. The main difference between variables that are available in STORMA and SUSENAS is found to be in the total household income data. Total household income in SUSENAS contains imputations for rent and housing. Since the exact imputation procedure has not been published by BPS and moreover such an imputation can easily lead to merely adding additional noise to the income variable we subtract this imputed income from the total household income variable in SUSENAS.

(Deaton and Zaidi, 2002). Again our results on NSE and cocoa didn't change much compared to the presented specifications. Given that we include a variety of demographic controls in our main specification the results should in general not be affected very strongly by using per-capita income instead of some sort of adult equivalence scale. 
In addition, we decided to drop households in the three highest income deciles from the SUSENAS data set. This procedure is motivated by two aspects. Villages in the STORMA area are comparatively small and are situated in rather remote areas. These villages therefore are far from becoming classified as urban areas within the next decades. In contrast, households in SUSENAS classified as rural are sometimes on the edge of becoming classified as urban as soon as the next census will provide BPS with a new sampling frame. Since urban areas in Indonesia are much richer than rural areas, we expect more populous villages to be richer than villages with a small number of inhabitants. Therefore, we would expect that most of the richer households in the rural SUSENAS sample are located in larger villages. In addition, when comparing demographic and socioeconomic characteristics of the households in STORMA and SUSENAS we find that the samples for the two different data sources compare very well, when restricting the SUSENAS sample to households within the 1-7 deciles (See Table A2 for the descriptive statistics) ${ }^{69}$

Moreover, we find that STORMA households compare favorably with rural households in Indonesia except to those residing on Java. Rural Javanese households tend to have lower household sizes, lower educational attainments, but a much higher share of total income coming from non-agricultural sources than the rest of rural Indonesia which might be due to the much higher degree of urbanization and the higher population density on the island. Moreover, agricultural self-employment is much less important on Java compared to the rest of Indonesia. In contrast, agricultural wage labor on Java seems to play a much more important role than in the rest of rural Indonesia, which might be due to larger farm sizes and the existence of large agricultural estates. In consequence, we drop households from rural Java from the subsequent analysis. However, the later results are robust to including Java in the analysis.

Bearing in mind the limitations of the final SUSENAS data set we estimate OLS regressions with household per capita income in logs as dependent variable. The regression coefficients can be interpreted similar to those in a simple Mincerian earnings regression. Table 4.8 shows the respective results for the 2001 round of our data set and the 2002 round for different regional aggregates using SUSENAS. Results for our 2004 and 2006 rounds as well as results from the SUSENAS 2005 round are provided in Table A3 in the appendix.

69 Our decision was derived from comparisons based on per-capita income, engagement in the four economic sectors and household size. However, the main results are robust to using the full sample from SUSENAS or choosing different cut-off points $(60,80$ or 90 percent). Furthermore, Table A2 presents statistics for the 2001 STORMA and the 2002 SUSENAS round. Descriptive results for the other survey rounds lead to the same conclusions. These additional statistics can be obtained from the authors upon request. 
Table 4.8: Regional OLS Regressions - Comparison

\begin{tabular}{|c|c|c|c|c|c|}
\hline & \multicolumn{5}{|c|}{ LN(INCOME PER CAPITA) } \\
\hline & STORMA & SUSENAS & SUSENAS & SUSENAS & SUSENAS \\
\hline & 2001 & 2002 & 2002 & 2002 & 2002 \\
\hline & & Rural & Rural & Rural & Rural \\
\hline & & $\begin{array}{l}\text { Central } \\
\text { Sulawesi }\end{array}$ & Sulawesi & $\begin{array}{l}\text { Indonesia } \\
\text { minus Java }\end{array}$ & Indonesia \\
\hline Sex & .124 & .034 & $.058 * *$ & $.074 * * *$ & $.076 * * *$ \\
\hline Age & .017 & -.003 & -.001 & $.004 * * *$ & $.004 * * *$ \\
\hline $\mathrm{Age}^{2}$ & .000 & .004 & .002 & $-.003 *$ & $-.004 * * *$ \\
\hline Max Education & .033 & $.018^{* * *}$ & $.013^{* * *}$ & $.010 * * *$ & $.011 * * *$ \\
\hline HH Size & $-.102 * *$ & $-.073 * * *$ & $-.068 * * *$ & $-.072 * * *$ & $-.070 * * *$ \\
\hline Dependency Ratio & $-.230 *$ & -.009 & $-.040 * * *$ & $-.053 * * *$ & $-.050 * * *$ \\
\hline Number of Men & -.059 & .036 & $.024 *$ & $.015 * * *$ & $.013 * * *$ \\
\hline \multicolumn{6}{|l|}{ Non-farm } \\
\hline self-employed & $.697 *$ & $.180 * * *$ & $.132 * * *$ & $.134 * * *$ & $.144 * * *$ \\
\hline Non-farm wage & $.875 * * *$ & $.142 * *$ & $.062 * *$ & $.097 * * *$ & $.111^{* * *}$ \\
\hline \multicolumn{6}{|l|}{ Agricultural } \\
\hline self-employed & $.465^{*}$ & -.015 & $-.055^{* *}$ & $-.054 * * *$ & $-.020 * * *$ \\
\hline Mixed & $1.237 * * *$ & $.198 * * *$ & $.119^{* *}$ & $.099 * * *$ & $.114 * * *$ \\
\hline Constant & $10.541 * * *$ & $11.847 * * *$ & $11.947 * * *$ & $11.771 * * *$ & $12.013 * * *$ \\
\hline $\mathrm{N}$ & 257 & 523 & 2,342 & 10,729 & 17,535 \\
\hline Adj. R-squared & .11 & .30 & .35 & .42 & .38 \\
\hline
\end{tabular}

Comparing OLS estimates of SUSENAS with STORMA shows that the coefficients on most covariates are very similar. Key determinants of the income generating process are in both data sets a subset of the household characteristics, in particular household size and composition and the education levels ${ }^{70}$, all of which are statistically significant and take signs as expected from economic theory. Most importantly, we observe that in other areas of Indonesia households that are predominantly engaged in the non-farm sector seem to do much better than households who derive most of their incomes from the agricultural sector. This observation is in line with our previous findings. Therefore, it seems

70 Since common findings suggests that better educated households are wealthier and that wealthier households obtain higher education levels, we think that the large magnitude in the education coefficient rather reflects the incorporation of direct and indirect effects of education on per-capita income levels. Including the value of assets as control variable in the STORMA regressions strongly reduced the magnitude of the education coefficient. Therefore, provided the same or at least similar underlying income generating process between STORMA and SUSENAS, results from SUSENAS for higher regional aggregates therefore seem to overstate the direct effect of education on income. 
as if roughly the same functional relationship seems to exist in most of rural Indonesia except Java. ${ }^{71}$

However, there are some noteworthy differences between our results and those from SUSENAS. The coefficients on agricultural self-employment turn negative and statistically significant for the different regional SUSENAS aggregates. In particular, when considering regional aggregates that go beyond Central Sulawesi the coefficients increases in magnitude while still being negative. What can be seen at the same time is that the magnitudes of non-farm employment coefficients also decline. This interesting difference might be due to the fact that agricultural wage labor is better paid for in other parts of rural Indonesia. Particularly on rubber and palm oil plantations it is likely that higher agricultural wages can be earned compared to small-scale plantations that prevail in CS.

\subsection{Conclusion}

Drawing on a new household panel data set for Central Sulawesi collected in the years 2001, 2004 and 2006 we find that both, the growth in and the level of rural incomes in the post-crisis period, can be explained by a common set of factors.

Firstly, in the wake of the general recovery of the Indonesian economy, nonagricultural household incomes increased constantly over the considered period of time. While we observe that more and more households derive part of their incomes from this sector, significant entrance barriers for poorer households to become engaged in profitable non-agricultural activities remain.

Secondly, we find that incomes from agriculture still constitute the financial backbone of rural households across the entire income distribution. Moreover, in contrast to the majority of the existing literature on rural Indonesia, we observe even strongly growing incomes from agricultural production which contributed to the observed increases in total household incomes. Consequently, the principal source of income growth between 2001 and 2006 differs between initially poor and rich households. Income growth among poor households can be primarily attributed to increases in agricultural self-employed income while richer households in addition benefited from strong increases in non-agricultural incomes.

71 In the regional SUSENAS specifications we observe that the significance level of a variety of covariates improves, when going to higher regional aggregates. This points to the circumstance that sample size issues are responsible for the observed differences in significance levels between the distinct SUSENAS specifications and STORMA. 
Investigating the reasons behind the unexpected high growth rate in agricultural incomes, we show that incomes from agriculture increased due to a shift in cropping patterns, particularly cash crops, in our case from coffee to cocoa. Higher output volumes and more favorable commodity prices for cocoa than coffee help to explain most of the increase in agricultural incomes. The change from coffee to cocoa instructively shows how switching cropping patterns can be a crucial strategy in order to achieve income growth particularly for the poorer section of the rural population. Moreover, it shows that the observed increases in the value of agricultural production at the regional level in Indonesia can partly be explained by local innovations and experimentation in the choice of crops, and not only by forest clearing, increases in world commodity prices or increases in production efficiency. The results presented above are robust to various econometric specifications.

In a further step we examine whether results from STORMA hold lessons for a larger regional context. Extending our previous investigations to the national level by analyzing data from SUSENAS, we find the following: (a) The basic income relationships obtained from STORMA can be found all over rural Indonesia, the exception being rural Java which depicts a much larger share of non-agricultural income sources than the other areas in Indonesia. (b) One important difference between STORMA and SUSENAS concerns the role of the agricultural self-employed sector. While this sector has been an important element towards income growth in the STORMA area, its effect on incomes seems to be smaller in other parts of rural Indonesia.

While we are confident about our main findings, we should also need point to limitations of our assessment. The comparatively small sample size in the STORMA data set affects the standard errors of the estimated regression coefficients which makes the evaluation of significance levels sometimes difficult. Moreover, since the panel data set was collected between 2001 and 2006, only a later part of the transformation process from coffee to cocoa production could be observed. Therefore, the effect of switching from coffee to cocoa is likely to represent only a partial effect. For instance, higher incomes from cocoa than coffee could have lifted the capital constraint of households already before 2001 which then enabled them to engage in non-agricultural activities.

Additionally, the generalization of our findings to other rural areas in Indonesia is constrained by data availability issues in SUSENAS. Since SUSENAS does not allow to: a.) decompose agricultural self-employed income into its subcomponents (perennial crops, annual crops, livestock income, etc.) and b.) know the specific type of crops a household grows, the scope and potential for improving cropping patterns in other areas of rural Indonesia is difficult to assess. However, other examples from Indonesia's recent history, e.g. the large shift to 
rubber and palm oil production, seem to underscore the relevance and scope for improving rural incomes by local innovations related to the change in cash crop patterns. 
Robert Rudolf - 978-3-631-75352-1

Downloaded from PubFactory at 01/11/2019 06:01:29AM

via free access 


\section{Appendix}

Appendix Essay 1 


\section{Ranking by development indicator}

HDI rank 2010 (out of 169 countries)

GNI per capita (PPP 2008 \$)

\section{Ranking by gender equality indicator}

GII rank 2008 (of 169)

GEM rank 2009 (of 109)

GGG rank 2010 (of 134)

Average rank of three gender indicators

\section{Gender sub-indicators - ratio female to male}

Population with at least secondary education ( 25 or older)

Tertiary enrollment rate

Labor force participation rate

Wage equality for similar work

Estimated earned income

Legislators, senior officials, and managers

Professional and technical workers

Seats in parliament

Time spent in housework

\section{Hours worked (2010 data)}

Average annual hours worked per worker

Average weekly hours (main job, age 25-54)

Early childhood education and care

Enrolment rates 4 years and under (\% of those aged 3 and 4 years, 2007)

Pre-primary education expenditure (annual PPP USD per student, 2006)

Share of public expenditure on pre-primary education (age $\geq 3$ years, 2006)

\begin{tabular}{|c|c|c|c|c|c|c|}
\hline Norway & Australia & Korea & Spain & UK & Singapore & Mexico \\
\hline
\end{tabular}

$\begin{array}{ccccccc}1 & 2 & 12 & 20 & 26 & 27 & 56 \\ 58,810 & 38,692 & 29,518 & 29,661 & 35,087 & 48,893 & 13,971\end{array}$

$\begin{array}{lllllll}5 & 18 & 20 & 14 & 32 & 10 & 68\end{array}$

1

223

$2.67 \quad 16$

61

$11 \quad 15$

16

$104 \quad 11$

61.7

12

20.7

$\begin{array}{lllllll}1.00 & .98 & .87 & .94 & 1.01 & .88 & .91\end{array}$

$1.62 \quad 1.30$

.69

1.24

1.40

$\begin{array}{ll}.94 & .85\end{array}$

$.75 \quad .67$

$1.00 \quad .72$

$.46 \quad .58$

$1.06 \quad 1.16$

$.66 \quad .38$

$1.48 \quad 1.81$

.73

.77

.84

.67

$-$

.74

.80

.86

.46

.82

.31

$\begin{array}{lllllll}1,414 & 1,686 & 2,193 & 1,663 & 1,647 & - & 1,866\end{array}$

$\begin{array}{lllllll}35.8 & 38.0 & 47.0 & 38.9 & 38.1 & - & 44.2\end{array}$

$\begin{array}{lllllll}91.8 & 32.2 & 27.3 & 125.9 & 89.9 & - & 60.4\end{array}$

$\begin{array}{lllllll}5,625 & 4,252 & 3,393 & 5,372 & 7,335 & - & 1,978\end{array}$

.91

.63

.46

.86

.93

.83 
Table A1.2: Determinants of Labor Force Participation by Sex

Dependent Variable: Working (yes/no)

\begin{tabular}{|c|c|c|c|c|}
\hline & \multicolumn{2}{|c|}{ Wives } & \multicolumn{2}{|c|}{ Husbands } \\
\hline & Logit & FE-Logit & Logit & FE-Logit \\
\hline Age 20-24 & $-1.72^{* * *}$ & $-1.63^{* * *}$ & -.006 & -.133 \\
\hline Age 25-29 & $-1.04^{* * *}$ & $-.783^{* * *}$ & $-.320 * *$ & $-1.08 * * *$ \\
\hline Age $30-34$ & $-.529 * * *$ & $-.420 * * *$ & .0001 & $-.399 * *$ \\
\hline Age 40-44 & .085 & .107 & $-.274^{* * *}$ & $.252^{*}$ \\
\hline Age 45-49 & $-.146^{*}$ & -.148 & $-.419^{* * *}$ & $.530^{* *}$ \\
\hline Age 50-54 & $-.548 * * *$ & $-.955^{* * *}$ & $-.569 * * *$ & $.772^{* *}$ \\
\hline Age 55-59 & & & $-1.14^{* * *}$ & .459 \\
\hline Age 60-64 & & & $-1.88^{* * *}$ & -.638 \\
\hline Years of schooling & $-.031 * * *$ & & $.065^{* * *}$ & \\
\hline $\mathrm{N}$ of sons age $0-14$ & $-.173^{* * *}$ & -.069 & $.285^{* * *}$ & .072 \\
\hline $\mathrm{N}$ of daughters age $0-14$ & $-.183^{* * *}$ & -.012 & $.186^{* *}$ & $.451^{* * *}$ \\
\hline $\mathrm{N}$ of sons age $15-30$ (econ. dep.) & .089 & -.051 & $.236^{* * *}$ & $.245^{* *}$ \\
\hline $\mathrm{N}$ of daughters age $15-30$ (econ. dep.) & .061 & .040 & $.211^{* * *}$ & $.287^{* * *}$ \\
\hline $\mathrm{N}$ of old females & $.496 * * *$ & $.416^{* * *}$ & -.047 & -.177 \\
\hline $\mathrm{N}$ of old males & .216 & .047 & $-.355^{*}$ & .069 \\
\hline Log likelihood & $-16,739$ & $-5,076$ & $-6,929$ & $-2,292$ \\
\hline Observations & 25,461 & 13,423 & 25,214 & 6,788 \\
\hline Individuals & 4,031 & 1,717 & 4,006 & 963 \\
\hline
\end{tabular}

Notes: All specifications include dummies for years of survey. Simple logit estimations aditionally include a constant, province dummies and standard errors are corrected for clustering of observations.

$* * * /^{* *} / *$ indicate a parameter estimate is significant at the $1 \% / 5 \% / 10 \%$ level, respectively. Data: KLIPS $1998-2008$. 
Table A1.3: Robustness Checks

\section{Dependent Variable: Life Satisfaction}

\begin{tabular}{|c|c|c|c|}
\hline & $\begin{array}{c}\text { Ref } \\
\text { unempl }\end{array}$ & $\begin{array}{c}\text { Indiv } \\
\text { earnings }\end{array}$ & $\begin{array}{c}\text { Wage/Non } \\
\text { wage }\end{array}$ \\
\hline & (1) & $(2)$ & (3) \\
\hline \multicolumn{4}{|l|}{ Family } \\
\hline Log per-capita income & $.194^{* * *}$ & & $.184^{* * *}$ \\
\hline Log of own earnings & & $.050^{*}$ & \\
\hline Log of partner's earnings & & $.124^{* * *}$ & \\
\hline Log of regional per-capita income & $-.699 * * *$ & $-.664^{* * *}$ & $-.695^{* * *}$ \\
\hline Own house & $.296 * * *$ & $.271^{* * *}$ & $.293^{* * *}$ \\
\hline $\mathrm{N}$ of old females & .071 & -.028 & .064 \\
\hline $\mathrm{N}$ of old males & $-.493^{* * *}$ & $-.447^{* *}$ & $-.502^{* * *}$ \\
\hline $\mathrm{N}$ of sons age $0-14$ & $-.148 * *$ & $-.199 * * *$ & $-.142^{* *}$ \\
\hline $\mathrm{N}$ of daughters age $0-14$ & -.098 & $-.147^{* *}$ & -.107 \\
\hline $\mathrm{N}$ of sons age $15-30$ (econ. dep.) & -.013 & -.021 & .001 \\
\hline $\mathrm{N}$ of daughters age $15-30$ (econ. dep.) & $-.127^{* *}$ & $-.168 * * *$ & $-.125^{* *}$ \\
\hline \multicolumn{4}{|l|}{ Own subjective health } \\
\hline \multicolumn{4}{|l|}{ Partner's subjective health } \\
\hline \multicolumn{4}{|l|}{ Own working hours } \\
\hline Hours $1-30$ & .114 & $-.276^{* *}$ & \\
\hline Hours $31-40$ & .173 & -.137 & \\
\hline Hours 41-50 & .130 & -.134 & \\
\hline Hours 51-60 & .138 & -.218 & \\
\hline Hours $60+$ & .165 & -.112 & \\
\hline \multicolumn{4}{|l|}{ Own working hours by job type } \\
\hline Hours $1-30$ wage & & & -.086 \\
\hline Hours $31-40$ wage & & & -.051 \\
\hline Hours 41-50 wage & & & -.005 \\
\hline Hours 51-60 wage & & & -.098 \\
\hline Hours $60+$ wage & & & -.094 \\
\hline Hours $1-30$ non-wage & & & -.184 \\
\hline Hours 31-40 non-wage & & & -.150 \\
\hline Hours 41-50 non-wage & & & $-.323^{* * * *}$ \\
\hline Hours 51-60 non-wage & & & -.150 \\
\hline Hours $60+$ non-wage & & & -.041 \\
\hline
\end{tabular}

\begin{tabular}{cccc}
\hline \multicolumn{3}{c}{ Husband } \\
\hline $\begin{array}{c}\text { Ref } \\
\text { unempl }\end{array}$ & $\begin{array}{c}\text { Indiv } \\
\text { earnings }\end{array}$ & $\begin{array}{c}\text { Wage/Non- } \\
\text { wage }\end{array}$ & $\begin{array}{c}\text { Subjetive } \\
\text { health }\end{array}$ \\
\hline (5) & $(6)$ & $(7)$ & $(8)$ \\
\hline $.198^{* * *}$ & & & \\
& $.183^{* * *}$ & $.196^{* * *}$ & $.134^{* * *}$ \\
& $.063^{* *}$ & & \\
$-.591^{* * *}$ & $-.666^{* * *}$ & $-.580^{* * *}$ & $-1.02^{* * *}$ \\
$.312^{* * *}$ & $.308^{* * *}$ & $.306^{* * *}$ & $.329^{* * *}$ \\
.001 & -.090 & -.006 & -.128 \\
$-.479^{* * *}$ & $-.452^{* *}$ & $-.472^{* * *}$ & -.174 \\
-.060 & -.073 & -.044 & -.144 \\
$-.140^{* *}$ & $-.168^{* *}$ & $-.132^{* *}$ & -.001 \\
-.046 & -.064 & -.033 & $-.239^{* *}$ \\
-.090 & $-.152^{* *}$ & -.094 & .008 \\
& & & $.524^{* * *}$ \\
& & & $.216^{* * *}$ \\
\hline $694^{* * *}$ & -.080 & & $.509^{* * *}$ \\
$.937^{* * *}$ & .184 & & $.639^{* * *}$ \\
$1.02^{* * *}$ & .233 & & $.640^{* * *}$ \\
$.919^{* * *}$ & .146 & & $.537^{* * *}$ \\
$.992^{* * *}$ & .207 & & $.586^{* * *}$
\end{tabular}

$.661^{* * *}$

$1.01^{* * *}$

$1.02 * * *$

$.931^{* * *}$

$1.01^{* * *}$

$.524^{* * *}$

$619 * * *$

$834^{* * *}$

$710^{* * *}$

$.780^{* * *}$ 


\section{Own other occupation}

Housewife/man

Retired

IIl

$-.128$

Other

$-.045$

Partner's working hours

Hours 1-30

Hours 31-40

$.531^{* * *} \quad-.045$

Hours 41-50

$.765 * * * \quad .208$

Hours 51-60

$.829 * * * \quad .243$

Hours 60+

$.727 * * * \quad .166$

Partner's working hours by job type

Hours 1-30 wage

Hours 31-40 wage

Hours 41-50 wage

$.789 * * * \quad .252$

$.481^{*}$

.016

Hours 51-60 wage

Hours 60+ wage

Hours 1-30 non-wage

Hours 31-40 non-wage

Hours 41-50 non-wage

Hours 51-60 non-wage

Hours $60+$ non-wage

Partner other occupation

Housewife/man $\quad .850^{* *}$

Retired .233

III

Other

$-.011$

Observations $\quad-11,941$

Individuals

33,034
13,271

13,271
3,185

$3,185 \quad 2,950$

$-10,321$
28,376
10,444
2,950

13,634
3,227

$.500 * * *$

$.792^{* * *}$

$.790^{* * *}$

$.703^{* * *}$

$.772^{* * *}$

$.389 * * *$

$.445^{* * *}$

$705 * * *$

$.550^{* * *}$

$.613^{* * *}$

.044

Notes: BUC ordered-logit estimation. All specifications include control variables for household head and spouse as well as dumunies for year of survey.

$* * * / * * / *$ indicate a parameter estimate is significant at the $1 \% / 5 \% / 10 \%$ level respectively. 
Table A1.4: Joint Happiness and Occupation Interactions

Dependent Variable:

\section{Family}

Log per-capita income

Log earnings husband

Log earnings wife

Log of regional per-capita income

Own house

$\mathrm{N}$ of old females

$\mathrm{N}$ of old males

$\mathrm{N}$ of sons age $0-14$

$\mathrm{N}$ of daughters age $0-14$

$\mathrm{N}$ of sons age 15-30 (econ. dep.)

$\mathrm{N}$ of daughters age 15-30 (econ. dep.)

\section{Wife's working hours}

Hours $1-30$

Hours 31-40

Hours 41-50

Hours 51-60

Hours 60+

Husband's working hours

Hours 1-30

Hours $31-40$

Hours 41-50

Hours 51-60

Hours $60+$

\section{Own occupation}

Housewife/man

Part-time

Full-time

Over-time

Other (incl. unemployed)

Occupation interactions

Househusb*Housewife

Househusb*Partwife

Househusb*Fullwife

Househusb* Overwife

Househusb* Otherwife

Parthusb*Housewife

Parthusb*Partwife

Parthusb*Fullwife

Parthusb*Overwife

Parthusb*Otherwife

Fullhusb*Housewife

Fullhusb*Partwife

Fullhusb*Fullwife

Fullhusb*Overwife

Fullhusb*Otherwife

Overhusb*Housewife

Overhusb*Partwife

Overhusb*Fullwife

Overhusb* Overwife

Overhusb* Otherwife
Joint Couple Life Satisfaction

\begin{tabular}{ccc}
\hline $\begin{array}{c}\text { Standard } \\
\text { model }\end{array}$ & $\begin{array}{c}\text { Indiv. } \\
\text { earnings }\end{array}$ & $\begin{array}{c}\text { Occup. } \\
\text { Interact }\end{array}$ \\
\hline$(1)$ & $(2)$ & $(3)$
\end{tabular}

$.118^{* * *}$

$.121^{* * *}$

$-.339 * * *$

$.168^{* * * *}$

.019

$.026 \quad-.026$

$-.259 * * *$

$-.248 * * *$

$-.257 * * *$

$-.048^{*}$

$-.077^{* * *}$

$-.056^{* *}$

$-.082 * * *$

$-.052^{* *}$

$-.054 * *$

$-.015$

$.064^{* *}$

$-.030$

$-.063^{* *}$

$-.064^{* *}$

$-154^{* * *}$

$-.019$

$-.068$

$-.035$

$-.084$

$-.020$

$-.075$

$-.052^{*}$

$-.094$

$\begin{array}{ll}.359^{* * *} & .014 \\ .496^{* * *} & .156^{* *} \\ .539^{* * *} & .186^{* * *} \\ .486^{* * *} & .144^{* *} \\ .527^{* * *} & .185^{* * *}\end{array}$

.264

.500

$-.202$

$-.113$

$-.210$

$-.049$

$-.251^{* * *}$

-.151 **

$-.074$

$-.194$

.031

$-.029$

.038

.061

$-.008$

(Reference)

$-.058$

$-.059 *$

$-.014$

.029
Individual Life

Satisfaction

Wife Husband

(4)

(5)

$.058^{* * *} \quad .059 * * *$

$\begin{array}{cc}-.197^{* * *} & -.149 * * * \\ .078^{* * *} & .089^{* * *} \\ -.139^{* * *} & .001 \\ .058^{* * *} & -.122^{* * *} \\ -.037^{* *} & -.017 \\ -.028^{*} & -.032^{* *} \\ -.005 & -.012 \\ -.040^{* * *} & -.026^{*}\end{array}$

$-.034 \quad-.066$

$.180-.295^{*}$

$.132 \quad .068$

(Reference) (Reference)

$-.374^{* * *} \quad-.274^{* *}$

$.203 \quad .369$

$.316 \quad .284$

$.281^{*} .221$

$.031 \quad .132$

.526 -

$.120^{* *} \quad .384^{* *}$

$-.211 \quad .293^{*}$

$-.104 \quad .334^{* *}$

$.068 \quad .353^{* *}$

$.309 * * \quad .193$

$.153^{* * *} \quad .088$

$-.108 \quad .066$

$-.016 \quad .086$

$.122^{* * *} \quad .092$

$.368^{* * *} \quad .025$

$.153^{* * *} \quad .157^{* * *}$

$-.099 \quad .091^{* *}$

$-.067 \quad .107^{* * *}$

$.086^{* *} \quad .121^{* * *}$

$.408^{* * *} \quad .102 * *$ 
Otherhusb*Housewife

Otherhusb*Partwife

$-.475^{* * *} \quad-.114^{* *} \quad .120$

Otherhusb*Fullwife

$-.319 * * *$

$-.166$

107

Otherhusb*Overwife

Otherhusb*Otherwife

Log likelihood

$-.355^{* * *}$

$-.209 * * *$

.177

Observations

$-31,316$

$.494^{* * *}$

$-.176^{* * * *}$

.115

$-.504^{* * *}$

.092

$-.0002$

Individuals

24,613

$-27,018$

$-31,315$

$-18,602$

24,613

24,740

$-18,615$

3.912

3,992

3,994

24,695

Notes: Linear flxed-effects estimations. All specifications include a constant. control variables for household head and spouse as well as dunmles for year of survey. ${ }^{m * *} / *^{* * *} / *$ Indicate a paraneter estimate is significant at the $1 \% / 5 \% / 10 \%$ level. respectively. Reference category for working hours in (1) and (2): 0 hours per week (not working). Reference occupation comblnation in (3): Husband works overtime \& worman is housewife. Data: KLIPS 1998-2008. 


\section{Appendix Essay 2}

Table A2.1: Effect of First Marriage on Life Satisfaction

\begin{tabular}{|c|c|c|c|c|c|c|c|c|}
\hline & \multicolumn{4}{|c|}{ Females } & \multicolumn{4}{|c|}{ Males } \\
\hline & $\begin{array}{l}\text { Ologit } \\
\text { (1) } \\
\end{array}$ & $\begin{array}{c}\text { BUC } \\
(2) \\
\end{array}$ & $\begin{array}{l}\text { FF } \\
(3)\end{array}$ & $\begin{array}{c}\text { FE-OLS } \\
(4) \\
\end{array}$ & $\begin{array}{c}\text { Ologit } \\
(5)\end{array}$ & $\begin{array}{c}\text { BUC } \\
(6) \\
\end{array}$ & $\begin{array}{l}\text { FF } \\
(7) \\
\end{array}$ & $\begin{array}{c}\text { FE-OLS } \\
(8) \\
\end{array}$ \\
\hline \multicolumn{9}{|l|}{ Transition to mar } \\
\hline \multicolumn{9}{|l|}{ Leads } \\
\hline $3-4$ years hence & $.296^{* *}$ & .189 & .125 & .054 & -.042 & $-.290^{*}$ & -.159 & $-.077^{*}$ \\
\hline $2-3$ years hence & $.194^{*}$ & .091 & -.054 & .023 & $.195^{*}$ & .045 & .072 & .019 \\
\hline 1-2 years hence & .160 & .049 & -.092 & .007 & .172 & .003 & .079 & .008 \\
\hline Within next year & $.170^{*}$ & -.074 & -.180 & -.012 & $.195^{* *}$ & .115 & .059 & .028 \\
\hline \multicolumn{9}{|l|}{ Lags } \\
\hline $0-1$ years & $1.30^{* * *}$ & $1.03^{* * *}$ & $.989^{* * *}$ & $.264^{* * *}$ & $1.55^{* * *}$ & $1.33^{* * *}$ & $1.34^{* * *}$ & $.332^{* * *}$ \\
\hline $1-2$ years & $.573^{* * *}$ & $.509^{* *}$ & $.377^{* *}$ & $.138^{* * *}$ & $.690 * * *$ & $.529 * * *$ & $.450^{* * *}$ & $.121^{* * *}$ \\
\hline $2-3$ years & .091 & .093 & .039 & .025 & $.703^{* * *}$ & $.497^{* * *}$ & $.414^{* *}$ & $.120^{* * *}$ \\
\hline $3-4$ years & -.011 & -.076 & -.194 & -.007 & $.791^{* * *}$ & $.691^{* * *}$ & $.684^{* * *}$ & $.168^{* * *}$ \\
\hline $4-5$ years & -.022 & -.032 & -.183 & -.004 & $.707^{* * *}$ & $.679^{* * *}$ & $.599 * * *$ & $.162^{* * *}$ \\
\hline 5 or more years & .088 & -.045 & -.117 & -.001 & $.800^{* * *}$ & $.831^{* * *}$ & $.724^{* * *}$ & $.197^{* * *}$ \\
\hline \multicolumn{9}{|l|}{ Oth mar stat } \\
\hline Other married & $.195^{* *}$ & $-.688^{* *}$ & $-.915^{* * *}$ & $-.186^{* * *}$ & $.503^{* * *}$ & .125 & .059 & .037 \\
\hline Seperated & $-.804^{* * *}$ & $-1.39 * * *$ & $-1.52^{* * *}$ & $-.403^{* * *}$ & $-.644^{* * *}$ & $-.899 * *$ & $-.722^{* *}$ & $-.227 * * *$ \\
\hline Divorced & $-.481^{* * *}$ & $-.880^{* * *}$ & $-1.04 * * *$ & $-.232^{* * *}$ & $-.513 * * *$ & $-.862^{* * *}$ & $-.749 * * *$ & $-.219^{* * *}$ \\
\hline Widowed & .006 & $-.605^{*}$ & $-.719^{* *}$ & $-.174 * *$ & -.099 & $-.890^{* *}$ & $-1.30 * * *$ & $-.234^{* *}$ \\
\hline \multicolumn{9}{|l|}{ Individual } \\
\hline Years schooling & $.122 * * *$ & $.048^{* *}$ & $.046^{* * *}$ & $.011 * * *$ & $.129 * * *$ & .022 & $.032^{*}$ & .004 \\
\hline Working & $.300^{* * *}$ & $.330^{* * *}$ & $.334^{* * *}$ & $.090^{* * *}$ & $.518^{* * *}$ & $.502^{* * *}$ & $.454^{* * *}$ & $.132^{* * *}$ \\
\hline Housewife & $.541^{* * *}$ & $.352^{* * *}$ & $.324^{* * *}$ & $.097 * * *$ & -.048 & .070 & .056 & -.001 \\
\hline Retired & $.629^{* * *}$ & $.486^{* * *}$ & $.405^{* * *}$ & $.131^{* * *}$ & $.240^{* *}$ & .038 & -.004 & .013 \\
\hline Illness & -.122 & -.019 & -.019 & -.011 & $-.507^{* * *}$ & $-.407^{* * *}$ & $-.488^{* * *}$ & $-.128^{* * *}$ \\
\hline In education & $.556 * * *$ & $.532^{* * *}$ & $.538^{* * *}$ & $.140^{* * *}$ & $.600^{* * *}$ & $.291^{* * *}$ & $.258^{* * *}$ & $.082^{* * *}$ \\
\hline Unemployed & $-.516^{* * *}$ & $-.259^{* *}$ & $-.287^{* *}$ & $-.093 * * *$ & $-.688 * * *$ & $-.489 * * *$ & $-.482^{* * *}$ & $-.155^{* * *}$ \\
\hline \multicolumn{9}{|l|}{ Household } \\
\hline Log hh pci & $.349^{* * *}$ & $.167^{* * *}$ & $.163^{* * *}$ & $.049^{* * *}$ & $.316^{* * *}$ & $.162^{* * *}$ & $.164^{* * *}$ & $.048^{* * *}$ \\
\hline Log reg pci & $-.783^{* * *}$ & $-.686 * * *$ & $-.783^{* * *}$ & $-.202^{* * *}$ & $-.552 * * *$ & $-.524^{* * *}$ & $-.656 * * *$ & $-.159 * * *$ \\
\hline Own house & $.030^{* * *}$ & $.344^{* * *}$ & $.327^{* * *}$ & $.089^{* * *}$ & $.584^{* * *}$ & $.322^{* * *}$ & $.290^{* * *}$ & $.083^{* * *}$ \\
\hline HH Size & .0001 & -.009 & -.014 & .0004 & $.034^{* *}$ & .039 & .033 & $.013^{* *}$ \\
\hline Head & $.435^{* * *}$ & $.466^{* * *}$ & $.461^{* * *}$ & $.139 * * *$ & $.414^{* * *}$ & $.516^{* * *}$ & $.434^{* * *}$ & $.149 * * *$ \\
\hline Spouse & $.439^{* * *}$ & $.371^{* *}$ & $.378^{* * *}$ & $.099^{* * *}$ & .428 & .776 & .201 & $.197^{*}$ \\
\hline No of child $0-14$ & -.017 & -.015 & .006 & -.006 & .006 & -.032 & -.013 & -.008 \\
\hline No of child $15-30$ & $-.060^{* *}$ & -.047 & -.047 & $-.014^{*}$ & -.002 & -.029 & -.031 & -.008 \\
\hline No of old females & .041 & .048 & .040 & .005 & -.033 & -.020 & -.032 & -.010 \\
\hline No of old males & $-.143^{* *}$ & -.093 & -.055 & -.031 & $-.203^{* * *}$ & $-.358 * * *$ & $-.344^{* * *}$ & $-.088^{* * *}$ \\
\hline Log likelihood & $-42,463$ & $-22,902$ & $-17,353$ & - & $-41,128$ & $-21,810$ & $-16,430$ & - \\
\hline Observations & 45,049 & 63,907 & 41,947 & 45,049 & 43,953 & 61,583 & 40,482 & 43,953 \\
\hline $\begin{array}{l}\text { Individuals } \\
\text { Clusters }\end{array}$ & $5, \overline{-}$ & $\begin{array}{c}29,024 \\
5,231\end{array}$ & $\begin{array}{c}5,170 \\
-\end{array}$ & 5,923 & 6.087 & $\begin{array}{c}27,372 \\
5,324\end{array}$ & 5,274 & $\begin{array}{c}6,087 \\
-\end{array}$ \\
\hline
\end{tabular}


Table A2.2: Effect of Working Days Reduction on Different Satisfaction Measures

Females

Males

\begin{tabular}{|c|c|c|c|c|c|c|}
\hline & Life Satisfation & Hours Satisfaction & Job Satisfaction & Life Satisfation & Hours Satisfaction & Job Satisfaction \\
\hline & (1) & (2) & (3) & (4) & (5) & (6) \\
\hline Other five-day & $-.041^{*}$ & $.134^{* * *}$ & .029 & .014 & $.129^{* * *}$ & $.029^{*}$ \\
\hline Below five day & -.050 & $.063^{*}$ & -.041 & $-.065^{* * *}$ & -.015 & $-.098^{* * *}$ \\
\hline \multicolumn{7}{|l|}{ Leads } \\
\hline 3-4 years hence & -.067 & -.090 & .057 & .020 & -.005 & .002 \\
\hline $2-3$ years hence & -.041 & -.030 & .082 & .034 & .032 & -.030 \\
\hline 1-2 years hence & $-.118^{* *}$ & -.031 & .012 & .019 & $.112^{* * *}$ & .041 \\
\hline Within the next year & -.092 & -.011 & $.109^{*}$ & .031 & $.130^{* * *}$ & $.067^{*}$ \\
\hline \multicolumn{7}{|l|}{ Lags } \\
\hline $0-1$ years & -.051 & -.032 & -.006 & $.060^{*}$ & $.324^{* * *}$ & $.113^{* * *}$ \\
\hline $1-2$ years & -.024 & .041 & .050 & .012 & $.280^{* * *}$ & $.103^{* * *}$ \\
\hline $2-3$ years & .039 & .018 & .101 & $.067^{*}$ & $.255^{* * *}$ & $.115^{* * *}$ \\
\hline $3-4$ years & -.009 & .095 & .092 & .069 & $.272^{* * *}$ & $.161^{* * *}$ \\
\hline 4-5 years & -.067 & .058 & .081 & .061 & $.195^{* * *}$ & $.210^{* * *}$ \\
\hline 5 or more years & -.051 & -.083 & -.104 & .005 & $.245^{* * *}$ & $.235^{* * *}$ \\
\hline Observations & 11,046 & 11,054 & 9,725 & 24,923 & 24,975 & 21,760 \\
\hline Individuals & 2,156 & 2,156 & 2.133 & 3,902 & 3,902 & 3,865 \\
\hline
\end{tabular}

Notes: Linear fixed-effects estimator. Other control variables include 5-year-age-cohorts, chummles for household head and spouse, years of schooling household size number of young (0-14

years) and old (15-30 years) children in the household. dumnies for marital status, log per-capita household income, log of own earnings, log per-capita regional income house ownership. 14

regional dummies, 10 year dummies, 10 occupation and 16 industry dunmies. $* * * * * / *$ indicate a paraneter estimate is significant at the $1 \% / 5 \% / 10 \%$ level. Data: KLIPS $1998-2008$ : job satisfaction only 2000-2008. 


\section{Appendix Essay 4}

Table A4.1: Description of variables

\begin{tabular}{|c|c|c|c|}
\hline Variable & Characteristic & Database & Level \\
\hline \multicolumn{4}{|l|}{$\begin{array}{l}\text { Individual } \\
\text { characteristics }\end{array}$} \\
\hline Age & Age of household head & $\begin{array}{l}\text { STORMA, } \\
\text { BPS }\end{array}$ & HH Head \\
\hline Sex & $\begin{array}{l}\text { Sex of household head } \\
(1=\text { male; } 0=\text { female })\end{array}$ & $\begin{array}{l}\text { STORMA, } \\
\text { BPS }\end{array}$ & HH Head \\
\hline $\begin{array}{l}\text { Years of Schooling } \\
\text { of HH Head }\end{array}$ & $\begin{array}{l}\text { Years of schooling completed } \\
\text { by hh head }\end{array}$ & $\begin{array}{l}\text { STORMA, } \\
\text { BPS }\end{array}$ & HH Head \\
\hline \multicolumn{4}{|l|}{$\begin{array}{l}\text { Household } \\
\text { characteristics }\end{array}$} \\
\hline Household Size & No. of household members & $\begin{array}{l}\text { STORMA, } \\
\text { BPS }\end{array}$ & Household \\
\hline Dependency Ratio & $\begin{array}{l}\text { No. of economic non-active hh mem- } \\
\text { bers (age }<15 \text { or }>60 \text { ) divided by \# of } \\
\text { economic active hh members }\end{array}$ & $\begin{array}{l}\text { STORMA, } \\
\text { BPS }\end{array}$ & Household \\
\hline Number of Men & No. of men in a household & $\begin{array}{l}\text { STORMA, } \\
\text { BPS }\end{array}$ & Household \\
\hline Max Education & $\begin{array}{l}\text { Maximum years of schooling of a } \\
\text { household member }\end{array}$ & $\begin{array}{l}\text { STORMA, } \\
\text { BPS }\end{array}$ & Household \\
\hline \multicolumn{4}{|l|}{ Income variables } \\
\hline $\begin{array}{l}\text { Real per-capita } \\
\text { Income }\end{array}$ & $\begin{array}{l}\text { HH income divided by hh size and de- } \\
\text { flated with provincial CPI data in IDR }\end{array}$ & $\begin{array}{l}\text { STORMA, } \\
\text { BPS }\end{array}$ & Household \\
\hline $\begin{array}{l}\text { Agricultural self- } \\
\text { employed income }\end{array}$ & $\begin{array}{l}\mathrm{HH} \text { income from self-employment in } \\
\text { the agricultural sector }\end{array}$ & $\begin{array}{l}\text { STORMA, } \\
\text { BPS }\end{array}$ & Household \\
\hline $\begin{array}{l}\text { Agricultural wage } \\
\text { income }\end{array}$ & $\begin{array}{l}\mathrm{HH} \text { income from wage-employment in } \\
\text { the agricultural sector }\end{array}$ & $\begin{array}{l}\text { STORMA, } \\
\text { BPS }\end{array}$ & Household \\
\hline $\begin{array}{l}\text { Non-agricultural } \\
\text { self-employed } \\
\text { income }\end{array}$ & $\begin{array}{l}\text { HH income from self-employment in } \\
\text { the non-agricultural sector }\end{array}$ & $\begin{array}{l}\text { STORMA, } \\
\text { BPS }\end{array}$ & Household \\
\hline $\begin{array}{l}\text { Non-agricultural } \\
\text { wage income }\end{array}$ & $\begin{array}{l}\mathrm{HH} \text { income from wage-employment in } \\
\text { the non-agricultural sector }\end{array}$ & $\begin{array}{l}\text { STORMA, } \\
\text { BPS }\end{array}$ & Household \\
\hline Livestock income & $\mathrm{HH}$ income from livestock farming & STORMA & Household \\
\hline Gathering income & $\mathrm{HH}$ income from gathering & STORMA & Household \\
\hline Cropping income & $\mathrm{HH}$ income from crop production & STORMA & Household \\
\hline $\begin{array}{l}\text { Annual cropping } \\
\text { income }\end{array}$ & Annual e.g. rice, maize & STORMA & Household \\
\hline $\begin{array}{l}\text { Perennial cropping } \\
\text { income }\end{array}$ & $\begin{array}{l}\text { Perennial e.g. cash crops like coffee, } \\
\text { cocoa }\end{array}$ & STORMA & Household \\
\hline Cocoa income & $\mathrm{HH}$ income from cocoa cultivation & STORMA & Household \\
\hline Coffee income & $\mathrm{HH}$ income from coffee cultivation & STORMA & Household \\
\hline
\end{tabular}




\begin{tabular}{|c|c|c|c|}
\hline \multicolumn{4}{|l|}{$\begin{array}{l}\text { Productivity } \\
\text { variables }\end{array}$} \\
\hline Cocoa yield per are & Cocoa income divided by area cocoa & STORMA & Household \\
\hline Coffee yield per are & Coffee income divided by area coffee & STORMA & Household \\
\hline Cocoa output per are & $\begin{array}{l}\text { Amount of cocoa harvested per month } \\
\text { per area of cocoa }\end{array}$ & STORMA & Household \\
\hline $\begin{array}{l}\text { Coffee output } \\
\text { per are }\end{array}$ & $\begin{array}{l}\text { Amount of cocoa harvested per month } \\
\text { per area of coffee }\end{array}$ & STORMA & Household \\
\hline \multicolumn{4}{|l|}{ Price variables } \\
\hline Cocoa price per kilo & $\begin{array}{l}\text { Reported farm gate prices per kilo in } \\
\text { IDR }\end{array}$ & STORMA & Household \\
\hline Coffee price per kilo & $\begin{array}{l}\text { Reported farm gate prices per kilo in } \\
\text { IDR }\end{array}$ & STORMA & Household \\
\hline \multicolumn{4}{|l|}{ Sector dummies } \\
\hline $\begin{array}{l}\text { Agricultural self- } \\
\text { employed }\end{array}$ & $\begin{array}{l}\mathrm{HH} \text { income from this sector }>50 \% \text { : } \\
\text { no( } 0) \text {, yes }(1)\end{array}$ & $\begin{array}{l}\text { STORMA, } \\
\text { BPS }\end{array}$ & Household \\
\hline Agricultural wage & $\begin{array}{l}\mathrm{HH} \text { income from this sector }>50 \% \text { : } \\
\text { no( } 0) \text {, yes }(1)\end{array}$ & $\begin{array}{l}\text { STORMA, } \\
\text { BPS }\end{array}$ & Household \\
\hline $\begin{array}{l}\text { Non-agricultural } \\
\text { self-employed }\end{array}$ & $\begin{array}{l}\text { HH income from this sector }>50 \% \text { : } \\
\text { no( }(0) \text {, yes }(1)\end{array}$ & $\begin{array}{l}\text { STORMA, } \\
\text { BPS }\end{array}$ & Household \\
\hline $\begin{array}{l}\text { Non-agricultural } \\
\text { wage }\end{array}$ & $\begin{array}{l}\mathrm{HH} \text { income from this sector }>50 \% \text { : } \\
\text { no( } 0) \text {, yes }(1)\end{array}$ & $\begin{array}{l}\text { STORMA, } \\
\text { BPS }\end{array}$ & Household \\
\hline Mixed & $\begin{array}{l}\text { HH income from non of the above } \\
\text { sectors > } 50 \%: \text { no }(0) \text {, yes }(1)\end{array}$ & $\begin{array}{l}\text { STORMA, } \\
\text { BPS }\end{array}$ & Household \\
\hline \multicolumn{4}{|l|}{ Other variables } \\
\hline Area owned & Agriculturally suitable in are & STORMA & Household \\
\hline Area cocoa & $\begin{array}{l}\text { Agricultural land planted with cocoa } \\
\text { in are }\end{array}$ & STORMA & Household \\
\hline Area coffee & $\begin{array}{l}\text { Agricultural land planted with coffee } \\
\text { in are }\end{array}$ & STORMA & Household \\
\hline Value of assets & $\begin{array}{l}\text { Estimated value of physical and finan- } \\
\text { cial assets in IDR }\end{array}$ & STORMA & Household \\
\hline Value of livestock & Estimated value of livestock in IDR & STORMA & Household \\
\hline $\begin{array}{l}\text { Expenditures on } \\
\text { fertilizer/pesticides }\end{array}$ & $\begin{array}{l}\text { HH expenditures on fertilizer and pes- } \\
\text { ticides per month }\end{array}$ & STORMA & Household \\
\hline $\begin{array}{l}\text { Share of rice fields } \\
\text { with irrigation }\end{array}$ & $\begin{array}{l}\text { Share of rice fields with no, semi- } \\
\text { technical or technical irrigation system }\end{array}$ & STORMA & Household \\
\hline Distance to road & $\begin{array}{l}\text { Distance to the next paved road in } \\
\text { hours }\end{array}$ & STORMA & Household \\
\hline Access to electricity & $\begin{array}{l}\text { Household is connected to electricity: } \\
\text { no( } 0) \text {, yes }(1)\end{array}$ & $\begin{array}{l}\text { STORMA, } \\
\text { BPS }\end{array}$ & Household \\
\hline $\begin{array}{l}\text { Access to extension } \\
\text { services }\end{array}$ & $\begin{array}{l}\text { Household received agricultural extension } \\
\text { service in last year (no }(0) \text {, yes }(1)\end{array}$ & STORMA & Household \\
\hline Distance to Palu & $\begin{array}{l}\text { Distance to the provincial capital Palu } \\
\text { in hours }\end{array}$ & STORMA & Household \\
\hline
\end{tabular}


Table A4.2: Comparison of Regional Means

\begin{tabular}{|c|c|c|c|c|c|}
\hline & $\begin{array}{l}\text { STOR- } \\
\text { MA '01 }\end{array}$ & $\begin{array}{l}\text { SUSE- } \\
\text { NAS '02* } \\
\text { Rural } \\
\text { Central } \\
\text { Sulawesi }\end{array}$ & $\begin{array}{l}\text { SUSENAS } \\
\text { '02* } \\
\text { Rural } \\
\text { Sulawesi }\end{array}$ & $\begin{array}{l}\text { SUSE- } \\
\text { NAS '02* } \\
\text { Rural } \\
\text { Indonesia } \\
\text { minus Java }\end{array}$ & $\begin{array}{l}\text { SUSE- } \\
\text { NAS '02* } \\
\text { Rural } \\
\text { Indonesia }\end{array}$ \\
\hline Household Size & $\begin{array}{l}5.42 \\
(2.00)\end{array}$ & $\begin{array}{l}4.49 \\
(1.58)\end{array}$ & $\begin{array}{l}4.63 \\
(1.65)\end{array}$ & $\begin{array}{l}4.65 \\
(1.63)\end{array}$ & $\begin{array}{l}4.34 \\
(1.53) \\
\end{array}$ \\
\hline Age of $\mathrm{HH}$ Head & $\begin{array}{l}43.8 \\
(14.0)\end{array}$ & $\begin{array}{l}40.3 \\
(12.6)\end{array}$ & $\begin{array}{l}41.8 \\
(12.3)\end{array}$ & $\begin{array}{l}41.7 \\
(11.8)\end{array}$ & $\begin{array}{l}42.4 \\
(11.9)\end{array}$ \\
\hline Sex of HH Head & $\begin{array}{l}.95 \\
(.21) \\
\end{array}$ & $\begin{array}{l}.96 \\
(.21)\end{array}$ & $\begin{array}{l}.94 \\
(.24)\end{array}$ & $\begin{array}{l}.94 \\
(.24)\end{array}$ & $\begin{array}{l}.94 \\
(.23)\end{array}$ \\
\hline Dependency Ratio & $\begin{array}{l}.70 \\
(.58) \\
\end{array}$ & $\begin{array}{l}.77 \\
(.63)\end{array}$ & $\begin{array}{l}.81 \\
(.67)\end{array}$ & $\begin{array}{l}.84 \\
(.68)\end{array}$ & $\begin{array}{l}.77 \\
(.62)\end{array}$ \\
\hline Number of Men & $\begin{array}{l}1.85 \\
(1.03) \\
\end{array}$ & $\begin{array}{l}1.39 \\
(.79) \\
\end{array}$ & $\begin{array}{l}1.39 \\
(.81)\end{array}$ & $\begin{array}{l}1.37 \\
(.81) \\
\end{array}$ & $\begin{array}{l}1.32 \\
(.75) \\
\end{array}$ \\
\hline $\begin{array}{l}\text { Years of Schooling of } \mathrm{HH} \\
\text { Head }\end{array}$ & $\begin{array}{l}6.77 \\
(3.36) \\
\end{array}$ & $\begin{array}{l}5.97 \\
(3.82)\end{array}$ & $\begin{array}{l}5.28 \\
(4.04) \\
\end{array}$ & $\begin{array}{l}5.14 \\
(4.02) \\
\end{array}$ & $\begin{array}{l}4.66 \\
(3.77) \\
\end{array}$ \\
\hline $\begin{array}{l}\text { Max. Years of Schooling of a } \\
\text { HH Member }\end{array}$ & $\begin{array}{l}8.68 \\
(2.87)\end{array}$ & $\begin{array}{l}7.84 \\
(3.22)\end{array}$ & $\begin{array}{l}7.67 \\
(3.53) \\
\end{array}$ & $\begin{array}{l}7.45 \\
(3.49)\end{array}$ & $\begin{array}{l}6.96 \\
(3.31) \\
\end{array}$ \\
\hline Total Per-Capita Income & $\begin{array}{l}95,076 \\
(106,003)\end{array}$ & $\begin{array}{l}96,197 \\
(29,569)\end{array}$ & $\begin{array}{l}100,031 \\
(31,176)\end{array}$ & $\begin{array}{l}107,400 \\
(33,735)\end{array}$ & $\begin{array}{l}102,846 \\
(30,244)\end{array}$ \\
\hline $\begin{array}{l}\text { Agricultural Self-employed } \\
\text { Income, per capita }\end{array}$ & $\begin{array}{l}60,266 \\
(68,679)\end{array}$ & $\begin{array}{l}60,651 \\
(42,831) \\
\end{array}$ & $\begin{array}{l}66,961 \\
(45,208)\end{array}$ & $\begin{array}{l}66,812 \\
(49,004)\end{array}$ & $\begin{array}{l}49,517 \\
(45,651)\end{array}$ \\
\hline $\begin{array}{l}\text { Agricultural Wage Income, } \\
\text { p.c. }\end{array}$ & $\begin{array}{l}8,319 \\
(17,016)\end{array}$ & $\begin{array}{l}12,397 \\
(27,955)\end{array}$ & $\begin{array}{l}7,660 \\
(23,961)\end{array}$ & $\begin{array}{l}12,349 \\
(30,776)\end{array}$ & $\begin{array}{l}15,064 \\
(31,656) \\
\end{array}$ \\
\hline $\begin{array}{l}\text { Non-farm Self-employed } \\
\text { Income, p.c. }\end{array}$ & $\begin{array}{l}10,906 \\
(64,371)\end{array}$ & $\begin{array}{l}13,307 \\
(30,015)\end{array}$ & $\begin{array}{l}15,560 \\
(32,885) \\
\end{array}$ & $\begin{array}{l}14640 \\
(33715) \\
\end{array}$ & $\begin{array}{l}19,886 \\
(37,579)\end{array}$ \\
\hline Non-farm Wage Income, p.c. & $\begin{array}{l}15,583 \\
(46,465)\end{array}$ & $\begin{array}{l}9,842 \\
(28,030) \\
\end{array}$ & $\begin{array}{l}9,428 \\
(28,503)\end{array}$ & $\begin{array}{l}13,208 \\
(34,940)\end{array}$ & $\begin{array}{l}17,943 \\
(37,987) \\
\end{array}$ \\
\hline $\begin{array}{l}\text { Share of Agricultural Self- } \\
\text { employed Income }\end{array}$ & $\begin{array}{l}.67 \\
(.37) \\
\end{array}$ & $\begin{array}{l}.64 \\
(.39) \\
\end{array}$ & $\begin{array}{l}.68 \\
(.39) \\
\end{array}$ & $\begin{array}{l}.64 \\
(.41)\end{array}$ & $\begin{array}{l}.50 \\
(.42) \\
\end{array}$ \\
\hline $\begin{array}{l}\text { Share of Agricultural Wage } \\
\text { Income }\end{array}$ & $\begin{array}{l}.14 \\
(.24)\end{array}$ & $\begin{array}{l}.14 \\
(.29) \\
\end{array}$ & $\begin{array}{l}.08 \\
(.23) \\
\end{array}$ & $\begin{array}{l}.12 \\
(.27) \\
\end{array}$ & $\begin{array}{l}.15 \\
(.30) \\
\end{array}$ \\
\hline $\begin{array}{l}\text { Share of Non-farm Self- } \\
\text { employed Income }\end{array}$ & $\begin{array}{l}.07 \\
(.22) \\
\end{array}$ & $\begin{array}{l}.13 \\
(.27)\end{array}$ & $\begin{array}{l}.15 \\
(.30)\end{array}$ & $\begin{array}{l}.13 \\
(.28) \\
\end{array}$ & $\begin{array}{l}.18 \\
(.33)\end{array}$ \\
\hline $\begin{array}{l}\text { Share of Non-farm Wage } \\
\text { Income }\end{array}$ & $\begin{array}{l}.12 \\
(.28) \\
\end{array}$ & $\begin{array}{l}.09 \\
(.25) \\
\end{array}$ & $\begin{array}{l}.09 \\
(.25) \\
\end{array}$ & $\begin{array}{l}.11 \\
(.28) \\
\end{array}$ & $\begin{array}{l}.16 \\
(.33) \\
\end{array}$ \\
\hline $\mathrm{N}$ & 257 & 523 & 2,342 & 10,729 & 17,535 \\
\hline
\end{tabular}

* SUSENAS means cover the deciles 1 to 7 of the original income distribution. Deciles 8 to 10 were dropped due to comparability reasons. Monetary values are real in Indonesian Rupiahs with base year 2001 and use regional CPIs provided by BPS. Incomes are monthly. Standard deviations in parentheses. Shares of the four income sources are with respect to total household income, not per capita. 
Table A4.3: Regional Multivariate Regression-Comparison II

\begin{tabular}{|c|c|c|c|c|c|c|}
\hline & \multicolumn{6}{|c|}{ LN(INCOME PER CAPITA) } \\
\hline & $\begin{array}{l}\text { STORMA } \\
2004\end{array}$ & $\begin{array}{l}\text { STORMA } \\
2006\end{array}$ & $\begin{array}{l}\text { SUSENAS } \\
2005 \\
\text { Rural } \\
\text { Central } \\
\text { Sulawesi }\end{array}$ & $\begin{array}{l}\text { SUSENAS } \\
2005 \\
\text { Rural } \\
\text { Sulawesi }\end{array}$ & $\begin{array}{l}\text { SUSENAS } \\
2005 \\
\text { Rural In- } \\
\text { donesia } \\
\text { minus Java }\end{array}$ & $\begin{array}{l}\text { SUSENAS } \\
2005 \\
\text { Rural } \\
\text { Indonesia }\end{array}$ \\
\hline Sex & .196 & -.267 & .065 & $.240 * * *$ & $.155^{* * *}$ & $.142 * * *$ \\
\hline Age & .027 & .051 & .009 & .004 & $.006 * * *$ & $.003 *$ \\
\hline $\mathrm{Age}^{2}$ & .000 & -.001 & -.009 & -.004 & $-.007 * * *$ & $-.004 * *$ \\
\hline Max Education & $.083 * *$ & -.056 & .007 & $.014 * * *$ & $.014 * * *$ & $.015^{* * *}$ \\
\hline $\begin{array}{l}\text { HH Size } \\
\text { Dependency }\end{array}$ & $-.159 * * *$ & $-.141 * *$ & $-.091 * * *$ & $-.076 * * *$ & $-.077 * * *$ & $-.075 * * *$ \\
\hline Ratio & -.012 & $-.321 * *$ & .009 & $-.059 * * *$ & $-.068 * * *$ & $-.065 * * *$ \\
\hline $\begin{array}{l}\text { Number of Men } \\
\text { Non-farm }\end{array}$ & .138 & $.152^{*}$ & .056 & $.035^{* *}$ & $.029 * * *$ & $.033 * * *$ \\
\hline $\begin{array}{l}\text { self-employed } \\
\text { Non-farm }\end{array}$ & $1.317 * * *$ & $.827 * * *$ & .083 & -.025 & -.013 & .009 \\
\hline $\begin{array}{l}\text { wage } \\
\text { Agriculture }\end{array}$ & $1.215^{* * *}$ & $.994 * * *$ & & & & \\
\hline $\begin{array}{l}\text { self-employed } \\
\text { Mixed }\end{array}$ & $.722 * * *$ & .096 & $-.112 * *$ & $-.237 * * *$ & $-.247 * * *$ & $-.242 * * *$ \\
\hline $\begin{array}{l}\text { Access to } \\
\text { Electricity }\end{array}$ & $1.172 * * *$ & -.289 & .290 & -.064 & $.085^{* *}$ & $.052 * *$ \\
\hline & .129 & $.680 * *$ & & & & \\
\hline Constant & $10.350 * * *$ & $10.910 * * *$ & $11.906 * * *$ & $11.762 * * *$ & $12.630 * * *$ & $11.679 * * *$ \\
\hline $\mathrm{N}$ & 257 & 257 & 530 & 2968 & 12,866 & 22,125 \\
\hline Adj. R-squared & .19 & .21 & .31 & .39 & .46 & .40 \\
\hline
\end{tabular}

SUSENAS regressions estimate over the deciles 1 to 7 of the original income distribution for the respective geographical area. Deciles 8 to 10 were dropped due to comparability reasons. Significance levels: $* * * / * * / *$ denote $.01, .05$ and .1 respectively (robust t-statistics used). We control for spatial differences using kecamatan (sub-district) dummies. Incomes are real monthly Indonesian Rupiahs with base year 2001 and use regional CPIs provided by BPS. Note that SUSENAS 2005 does not disaggregate wage income into agricultural and non-agricultural wage. Reference category is total wage income in this case. 
Robert Rudolf - 978-3-631-75352-1

Downloaded from PubFactory at 01/11/2019 06:01:29AM

via free access 


\section{Bibliography}

Adams, R. H. (1995). Agricultural income, cash crops, and inequality in rural Pakistan. Economic Development and Cultural Change 43 (3), 467-491.

Adler, J. (2006). Daughter/Wife/Mother or Sage/Immortal/Bodhisattva? Women in the Teaching of Chinese Religions. ASIANetwork Exchange, 14(2).

Ahn, C. Y., Singh, I., Squire, L. (1981). A Model of an Agricultural Household in a Multi-Crop Economy: The Case of Korea. The Review of Economics and Statistics, 63(4), 520-525.

Akerlof, G. A. and Kranton, R. E. (2000). Economics and identity. Quarterly Journal of Economics, 115, 715-53.

Alesina, A., Di Tella, R. and R. MacCulloch (2004). Inequality and happiness: are Europeans and Americans different? Journal of Public Economics, 88, 2009-42.

Alesina, A., and Rodrik, D. (1994). Distributive Politics and Economic Growth. Quarterly Journal of Economics, 108, 465-490.

Ashraf, N., X. Giné, and D. Karlan (2009). Finding missing markets (and a disturbing epilogue): Evidence from an export crop adoption and marketing intervention in Kenya. American Journal of Agricultural Economics 91(4), 973-990.

Baetschmann, G., Staub, K. E., and Winkelmann, R. (2011). Consistent estimation of the fixed effects ordered logit model. University of Zurich Working Paper Series.

Baltagi, B. H. (2008). Econometric Analysis of Panel Data. Chichester: Wiley Fourth Edition.

Bank of Chosun (1948). Chosun Kyongje Yongam (Annual economic review of Korea). Seoul.

Barbier, E. (1989). Cash crops, food crops, and sustainability: The case of Indonesia. World Development 17 (6), 879-895.

Barraclough, S. L. (1999). Land Reform in Developing Countries: The Role of the State and other Actors. UNRISD Discussion Paper No. 101.

Barrett, C. and M. Aboud (2001). Income diversification, poverty traps and policy shocks in Côte d'Ivoire and Kenya. Food Policy 26 (4), 367-384.

Basu, K., A. Narayan, and M. Ravallion (2001). Is literacy shared within households? theory and evidence for Bangladesh. Labour Economics 8 (6), 649665.

Baum, C., M. Shaffer, and S. Stillman (2003). Instrumental variables and gmm: Estimation and testing. Department of Economics, Boston College working papers (545). 
Becker, G. S. (1965). A theory of the allocation of time. Economic Journal, 75, 493-517.

Blanchflower, D. G. and A. J. Oswald, A. J. (1998). What makes an Entrepreneur? Journal of Labor Economics, 16(1), 26-60.

Blundell, R. and S. Bond (1998). Initial conditions and moment restrictions in dynamic panel data models. Journal of Econometrics 87 (1), 115-143.

Boadway, R., and Bruce, N. (1984). Welfare Economics. New York: Blackwell.

Booth, A. L., and J. C. van Ours (2008). Job Satisfaction and Family Happiness: The Part-time Work Puzzle. Economic Journal, 118, 77-99.

Booth, A. L., and J. C. van Ours (2009). Hours of Work and Gender Identity: Does Part-time Work Make the Family Happier? Economica, 76, 176196.

Boyce, J. K., Rosset, P., Stanton, E. A. (2007). Land Reform and Sustainable Development. In: Boyce, J. K., Narain, S., Stanton, E. A. (ed.). Reclaiming nature: environmental justice and ecological restoration. Anthem Press, London, New York.

BPS (2010, July). Poverty rate in Indonesia 2010. Technical report, Badan Pusat Statistik.

Brickman, P., and Campbell, D. T. (1971). Hedonic relativism and planning the good society. In: M. H. Appley (Ed.), Adaptation-level theory. New York: Academic Press.

Brown, P. H. (2009). Dowry and Intrahousehold Bargaining. The Journal of Human Resources, 44(1), 25-46.

Bussolo, M., O. Godart, J. Lay, and R. Thiele (2007). The impact of coffee price changes on rural households in Uganda. Agricultural Economics 37 (2-3), 293-303.

Chandler, P. and Bock, R. (1991). Age change in adult stature. Trend estimation from mixed longitudinal data. Annals of Human Biology, 18(5), 433-40.

Cheong, Y.-I. (1975). The measure and analysis of farm land (1911-1971). Journal of Economics, 14(2), 22-43. (Korean Journal, in Korean).

Cherdchuchai, S. and K. Otsuka (2006). Rural income dynamics and poverty reduction in Thai villages from 1987 to 2004. Agricultural Economics 35 (s3), 409-423.

Choi, S.-J. and Schwekendiek, D. (2009). The biological standard of living in colonial Korea, 1910-1945. Economics and Human Biology, 7, 259-264.

Chung, W., and Das Gupta, M. (2007). The Decline of Son Preference in South Korea: The Roles of Development and Public Policy. Population and Development Review, 33(4), 757-783. 
Clapp, R. W., Jacobs, M. M., Loechler, E. L. (2008). Environmental and Occupational Causes of Cancer. New Evidence, 2005-2007. Review of Environmental Health, 23(1), 1-37.

Clark, A. E. (1997). Job satisfaction and gender: why are women so happy at work? Labour Economics, 4, 341-72.

Clark, A. E. (2003). Unemployment and social norms: psychological evidence from panel data. Journal of Labor Economics, 21, 323-51.

Clark, A. E., Diener, E., Georgellis, Y., and R. E. Lucas (2008). Lags and Leads in Life Satisfaction: A Test of the Baseline Hypothesis. The Economic Journal, 118(June), F222-F243.

Clark, A. E., Frijters, P., and M. A. Shields (2008). Relative income, happiness, and utility: An explanation of the Easterlin Paradox and other puzzles. Journal of Economic Literature, 46(1), 95-144.

Clark, A. E. and Georgellis, Y. (2010). Back to Baseline in Britain: Adaptation in the BHPS.

Clark, A. E., and Oswald, A. J. (1994). Unhappiness and unemployment. Economic Journal, 104, 648-59.

Clasen, R. and Moon, Y.-K. (2010). Family Status, Working Experience, And Korean Women's Attitude to Feminism. Korean Studies Forum, 4, 245266.

Cline, M., Meredith, K. E., Boyer, J. T., and Burrows, B. (1989). Decline of height with age in adults in a general population sample: estimating maximum height and distinguishing birth cohort effects from actual loss of stature with aging. Human Biology, 61(3), 415-25.

Conseil d'Analyse Economique \& Sachverständigenrat zur Begutachtung der gesamtwirtschaftlichen Entwicklung (2010). Wirtschaftsleistung, Lebensqualität und Nachhaltigkeit: Ein umfassendes Indikatorensystem. Paderborn: Bonifatius.

Das, M. and A. van Soest (1999). A panel data model for subjective information on household income growth. Journal of Economic Behavior \& Organization, 40, 409-426.

Datt, G. and M. Ravallion (1998a). Farm productivity and rural poverty in India. Journal of Development Studies 34 (4), 62-85.

Datt, G. and M. Ravallion (1998b). Why have some Indian states done better than others at reducing rural poverty? Economica 65 (2), 17-38.

Deaton, A. (1997). The Analysis of Household Surveys: A Microeconometric Approach to Development Policy. The World Bank.

Deaton, A. (2008). Height, health, and inequality: the distribution of adult heights in India. American Economic Review, 98(2), 468-474. 
Deaton, A. and S. Zaidi (2002). Guidelines for constructing consumption aggregates for welfare analysis. World Bank Policy Research Working Paper 135.

Deininger, K. (2003). Land Policies for Growth and Poverty Reduction. World Bank and Oxford University Press.

Deininger, K., and Binswanger, H. (1999). The Evolution of the World Bank's Land Policy: Principles, Experience, and Future Challenges. The World Bank Research Observer, 14(2), 247-76.

Deininger, K., Squire, L. (1998). New ways of looking at old issues: inequality and growth. Journal of Development Economics, 57, 259-287.

De Janvry, A., and Sadoulet, E. (2002). World poverty and the role of agricultural technology: Direct and indirect effects. Journal of Development Studies, 38(4), 1-26.

Deolalikar, A. B. (1981). The Inverse Relationship between Productivity and Farm Size: A Test Using Regional Data from India. American Journal of Agricultural Economics, 63, 275-279.

Dercon, S. (1996). Risk, crop choice, and savings: Evidence from Tanzania. Economic Development and Cultural Change 44(3), 485-513.

Dercon, S., D. Gilligan, J. Hoddinott, and T. Woldehanna (2009). The impact of agricultural extension and roads on poverty and consumption in fifteen Ethiopian villages. American Journal of Agricultural Economics 91 (4), 1007-1021.

Dewi, S., B. Belcher, and A. Puntodewo (2005). Village economic opportunities, forest dependence, and rural livelihoods in east Kalimantan, Indonesia. World Development 33 (9), 1419-1434.

Di Tella, R., Haisken-De New, J. and R. MacCulloch (2010). Happiness adaptation to income and status in an individual panel. Journal of Economic Behavior and Organization, 76(3), 834-852.

Di Tella, R., and MacCulloch, R. (2006). Some uses of happiness data in Economics. Journal of Economic Perspectives, 20(1), 25-46.

Di Tella, R., MacCulloch, R. and A. Oswald (2001). Preferences over inflation and unemployment: evidence form surveys of happiness. The American Economic Review, 91(1), 335-341.

Dolan, P., Peasgood, T. and M. White (2008). Do we really know what makes us happy? A review of the economic literature on the factors associated with subjective well-being. Journal of Economic Psychology, 29(1), 94122.

Easterlin, R. A. (1974). Does Economic Growth Improve the Human Lot? Some Empirical Evidence. In: Paul A. David, Melvin W. Reder (edit.), Nations 
and Households in Economic Growth: Essays in Honour of Moses Abramovitz, Academic Press, Inc., New York.

Easterlin, R. A. (2003). Explaining happiness. PNAS, 100(19), 11176-11183.

Estudillo, J., Y. Sawada, and K. Otsuka (2006). The green revolution, development of labor markets and poverty reduction in the rural Philippines. Agricultural Economics 35 (s3), 399-407.

Fafchamps, M. (1992). Cash crop production, food price volatility, and rural market integration in the third world. American Journal of Agricultural Economics 74 (1), 90-99.

Fan, S., A. Gulati, and S. Thorat (2008). Investments, Subsidies and pro-poor growth in rural India. Agricultural Economics 39 (2), 163-170.

FAOSTAT (2011). Retrieved at 15 January 2011, http://www.faostat.org/.

Fan, S., and Chan-Kang, C. (2005). Is small beautiful? Farm Size, Productivity and Poverty in Asian Agriculture.

Feder, G. and Feeny, D. (1991). Land Tenure and Property Rights: Theory and Implications for Development Policy. World Bank Econ Review, 5(1), 135-153.

Feder, G. and Umali, D. L. (1993). The adoption of agricultural innovations : A review. Technological Forecasting and Social Change, 43(3-4), 215-239.

Ferrer-i-Carbonell, A. and P. Frijters (2004). How Important is Methodology for the Estimates of the Determinants of Happiness? Economic Journal, 114, 641-659.

Ferrer-i-Carbonell, A. and B.M.S. Van Praag (2002). The Subjective Costs of Health Losses due to Chronic Diseases: An Alternative Model for Monetary Appraisal. Health Economics, 11, 709-722.

Fields, G., P. Cichello, S. Freije, M. Menendez, and D. Newhouse (2003). For richer of for poorer? evidence from Indonesia, South Africa, Spain and Venezuela. Journal of Economic Inequality 1 (1), 67-99.

Frankenberg, E., J. Smith, and D. Thomas (2003). Economic shocks, wealth and welfare. Journal of Human Resources 38 (2), 280-321.

Frederick, S., and Loewenstein, G. (1999). Hedonic adaptation. Well-being: The foundations of hedonic psychology. In: Kahneman, D., Diener, E., and N. Schwarz (Eds.). Well-being: The foundations of hedonic psychology. New York.

Frey, B.S. and A. Stutzer (2002). What Can Economists Learn from Happiness Research? Journal of Economic Literature, 40(2), 402-435.

Frijters, P. (2000). Do Individuals Try to Maximize General Satisfaction? Journal of Economic Psychology, 21(3), 281-304. 
Frijters, P., Haisken-DeNew, J. P., and M. A. Shields (2004). Money Does Matter! Evidence from Increasing Real Income and Life Satisfaction in East Germany Following Reunification. The American Economic Review, 94(3), 730-740.

Frijters, P., Johnston, D. W., and M. A. Shields (2008). Happiness Dynamics with Quarterly Life Event Data. IZA DP No. 3604. (forthcoming in Scandinavian Journal of Economics)

Galor, O., Moav, O., and Vollrath, D. (2009). Inequality in Landownership, the Emergence of Human-Capital Promoting Institutions, and the Great Divergence. Review of Economic Studies, 76, 143-179.

Gardner, J. and A. J. Oswald (2006). Do divorcing couples become happier by breaking up? Journal of the Royal Statistical Society A, 169(2), 319-336.

Gibson, J. and S. Olivia (2010). The effect of infrastructure access and quality on non-farm enterprises in rural Indonesia. World Development 38 (5), 717-726.

Greene, W. H. (2003). Econometric Analysis. Prentice Hall.

Grimm, M., Klasen, S., McKay, A. (eds.) (2007). Determinants of Pro-Poor Growth: Analytical Issues and Findings from Country Cases. Palgrave McMillan.

Haddad, L., Hoddinott, J., and Alderman, H. (Eds) (1997). Intrahousehold Resource Allocation in Developing Countries: Models, Methods and Policy. Baltimore: Johns Hopkins University Press.

Hill, R. V. (2010). Investment and abandonment behavior of rural households: An empirical investigation. American Journal of Agricultural Economics 92 (4), 1065-1086.

Hochschild, A. R. (1989). The second shift. New York: Viking.

Hoddinott, J., Maluccio, J. A., Behrmann, J. R., Flores, R., and Reynaldo, M. (2008). Effect of a nutrition intervention during early childhood on economic productivity in Guatemalan adults. The Lancet, 371, 411-16.

Jang, S-N., Cho, S-I., Chang, J., Boo, K., Shin, H-G., Lee, H., and L. F. Berkman, (2009). Employment status and depressive symptoms in Koreans: results from a baseline survey of the Korean longitudinal study of aging. Journal of Gerontology: Social Sciences, 64B(5), 677-683.

Jeon, Y.-D., and Kim, Y.-Y. (2000). Land Reform, Income Redistribution, and Agricultural Production in Korea. Economic Development and Cultural Change, 48 (2), 253-268. 
Kahneman, D. (2000). Evaluations by Moments: Past and Future. In: Kahnemann, D., and Tversky, A. (Eds.). Choices Values and Frames. New York: Cambridge University Press.

Kahneman, D., and Krueger, A. B. (2006). Developments in the Measurement of Subjective Well-Being. Journal of Economic Perspectives, 20(1), 3-24.

Kang, S.-J. (2010). The Analysis on the Determinants of Life Satisfaction in Korea. Kyongjehak Yongu, 58(1), 5-36. (한국인의 생활만족도 결정요인 분석, in Korean)

Keidel, A. (1981). Korean Regional Farm Product and Income: 1910-1975. KDI, Seoul, Korea.

Kim, H. and Voos, P. B. (2007). The Korean economic crisis and working women. Journal of Contemporary Asia, 37(2), 190-208.

Kim, N. N. (2009). 한국 GDP 의 장기추이와 국제비교 (Korean Long-Term Transition and International Comparison.). Naksungdae Institute of Economic Research Working Paper 2009-5.

Kim, N. N., and Park, K. J. (2007). 해방 전후(1936-1956) 서울의 물가와 임금 (Consumer Price Index and Real Wage in Seoul, 1936-1956). 경제 사 학 제 42 호 (Economic History Studies), 42, 75-105.

Kim, S.-K. (2007). Family, Gender, and Sexual Inequality. In: Kim, H.-R. and Song, B. (2007): Modern Korean Society: its development and prospect. 131-157. U California, Berkeley: Institute of East Asian Studies.

Kimura, M. (1993). Standards of living in colonial Korea: Did the masses become worse off or better off under Japanese rule? Journal of Economic History, 53, 629-652.

Komlos, J. (1993). The secular trend in the biological standard of living in the United Kingdom, 1730-1860. Economic History Review, 46(1), 115-144.

Komlos, J. and Baten, J., eds. (1998). The biological standard of living in comparative perspective. Stuttgart, Germany.

Kopczynski, M. (2007). Agrarian reforms, agrarian crisis and the biological standard of living in Poland, 1844-1892.

Korea Agricultural Economic Research Institute (KAERI) (1989). Nongchikaehyoksa Yonku (A study on the history of agricultural land reform). Seoul.

Kroll, C. (2011). Measuring Progress and Well-Being. Achievements and Challenges of a New Global Movement. FES Study, Bonn.

Lanjouw, J. and P. Lanjouw (2001). The rural non-agricultural sector: Issues and evidence from developing countries. Agricultural Economics 26 (1), 1-23.

Lee, B. S., Jang, S., and J. Sarkar (2008). Women's labor force participation and marriage: The case of Korea. Journal of Asian Economics, 19, 138-154. 
Lee, K. W. and K. Cho (2005). Female Labor Force Participation during Economic Crises in Argentina and the Republic of Korea. International Labour Review 144(4), 423-449.

Lee, M. (1998). Women's Education, Work, and Marriage in Korea: Women's Lives Under Institutional Conflict. Doctoral Thesis, Seoul: Seoul National University Press.

Lee, S.-H. (2008). Preferences and Choice Constraints in Marital Sorting: Evidence from Korea. Stanford Institute for Economic Policy Reasearch Discussion Paper 07-042.

Lise, J. and S. Seitz (2011). Consumption Inequality and Intra-household Allocations. Review of Economic Studies, 78, 328-355.

Lucas, R. E., Diener, E. and E. M. Suh (1996). Discriminant Validity of WellBeing Measures. Journal of Personality and Social Psychology, 71(3), 616-628.

Luttmer, E. F. P. (2005). Neighbors as Negatives: Relative Earnings and WellBeing. Quarterly Journal of Economics, 120(3), 963-1002.

Lykken and Tellegen (1996). Happiness is a Stochastic Phenomenon. Psychological Science, 7(3), 186-189.

Maddison, A. (2003). The World Economy: Historical Statistics. OECD, Paris.

Mankiw, G., P. Romer, and D. Weil (1992). A contribution to the empirics of economic growth. Quarterly Journal of Economics 107 (2), 407-437.

Micevska, M. and D. Rahut (2008). Rural nonfarm employment and incomes in the Himalayas. Economic Development and Cultural Change 57 (1), 163193.

Ministry of Agriculture, Forestry and Fishery (MAFF) (1966). Farmland Reform in Korea. Seoul.

Minten, B. and Barrett, C. B. (2008). Agricultural Technology, Productivity, and Poverty in Madagascar. World Development, 36(5), 797-822.

Moradi, A. (2005). Ernährung, wirtschaftliche Entwicklung und Bürgerkriege in Afrika südlich der Sahara (1950-2000). Inaugural-Dissertation. Universität Tübingen.

Morgan, S. (2008). Stature and economic development in South China, 1810 1880. Explorations in Economic History, 26(1), 53-69.

Morrow, R. B., and Sherper, K. H. (1970). Land Reform in South Korea. Agency for International Development Spring Review. USAID/Korea.

Nargis, N. and M. Hossain (2006). Income dynamics and pathways out of rural poverty in Bangladesh. Agricultural Economics 35 (s3), 425-435. 
OECD (2009). Education at a Glance 2009: OECD Indicators, OECD Publishing.

OECD (2011). Society at a Glance 2011: OECD Social Indicators, OECD Publishing. http://dx.doi.org/10.1787/soc_glance-2011-en

OECD (2011). OECD Statistics online (stats.oecd.org).

Oh, C.-H. (2008). Land Reforms and The Transformation of Rural Community: Comparative Studies on Two Districts in Kyunggi-Do. Comparative History Studies, 14(2), 77-121 (in Korean).

Oswald, A. J. and N. Powdthavee (2008). Does happiness adapt? A longitudinal study of disability with implications for economists and judges. Journal of Public Economics, 92, 1061-1077.

Otsuka, K., Chuma, H., Hayami, Y. (1992). Land and Labor Contracts in Agrarian Economies: Theory and Facts. Journal of Economic Literature, 30(4), 1965-2018.

Pak, K. H. (1966a). Outcome of Land Reform in the Republic of Korea. In: FAO. Country Report: Republic of Korea.

Pak, K. H. (1966b). The First Five-Year Economic Plan in Korea with Special Reference to Agriculture. In: FAO. Country Report: Republic of Korea.

Pak, K. H. (1968). Economic Effects of Farmland Reform in the Republic of Korea. In: Brown, J. R., and Lin, S. (ed.). Land Reform in Developing Countries. University of Hartford.

Pak, K. H., Han, B., Lee, K. H., Park, J. H., and Han, K. C. (1966). A Study of Land Tenure System in Korea. Korean Land Economics Research Center, Seoul.

Pak, S., Schwekendiek, D., and Kim, H.-K. (2010). Height and Living Standards in North Korea, 1930s-1980s. Economic History Review, no. doi: 10.1111/j.1468-0289.2009.00509.x.

Perron, P. (1989). The Great Crash, the Oil Price Shock, and the Unit Root Hypothesis. Econometrica, 57(6), 1361-1401.

Persson, T., and Tabellini, G. (1994). Is Inequality Harmful for Growth? American Economic Review 84, 600-621.

Phipps, S. and P. Burton (1998). What's Mine is Yours? The Influence of Male and Female Incomes on Patterns of Household Expenditure. Economica, 65, 599-613.

Pradhan, M., Ravallion, M., (2000). Measuring poverty using qualitative perceptions of consumption adequacy. Review of Economics and Statistics, 82, $462-471$.

Ravallion, M., and Chen, S. (2007). China's (uneven) progress against poverty. Journal of Development Economics, 82, 1-42. 
Ravallion, M. and G. Datt (2002). Why has economic growth been more propoor in some states of India than in others? Journal of Development Economics 68 (2), 381-400.

Ravallion, M. and M. Lokshin (2007). Lasting impacts of Indonesia's financial crisis. Economic Development and Cultural Change 56 (1), 27-56.

Ray, D. (1998). Development Economics. Princeton University Press.

Rodrik, D., Grossman, G. Norman, V. (1995). Getting Interventions Right: How South Korea and Taiwan Grew Rich. Economic Policy, 10(20), 53-107.

Rogers, S. J., DeBoer, D. D. (2001). Changes in Wives' Income: Effects on Marital Happiness, Psychological Well-Being, and the Risk of Divorce. Journal of Marriage and Family, 63(2), 458-472.

Rosegrant, M. and R. Evenson (1992). Agricultural productivity and sources of growth in South Asia. American Journal of Agricultural Economics 74(3), 757-761.

Rosegrant, M., F. Kasryno, and N. Perez (1998). Output response to prices and public investment in agriculture: Indonesian food crops. Journal of Development Economics 55 (2), 333-352.

Ross, C. E., Mirowsky, J., and K. Goldsteen (1990). The impact of family on health: The decade in review. Journal of Marriage and the Family, 52, 1059-1078.

Rudolf, R. and S.-Y. Cho (2011). The Gender-Specific Effect of Working Hours on Family Happiness in South Korea. CRC-PEG Discussion Paper No. 77, University of Göttingen.

Schwarze, S., S. Erasmi, J. Priess, and M. Zeller (2009). Do national parks reduce deforestation? The effectiveness of the Lore Lindu National Park in Indonesia. STORMA Discussion Paper No. 30.

Silventoinen, K. (2003). Determinants of Variation in Adult Body Height. Journal of Biosocial Science, 35, 263-285.

Singh, R. B. (2000). Environmental consequences of agricultural development: a case study from the Green Revolution state of Haryana, India. Agriculture, Ecosystems \& Environment, 82(1-3), 97-103.

Steckel, R. H. (1995). Stature and the standard of living. Journal of Economic Literature 33, 1903-1940.

Steckel, R. H. (2009). Heights and human welfare: Recent developments and new directions. Explorations in Economic History, 46(1), Special Issue on Heights and Human Welfare, 1-23.

Stiglitz, J. E., Sen, A., and Fitoussi, J.-P. (2009). Report by the Commission on the Measurement of Economic Performance and Social Progress. Paris. 
Stutzer, A. (2004). The role of income aspirations in individual happiness. Journal of Economic Behavior and Organisation, 54(1), 89-109.

Stutzer, A. and B. Frey (2006). Does marriage make people happy, or do happy people get married? The Journal of Socio-Economics, 35, 326-347.

Sunderlin, W., A. Angelsen, and D. Derwawan (2001). Economic crisis, small farmer well-being, and forest cover change in Indonesia. World Development 29 (5), 767-782.

Suryahadi, A., D. Suryadarma, and S. Sumarto (2009). The effects of location and sectoral components of economic growth on poverty: Evidence from Indonesia. Journal of Development Economics 89, 109-117.

Temple, J. (1999). The new growth evidence. Journal of Economic Literature 37 (1), 112-156.

Timmer, C. (2007). A historical perspective on pro-poor growth in Indonesia. In: M. Grimm, S. Klasen, and A. McKay (Eds.), The determinants of propoor growth. Hampshire: Palgrave.

UNDP (2005). Korean Human Development Report on Gender.

UNDP (various years). Human Development Report.

Waaler, H. (1984). Height, weight and mortality. The Norwegian experience. Acta Medica Scandinavica, 679, 1-59.

Windmeijer, F. (2005). A finite sample correction for the variance of linear efficient two-step gmm estimators. Journal of Econometrics 126 (1), 25-51.

Winkelmann, L. and R. Winkelmann (1998). Why Are the Unemployed So Unhappy? Evidence from Panel Data. Economica, 1998, 65, 1-15.

Woolard, I. and S. Klasen (2005). Determinants of income mobility and household poverty dynamics in South Africa. Journal of Development Studies 41 (5), 865-897.

Wooldridge, J. (2006). Econometric Analysis of Cross-Section and Panel Data. Cambridge: MIT Press - Second Edition.

World Bank (2004). Republic of Korea: Four Decades of Equitable Growth. A Global Learning Process and Conference. Shanghai, May 25-27, 2004.

World Bank (2006). Indonesia: Revitalizing the rural economy. The World Bank, Washington, D.C.

World Bank (2007). World Development Report 2008: Agriculture for Development. World Bank, Washington, D.C.

World Economic Forum (2010). The Global Gender Gap Report 2010.

Zeller, M., S. Schwarze, and T. van Rheenen (2002). Statistical sampling frame and methods used for the selection of villages and households in the scope of the research program on stability of rainforest margins in Indonesia. 
STORMA Discussion Paper Series 1, STORMA, University of Goettingen.

Zhang, Y. B., Lin, M.-C., Nonaka, A. and K. Beom (2005). Harmony, Hierarchy and Conservatism: A Cross-Cultural Comparison of Confucian Values in China, Korea, Japan, and Taiwan. Communication Research Reports, 22(2), 107-115.

Zivot, E. and D. W. K. Andrews (1992). Further Evidence on the Great Crash, Oil-Price Shock, and the Unit-Root Hypothesis. Journal of Business \& Economic Statistics, 10(3), 25-44. 


\title{
Göttlinger Studien zur Entwicklungsökonomlk GöttIngen Studies in Development Economics
}

\author{
Herausgegeben von / Edited by Hermann Sautter
} und / and Stephan Klasen

Die Bände 1-8 sind über die Vervuert Verlagsgesellschaft (Frankfurt/M.) zu beziehen.

Bd. / Vol. 9 Hermann Sautter/Rolf Schinke (eds.): Social Justice in a Market Economy. 2001.

Bd. / Vol. 10 Philipp Albert Theodor Kircher: Poverty Reduction Strategies. A comparative study applied to empirical research. 2002.

Bd./ Vol. 11 Matthias Blum: Weltmarktintegration, Wachstum und Innovationsverhalten in Schwellenländern. Eine theoretische Diskussion mit einer Fallstudie über „Argentinien 19901999". 2003.

Bd./Vol. 12 Jan Müller-Scheeßel: Die Privatisierung und Regulierung des Wassersektors. Das Beispiel Buenos Aires / Argentinien. 2003.

Bd. / Vol. 13 Ludger J. Löning: Economic Growth, Biodiversity Conservation, and the Formation of Human Capital in a Developing Country. 2004.

Bd. / Vol. 14 Silke Woltermann: Transitions in Segmented Labor Markets. The Case of Brazil. 2004.

Bd./Vol. 15 Jörg Stosberg: Political Risk and the Institutional Environment for Foreign Direct Investment in Latin America. An Empirical Analysis with a Case Study on Mexico. 2005.

Bd. / Vol. 16 Derk Bienen: Die politische Ökonomie von Arbeitsmarktreformen in Argentinien. 2005.

Bd. / Vol. 17 Dierk Herzer: Exportdiversifizierung und Wirtschaftswachstum. Das Fallbeispiel Chile. 2006.

Bd. / Vol. 18 Jann Lay: Poverty and Distributional Impact of Economic Policies and External Shocks. Three Case Studies from Latin America Combining Macro and Micro Approaches. 2007.

Bd./ Vol. 19 Kenneth Harttgen: Empirical Analysis of Determinants, Distribution and Dynamics of Poverty. 2007.

Bd. / Vol. 20 Stephan Klasen / Felicitas Nowak-Lehmann: Poverty, Inequality and Migration in Latin America. 2008.

Bd./ Vol. 21 Isabel Günther: Empirical Analysis of Poverty Dynamics. With Case Studies from SubSaharan Africa. 2007.

Bd./Vol. 22 Peter Dung: Malaysia und Indonesien: Wirtschaftliche Entwicklungsstrategien in zwei Vielvölkerstaaten. 2008.

Bd./ Vol. 23 Thomas Otter: Poverty, Income Growth and Inequality in Paraguay During the 1990s. Spatial Aspects, Growth Determinants and Inequality Decomposition. 2008.

Bd. / Vol. 24 Mark Misselhorn: Measurement of Poverty, Undernutrition and Child Mortality. 2008.

Bd./Vol. 25 Julian Weisbrod: Growth, Poverty and Inequality Dynamics. Four Empirical Essays at the Macro and Micro Level. 2008.

Bd./Vol. 26 Johannes Gräb: Econometric Analysis in Poverty Research. With Case Studies from Developing Countries. 2009.

Bd./ Vol. 27 Sebastian Vollmer: A Contribution to the Empirics of Economic and Human Development. 2009.

Bd. / Vol. 28 Wokia-azi Ndangle Kumase: Aspects of Poverty and Inequality in Cameroon. 2010. 
Bd./ Vol. 29 Adriana Rocío Cardozo Silva: Economic Growth and Poverty Reduction in Colombia. 2010.

Bd. / Vol. 30 Ronald Kröker: Ansätze zur Implementierung von RSE (CSR) in einem lateinamerikanischen Entwicklungsland. Das Beispiel Paraguay - Eine wirtschafts- und unternehmensethische Untersuchung. 2010.

Bd./Vol. 31 Maria Ziegler: Institutions, Inequality and Development. 2011.

Bd./ Vol. 32 Melanie Grosse: Measurement of Trends in Wellbeing, Poverty, and Inequality with Case Studies from Bolivia and Colombia. 2011.

Bd./ Vol. 33 Boris Branisa Caballero: Social Institutions, Gender Inequality, and Regional Convergence in Developing Countries. 2012.

Bd. / Vol. 34 Mirko Bendig: Empirical Analysis of Participation Patterns in Microfinancial Markets. The Cases of Ghana and Sri Lanka. 2012.

Bd./ Vol. 35 Robert Rudolf: Employment, Well-Being and Gender: Dynamics and Interactions in Emerging Asia. 2012.

www.peterlang.de 